\title{
THE ANOMALIES OF HOSPITAL ORGANIZATION: THE IMPLICATIONS FOR MANAGEMENT
}

By

ALAN DONALD BAUERSCHMIDT

A DISSERTATION PRESENTED TO THE GRADUATE COUNCIL OF THE UNIVERSTTY OF FLORIDA

IN PARTLAL FULFWLMENT OF THE REQUIREMFNTS FOR THE DEGREE OF DOCTOR OF PHILOSOPHY

UNIVERSITY OF FLORIDA

1968 


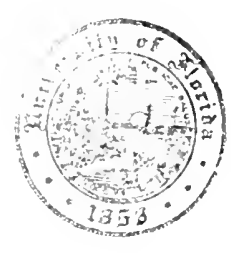

UNIVERSITY OF FLORIDA

31262085522091 
TABLE OF CONTENTS

Chapter

Page

I. INTRODUCTION............................ I

11. ORGANIZATIONAL OBJECTIVES,................ 33

111. THE LINE ORGANIZATION.................... 58

IV. THE STAFF ORGANIZATION................... 103

V. AN ANOMALY: LINE IS STAFF AND STAFF IS LINE......... 123

V1. AN ANOMALY: TWO CHAINS OF COMMAND.............. 142

V11. AN ANOMALY: HOSTPITALS ARE BECOMING MORE BUREAUCRATIC IN STRUCTURE................. 158

VIII. THE PROTOTYPE ORGANIZATION................ 177

IX. TOWARD EUPSYCHIAN MANAGEMENT................ 229

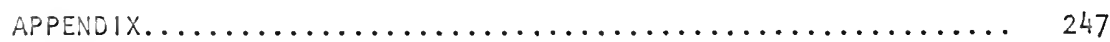

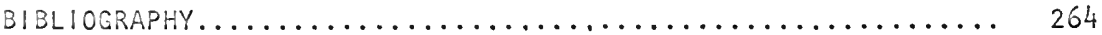

BIOGRAPHICAL SKETCH...................... 276 


\section{CHAPTER ।}

\section{INTRODUCTION}

In spite of the variety of concepts which can be labeled as organization theory each can be observed to have its basis in the notion that a universality of organization structure exists and can be described. This notion can be as fundamental, and as ancient, as the discussions regarding the basic order of the universe and its smallest parts. Or, it can be as sophisticated, and as current, as the levels of order expressed in the concepts of general systems theory. ' Cosmos is accepted over chaos through rational perception whether first causes are attributed to a toss of the dice or a divine wisdom.

If the formal organization is taken out of the basic order of the universe and examined in its separate characteristics, as is more generally attempted by the theorist, the same universal form of structure is commented upon. However, this common form of structure is variously described as to its source. Some authorities mark the pervasiveness of the universal structure as an attribute of its problem-solving and coordinative ability. ${ }^{2}$ other authorities, of which Herzberg and Etzioni are representative, see the existence of

IKenneth Boulding, "General Systems Theory--The Skeleton of Science," Management Science, 11 (April, 1956), 197.

2 James D. Mooney, in Principles of Organization (Revised Edition; New York: Harper and Brothers, Publishers, 1947), p. 1, provides that: 
universality of organizational structure in the predominance of a particular organization in the social scheme. 3

Much of the controversy among authorities regarding the universality of organization structure hinges upon the place accorded to "principles of organization" in the various concepts of organization theory. There appears to be two distinct levels of analysis in this regard: that which directs itself to observations about organization and are descriptive of universal features; and, that which seeks to prescribe for organization structure based upon the logic of

10rganization is the form of every human association for the attainment of a common pupose," and that certain features are essential to all forms of organization. Chester Barnard, in The Functions of the Executive (Cambridge, Mass.: Harvard University Press, 1938), pp. 94-95; allows that both simple and complex forms of organization have their similarity as impersonal systems of coordinated human effort. Rocco Carzo, Jr. and John $N$. Yanouzas employ the systems concepts in Formal Orcanization: A Systems Approach (Homewood, I11.: Richard D. Irwin, Inc., 1967), P. 534, to derive the concept of organization as a problem-solving routine based on a simple and natural human response to complex tasks.

3 Frederick Herzberg maintains that the business organization has provided its coloration to all other institutions that serve Western society. See his Work and the Nature of Man (Cleveland, Ohio: The World Publishing Co., 1966), p. I. Amitai Etzioni, in "Authority Structure and Organizational Effectiveness," Administrative Sciences Quarterly, IV (June, 1959), 51, remarks that the concept of universality can be traced to the fact that organization theory was originally developed on the basis of observations and analysis of governmental and private business bureaucracies. Contrasting the approaches of the social versus the administrative scientist, Amitai Etzioni, in Modern Organizations (Englewood Cliffs, N.J.: Prentice-Hall, Inc., 1964), P. 2l, provides that the scope of the former is much broader, and through structural analysis reveals much of the discrepancy occurring through adherence to the earlier administrative model. 
universals. 4 However considered, the concept of principles pervades the literature addressing itself to the study of organizations, with the general context directed toward those facets of organization which are universal. 5 Even those investigators who mount the most vigorous attack upon the pervasiveness of these universalities acknowledge their presence in the attempt. 6

Many of the criticisms taken in regard to universality of organization structure are not directed toward the underlying principles, but, rather, are directed at what must be considered as unique applications of structure and process in specific types of organization. These

4 Representative of the descriptive approach are the comments of William G. Scott, in Organization Theory: A Behavioral Analysis for Management (Homewood, I11.: Richard D. Irwin, Co., 1967), P. 149; and, E. Wight Bakke, "Concept of the Social Organization," Modern Organization Theory, ed., Mason Haire (New York: John Wiley and Sons, Inc., 1959), pp. 34-35. Amitai Etzioni, in A Comparative Analysis of Complex Organizations (New York: The Free Press, 1961), p. xiii, takes the second approach to task without identifying the culprits. Mooney, p. I, provides the classical example of the essentiality of certain organizational features which justify the claim of principles.

5 peter M. Blau and W. Richard Scott, in Formal Organizations (San Francisco: Chandler Publishing Co., 1962), pp. 8-9, refer to: ". . the principles that govern organizational life." John M. Pfiffner and Frank P. Sherwood, in Administrative Organization (Englewood Cliffs: N.J.: Prentice-Hall, Inc., 1960), P. 30, note that: ". . . the existence of a common core of practice and pattern in organizations seems to have achieved reasonably substantial consensus."

${ }^{6}$ Chris Argyris refers to the basic "genes" of organizational structure in Integrating the Individual and the Organization (New York: John Wiley and Sons, Inc., 1964), PP. 14-15. 
approaches have led to the concept of comparative analysis which will reveal the fundamental nature of organizations. 7 These approaches to organization theory will receive major attention in this paper in view of their centrality to the question of anomalous structure.

The concept of a universality of organization structure underlies the practice of management. 8 This structure provides the basis for the application of managerial techniques associated with the coordinative process of management. Mooney points out, with certain mental agility, the concept that administration, or management, presupposes organization-yet management precedes organization for the coordinative process is subordinate to management. 9 It is on this basis that Mooney's principles of organization have been misconstrued to imply that there exists one best prescription for organization, rather than one best description. 10

Additional insight into the source of the management function in the universality of organization structure is provided by John F. Mee,

7 Daniel Katz and Robert L. Kahn, remark in The Social Psychology of Organizations (New York: John Wi ley and Sons, Inc., 1966), p. 110, that: "Though there are undoubtedly unique aspects in any social situation, there are also common patterns, and the deeper we go, the greater the genotypic similarities become." Etzioni, Comparative Analysis, p. xi i , provides the proposition that comparative analysis will reveal the universal propositions of organization theory if such exist.

William G. Scott, "Organization Theory: An Overview and an Appraisal," Journal of the Academy of Management, IV (April, 1961), 8.

9 Mooney, pp. 3-4.

10 James G. March and Herbert A.Simon, Organizations (New York: John Wiley and Sons, Inc., 1958), p. 30. 
who remarks on the historic appearance of management thought independently in various countries of Western society which are presumed to share in the characteristic structure. "I March and Simon note that the task F. W. Taylor set himself in investigating the effective use of human beings in industrial organizations--the management process--quickly developed into the general task of organization theory: the analysis of the interaction between humans and the social and task environments. created by organizations. 12 Katz and Kahn comment that much of existing organization theorizing has been directed toward the development of managerial philosophy and techniques to the detriment of acceptance of the nuances of description and recognition of the openness of the organizational system. 13 In each of these instances it is apparent that a vital link exists between the practice of management and the structure of organizations.

If a universality of organizational structure exists and management is the process of coordination within an organization then a process of management can also be described which is universal to all organizations. Terry has noted the consequence of such observations as follows:

Since the management process is universal, what is meaningful about one manager's work applies likewise to that of all managers. The management process represents the common fabric of

11 John F. Mee, Management Thought in a Dynamic Economy (New York: New York University Press, 1963), P. xix.

12 March and Simon, p. 12.

13 Katz and Kahn, pp. 26-27. 
similarity among managers and serves to expedite the study of management. It is universally found wherever men work together to achieve common objectives. . . There is ample evidence to show that these managerial functions can be applied effectively by the same managers to different enterprises. 14

While Koontz and O'Donnel I remark:

Managers perform the same functions regardless of their place in the organization structure or the type of enterprise in which they are engaged. . .it means that anything significant that is said about the functions of one manager applies to all managers . . it is now possible to develop a theory of management applicable to all executives in all occupations. 15

It is, however, important to recognize that these authorities do not imply that the methods of management will be alike in all organizations. The identical nature of the process of management is limited to those aspects of organizational structure which are universal and in accord with the "principles" of organization. The process of management must then be such functions as are organic to all organizational processes and their related structures. And, with these processes of management are associated various managerial techniques which provide the mechanism for carying out these organic functions. 16

If hospital organizations depart from the universal structure of organization to any significant degree then the application of standard

${ }^{14}$ George R. Terry, Principles of Management (5th ed. rev.; Homewood, 111.: Richard D. Irwin, Inc., 1968).

15 Harold Koontz and Cyril O'Donnell, Principles of Management (3rd Edition; New York: McGraw-Hill Book Co., 1964), p. 45.

16 1bid. 
management techniques within the hospital structure would be inappropriate. If these management techniques developed within the fields of business and public administration are inappropriate, then a new source of management technology for hospital institutions must be developed. It therefore rests with a discussion of the universality of organizational structure to determine whether the process of management and its associated technology are justifiably transferable among organizations.

Two authorities who are perhaps representative of the critics applying themselves to the concept of lack of universality among organizational structures at this general level of consideration are Amitai Etzioni and the co-authors Daniel Katz and Robert L. Kahn. 17 Katz and Kahn maintain that a single broad dichotomy can be made between organizational structures of an economic and non-economic variety based upon whether the transformation process accomplished by the organization is related to the processing of objects or the molding of people. 18 To these authors the difference is so basic in its structural aspects that transference of managerial techniques between the two must be actively resisted--with particular mention made to the transference of technique between the industrial and hospital organizations. 19 Etzioni, from another point of view, provides for three basic structures of organization which have "natural" barriers to the transference of both managers and

\footnotetext{
17Etzioni, Comparative Analysis. Katz and Kahn. $18_{\text {Katz and Kahn, Pp. } 115-116 .}$ 19 libid.
} 
their techniques. These separate organizational forms are identified by the norm of compliance exacted in the managerial process and are categorized as coercive, remunerative, and normative. ${ }^{20}$ Under this analysis hospitals are classified as normative compliance organizations while business organizations are characterized as exacting remunerative compliance. 21 Even those theoretical studies which do not provide for rigid structural separation and encompass a more universal concept include sufficient doubt to suggest that transference of managerial techniques may be precluded. 22

At a more pragnatic level it could be maintained that the appearance of a separate field of management study such as hospital administration would indicate that an anomalous structure of organization exists in hospitals. This phenomenon should suggest that the techniques associated with the management process as universally defined have failed in adaptation to some undefined hospital administrative process. ${ }^{23}$ If the underlying structural anomalies can be identified as existing, in

20 Etzioni, Comparative Analysis, p. 274.

21 bid., p. 42 .

${ }^{22}$ Samuel $W$. Bloom maintains, in The Doctor and His Patient (New York: The Free Press, 1963), P. 160, that the analogy between hospitals, in their present bureaucratic form, and the remainder of our social institutions, can be carried just so far before the path of hospital analysis takes its own turn.

23 paul J. Gordon, in "The Top Management Triangle in Voluntary Hospitals (1)," Academy of Management Journal, IV (December, 1961), 205. remarks on the complaints of hospital administrators that management principles do not apply in their specialized field. 
fact, then perhaps those managerial techniques which are unrelated to such anomalies may yet be salvaged for transfer to the hospital organization. $^{24}$ The significance of such an attempt lies well beyond the limited area of hospital administration. Litchfield has commented that in spite of abundant evidence supporting the conviction that there is much in common in administration we appear to witness the lack of generic administrative process through the appearance of a series of isolated types of administration. 25

Quite specifically, it would appear to be necessary to determine whether a complete dichotomy of structural forms exists, or whether the departure of the hospital structure from the universal structure is along a discernible continum which allows for appropriate modification of managerial methods. Broad dichotomies of structure, because of their link to the management process, create extensive gaps between what might appear superficially to be related disciplines of training and research. Dichotomies of training and research inhibit the transfer of techniques between the unrelated management processes even if "cut-and-try" methods might prove successful. Separate disciplines of training and research

24

This possibility goes beyond the recommendation of Wallace $S$. Sayre, in "Principles of Administration--1," Hospitals, XXX (January 16, 1956), 34, to cut and try the principles for fit in the hospital situation.

25 Edward H. Litchfield, in "Notes on a General Theory of Administration," Administrative Sciences Quarterly, I (June, 1956), 7-8, remarks specifically on the appearance of such fields of study as hospital administration, public administration, military administration, hotel administration, and school administration. 
create unique forms of terminology, and the foundations which prepare students for participation in special programs of study tend to be dichotomized in turn. If the process of management is unique to a business form of organization then it would be senseless to require a prospective graduate student in hospital or educational administration to master the essentials of an undergraduate program in business administration or management. And, if the structural mechanisms of the separate forms are such as to divide the management process into different forms the development of techniques associated with the management of business organizations should not be offered as a remedy for the many problems which face our hospital institutions today. In turn, the business management student should not expect to learn much of value through an understanding of the management process in hospital organizations.

It would appear that the separate possibilities of dichotomy versus continuum form two separate camps that defy simple resolution. If organization theory is to be meaningful it must attempt to explain how organizations seek to meet their goals by integrating personal skills and productive resources. 26 Organization theory must contain more than the necessary abstraction of a general model claimed by Etzioni. 27 This content must be such that it cuts across the ordinary distinctions between the social science disciplines. 28

${ }^{26}$ John G. Hutchinson, Organizations: Theory and Classical Concepts (New York: Holt, Rinehart and Winston, 1967), p. 156.

27 Amitai Etzioni, Modern Organizations, p. 18.

${ }^{28}$ Talcott Parsons, "Suggestions for a Sociological Approach to the Theory of Organizations--1," Administrative Sciences Quarterly, 1 (September, 1956), 64. 
As Parsons has stated:

There is a tendency in our society to consider different types of organizations as belonging to the fields allocated to different academic disciplines. . . The tendency to divide the field obscures both the importance of the common elements and the systematic basis of the variations from one type to another. 29

Wilson observes that: "Hospitals are among the most complex organizations in modern society, characterized by extremely fine division of labor and an exquisite repertory of technical skills."30 Recognizing this observation the search should be continued along the lines suggested by Starkweather for the basis of an organization theory which encompasses the special features of hospitals. 3 !

Perhaps the most basic division which is noted between hospital organizations and the normative organizations within which managerial techniques are highly developed is the non-profit nature of the former. This basis for dichotomizing organization structures is often alluded to in the more popularized writings and is offered in explanation of some particular failing of one form of organization or another. Even in the more sophisiticated literature there is some structuring of organizational types which introduce the suggestion of an economic motive providing the

${ }^{29}$ Talcott Parsons, "Suggestions for a Sociological Approach to the Theory of Organizations--11," Administrative Sciences Quarterly, 1 (December, 1956), 238.

30 Robert N. Wilson, "The Social Structure of a General Hospital," Annals o" the American Academy of Political and Social Sciences, No. 346 (March, 1963 , P. 67.

31 David B. Starkweather, "The Classicists Revisited," Hospital Administration, XII (Summer, 1967), 69. 
basis for the managerial process. 32 This issue will not be pursued at this point for it will be demonstrated that the question of the profit nature of a particular organization is subsumed under the topic of organizational objectives which is treated more fully in the following chapter. For immediate purposes it would be sufficient to note that the basic objective premise upon which managerial theory rests is the provision of service to that society of which the organization is a part. In this respect the hospital and the business organization are basically in accord.

It will be suggested that a significant departure between the fields of business and public administration and that of hospital administration exists in the degree to which the participants in the two similar structures identify with professional versus organizational norms and values. 33 It will therefore be argued that hospital organizations differ from the universal organization structure to the relative degree in which each employs professionals in various organizational roles. 34 It will further

32 As mentioned before, Etzioni, in Comparative Analysis, p. xvi, identifies the bases of compliance in the control sources identified as coercion, economic assets, and normative values, resulting in the separate organizational forms of coercive, utilitarian, and normative compliance. Parsons, in "Suggestions--11," pp. 228-230; provides four organizational classifications of which two economic and integrative organizations reflect a separating out of the hospital organization from the structure provided for economic organizations.

33 Basil S. Georgopoulos, in "The Hospital System and Nursing: Some Basic Problems and Issues," Nursing Forum, V, No. 3 (1966), p. 14, remarks on this phenomenon in the hospital system.

34 Blau and Scott, PP. 206-214, note the remarkable separation between "bureaucrat $i c^{\prime \prime}$ and "professional" organizations within a similar 
be maintained that in this respect hospital organizations can be considered as a prototype lying at the extreme of a continuum along which other organizations are proceeding. 35

The position will be taken that the professional participation in hospital organizations includes the large number of members who are emerging as professionals. Georgopoulos and Mann, indicate that those on the road to professionalization include the nurses, the administrator, the medical librarians, the medical technologists, the dietitians, and others in paramedical positions. 36 Etzioni would allow that these categories should only be classified as semi-professionals because they do appear as salaried members of organizations and accede to the authority structure of the organization. 37

For purposes of discussion the criterion established by Vollmer and Mills can be considered to apply; that is: "We suggest, therefore, that the concept of 'profession' be applied only to an abstract model of occupational organization and that the concept of 'professionalization'

context but directed toward the dissipation of the managerial functions among various organizational members.

35 paul J. Gordon, in "The Top Management Triangle in Voluntary Hospita!s (11)," Academy of Management Journal, V (April, 1962), 66; and, Gordon, "Top Management Triangle (1),"; .209 , cites the hospital organization as a prototype but on a basis concerned with the multiple form of contractual relationships existing between the patient, physician, and hospital.

36 Basil S. Georgopoulos and Floyd C. Mann, "The Hospital as an Organization," Hospital Administration, VII (Fall, 1962), 58.

37Etzioni, Modern Organizations, pp. 77-78. 
be used to refer to the dynamic process whereby many occupations can be observed to change certain crucial characteristics in the direction of a 'profession,' even though some of these may not move very far in this direction.138 The abstract model of a "profession" noted by Vollmer and Mills is provided by Cogan, as follows:

A profession is a vocation whose practice is founded upon an understanding of the theoretical structure of some department of learning or science, and upon the abilities accompanying such understanding. This understanding and these abilities are applied to the vital practical affairs of man. The practices of the profession are modified by knowledge of a generalized nature and by the accumulated wisdom and experience of mankind, which serve to correct the errors of specialism. The profession serving the vital needs of man, considers its first ethical imperative to be altruistic service to the client. 39

Other authorities included by Vollmer and Mills in their work provide similar definitions to the above, but two should be mentioned who include additional insight into the concept of profession. A. M. Carr-Saunders states:

A profession may perhaps be defined as an occupation based upon specialized intellectual study and training, the purpose of which is to supply skilled service or advice to others for a definite fee or salary. I say fee or salary. It is sometimes held that the typical professions, or even that the only true professions, are those in which the practitioners are free lance workers and therefore remunerated by fee. . remuneration is only of the

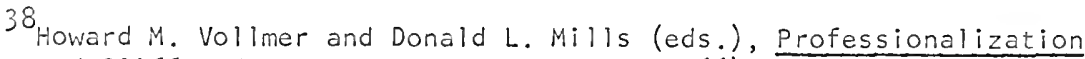
(Englewood Cliffs, N.J.: Prentice-Hall, Inc., 1966), pp.vii-viii.

39 Morris L. Cogan, "Toward a Definition of Profession," Harvard Educational Review, XXIII (Winter, 1953), 49; cited by Vollmer and Mills, p. vii. 
essence of the matter insofar as it may be direct and definite. 40 Greenwood considers the attributes of a profession to include: (1) systematic theory, (2) authority, (3) community sanctions, (4) ethical codes, and (5) a culture. 4

One of the largest occupational categories employed in the typical general hospital is that of the professional, or registered, nurse. Along with her "practical" counterpart, nurses make up the single largest occupational component of the hospital structure. 42 This is by no means the extent of professional participation in general hospitals but the nurse is most typical in regard to the source of her professional identification. 43

${ }^{40}$ A. M. Carr- Saunders, "Professions: Their Organization and Place in Society, " Professionalization, eds. Howard M. Vollmer and Donald L. Mills (Englewood Cliffs, N.J.: Prentice-Hall, Inc., 1966), p. 4.

41 Ernest Greenwood, "Attributes of a Profession," Professionalization, eds. Howard M. Vollmer and Donald L. Mills (Englewood Cliffs, N.J.: Prentice-Hall, inc., 1966), p. 10.

42 American Nurses' Association, Facts about Nursing (New York: American Nurses' Association, 1967), p. 19; and, American Hospital Association, "Hospital Statistics," Hospitals: Guide Issue, ILI, 2 (August, 1, 1967), 542.

43 American Nurses' Association, p. 19, includes 23.6 per cent of the staff of American hospitals in the arbitrary category of professionals when compared to the overall staffing count compiled by the American Hospital Association, and reported in "Hospital Statistics," p. 452. Seventeen per cent of the total staff of American hospitals are registered nurses, as indicated by the same data; the American Nurses'Association does not consider the practical nurse in the professional category, but they make up approximately 7 per cent of the total hospital staff. The remainder of the professional category included by the American Nurses' Association are such occupations as medical technologist, dietitian, social worker, and radiologic technologist. This method of classification is comparable to that mentioned by Georgopoulos and Mann, p. 58. 
Wessen notes that:

The ideology of the nurses. . is an outgrowth of the history of their profession. The very basis for the professionalization of nursing was rooted in the necessity for improving the quality of personnel who served hospital patients. In order to improve personnel, it was necessary to implant in them ideals of service of a very exalted sort; the profession of nursing thus became, $i^{n}$ the eyes of women like Florence Nightingale, a sacred calling.

While these factors may have played a large part in the degree of professionalization which has taken place among the various categories of occupations contained in the hospital structure, undoubtedly the close proximity of that epitome of professionalization, the physician, can also be counted among first causes. In most respects it can be recognized that the abstract model of the professional is most closely resembled by the concept of the physician in our society. The model of the physician is close at hand in the hospital setting and the values and attitudes of that profession are readily transferable to other participants in the health care system.

Otheremerging professions may not have as ready a model at hand to guide their striving for recognition as professionals; however, it cannot be denied that a tendency toward such indentification is sought by many diverse occupational groupings. 45 There are many theories advanced as to the reasons for this phenomenon beyond the simple motive of prestige.

${ }^{44}$ Albert F. Wessen, "Hospital I deology and Communication between Ward Personnel," Patients, Physicians and 11 lness, ed. E. Gartly Jaco (New York: The Free Press, 1958), p. 463.

${ }^{45}$ Vollmer and Mills, P. 2. 
Blumer includes the striving for prestige as but one explanation among many:

Professionalization represents an indigenous effort to introduce order into areas of vocational life which are prey to the freeplaying and disorganizing tendencies of a vast, mobile, and differentiated society undergoing continuous change. Professionalization seeks to clothe a given area with standards of excellence, to establish rules of conduct, to develop a sense of responsibility, to set criteria for recruitment and training, to ensure a measure of protection for members, to establish collective control over the area, and to elevate it to a position of dignity and social standing in the society. . . The pursuit of such complex goals is one of the most notable trends in the shaping of modern life; the movement toward professionalization is expanding in scope and becoming more sophisticated in character. 46

Goode comments that the degree of industrialization of a society is a determining factor in the rate at which professionalism is advanced. 47 Industrial societies are increasingly dependent upon professional skills, and the United States is probably typical in that there has been little change in the ratio of traditional professions to total population, but a many fold increase in total numbers of professionals to population has occurred over a brief period of time. 48 These newer professions as well as those of a more traditional standing are increasingly finding their

${ }^{46}$ Herbert Biumer, "Preface," Professionalization, eds. Howard M Vollmer and Donald L. Mills (Englewood Cliffs, N.J.: Prentice-Hall, Inc., 1966), p. xi.

47 William J. Coode, "Community Within a Community: The Professions," American Sociological Review, XXI1 (April, 1957), 195.

48

1 bid. 
place within the formal organization. 49

In respect to the degree of professional participation in the formal structure of an organization the hospital may be considered a model toward which other organizations are proceeding. The hospital could be thought of as having provided a proving ground upon which management solution to the problem attendent upon professionalization has been tested. Problems which hospitals are attempting to master today may be the problems of general business management tomorrow. If hospitals are representative of the universal structure of organizations, departing along a continuum from the modal organization in that degree to which it is marked by accommodation to the larger number of participating professionals, and if business and other institutions are progressing on a trend toward greater professional participation, then the hospital may provide the solution to incipient managerial problems or at least suggest the range of problems which will someday have to be faced.

Many superficial aspects of the range of problems associated with professional participation have already been commented upon in other reports. 50

49 Warren G. Bennis, in Changing Organizations (New York: McGrawHill Book Co., 1966), P. 25, notes: "Professional specialists, holding advanced degrees in such abstruse sciences as cryogenics or computer logic as well as the more mundane business disciplines, are entering all types of organizations at a higher rate than any other sector of the labor market."

50 W. Richard Scott, "professionals in Bureaucracies--Areas of Conflict," Professionalization, eds. Howard M. Vollmer and Donald L. Mills (Englewood Cliffs, N.J.: Prentice-Hall, Inc., 1966). 
Scott comments that: "It appears that the higher the general prestige of the professional group and the more central their skills to the functioning of the organization, the more likely they are to be successful in their attempt to control the conditions under which they work, with the result that there is less actual conflict between professionals and representatives of the bureaucracy. 151 Kast and Rosenzweig addressing themselves specifically to the situation in hospital organizations remark that a continual power conflict exists between the various professionals and the administration, and that this conflict resists analysis by the traditional models of organization. 52 And, William G. Scott comments that the impact of professionalization may be so profound that the way of performing work in bureaucracies may become obsolete, and new forms of organization must be revealed. 53 Elsewhere he notes, on this same basis, that the goal of organizational theory must be the development of organizational forms which allow for the opportunity of self-realization of the individual within the organization. 54 This latter proposition, and its link with professionalization in the prototype organization, will be of major concern in this paper.

5 lbid., p. 275.

52 Fremont E. Kast and James E. Rosenzqeig, "Hospital Administration and Systems Concepts," Hospital Administration, XI (Fall, 1966), 25.

53william G. Scott, Organization Theory: A Behavioral Analysis, p. 260. 54 ibid., p. 258. 
As has already been noted Katz and Kahn provide a sharp dichotomy between those organizations whose through-put is the transformation of objects versus those which are concerned with the molding of people-essentially the separation of business from non-business forms of organization with hospitals and educational institutions included as typical of the latter, and with due exception provided for those business organizations labeled as "tertiary economic structures" which provide service functions. 55 While notable differences in the structure of organizations and the process of management may be related to the materials which provide the basis for the productive process conducted in the organization a more suitable differentiation is provided by the technological methods employed in the processing function. In other words it is product which dictates the technology of production and its associated managerial p rocess and organizational structure rather than the nature of the material being transformed. The basis of this contention rests in the observation that the objective of the organization, as it is linked to the larger society, provides the basis for structure, process, and technology. 56

New evidence indicates that the departure from the structure of the universal organization is functionally related to the technology of production. 57

55 Katz and Kahn, p. 115.

${ }^{56}$ This point will be more fully developed in Chapter 11.

57 Joan Woodward, Industrial Organization: Theory and Practice (London: Oxford University Press, 1965), p. 50. 
That is: ". . . forms with similar production systems appeared to have similar organizational structures." 58 The extremes of technology identified by Joan Woodward are production of units to customers' requirements and continuous flow production of liquids, gases, and crystalline substances with mass production of individual items assuming a middle ground position. 59 Intermediate between the mass production techniques and each of the extremes lie batch methods of production. 60 Woodward's study of 100 industrial firms in South Essex allowed a separation into those which conformed to "mechanistic" and "organic" forms of organizational structure. '61 "MMechanistic' systems are characterized by rigid breakdown into functional specialism, precise definition of duties, responsibility and power, and a well developed command hierarchy through which information filters up and decisions and instructions flow down." 62 "'organic" systems are more adaptable; jobs lose much of their formal definition, and communications up and down the hierarchy are more in the nature of consultation than of the passing up of information and the receiving of orders." 63 Woodward's conclusions provided that:

- . there was a tendency for organic management systems to predominate at the extremes of the technical scale, while mechanistic systems predominated in the middle ranges. Clear cut definition of duties and responsibilities was characteristic of firms in the middle ranges, while flexible organization

58 lbid. $\quad 59$ lbid., pp. 38-39. 601bid.

6lWoodward, p. 23, citing Tom Burns, Management in the Electronic Industry--a Study of Eight English Companies. Social Science Research Centre, University of Edinburgh; and Honor Croome, The Human Problem of Innovation (H.M.S.O., 1960).
62
lbid.
63 lbid. 
with a high degree of delegation both of authority and of responsibility for decision-making, and with permissive and participating management, was characteristic of firms at the extremes. There was less "organizational consciousness" at the extremes; it was the firms in the middle ranges which found it easier to produce organization charts.

Much of the criticism over the employment of management techniques associated with the management process derived from the structure of the universal organization is based upon the concept that the management process is exclusively associated with mass production technology. 65 The defense of the integrity of a separate administrative process such as hospital administration is often offered in terms of the inapplicability of these productive techniques to the hospital situation. Georgopoulos and Mann, in commenting upon the differences between hospitals and business, include the following comment in regard to the former:

The nature and volume of work are variable and diverse, and subject to relatively little standardization. The hospital cannot lend itself to mass production techniques, to assembly ine operations, or to automated functioning. 66

And elsewhere Georgopoulos comments:

- . the main objective of the hospital is to render personalized care and treatment to individual patients, according

64 Woodward, p. 64.

${ }^{65}$ Etzioni, in Comparative Analysis, p. 214 , comments that utilitarian that is, economic organizations are as a rule highly routinized. He describes as typical of business organizations the mechanistic structure and process described by Woodward.

${ }^{66}$ Georgopoulos and Mann, p. 63. 
to their particular problems and needs, rather than mass production or the manufacture of some uniform product. Consequently, much of the work in the system cannot be standardized or mechanized. 67

However, as the work of Woodward indicates, the mass production model of the business organization is a limited case.

This phenomenon of diverse forms of accommodation to technology is well recognized in the management literature at the same time as the universality of structure and management process is being supported. Ernest Dale, the foremost empiricist in management thought, has commented upon the diversity of technology employed in various enterprises and how the technology employed limits the structure of organization which can be utilized. 68 But in spite of this diversity of structure and associated technology, Dale maintains that common organizational characteristics can be distinguished. 69 Therefore, it can be accepted that the management process and its collateral techniques are associated with a wide range of organizational forms.

More important for present purposes is the observed similarity between the unit production methods of industry described by Woodward and the patient care process performed in general hospitals. The product or service produced in the unit production firm is tailored to the customer's

67 Georgopoulos, p. 12.

68 Ernest Dale, Management Theory and Practice (New York: McGrawHill Book Co., 1965), P. 197.

69

lbid. 
specification. As scott has noted, the foreman in charge must be highly qualified and capable of handling the variety of technical problems Which often occur with the production of a customer's order under job order conditions. 70 The nurse in charge of the comparable task in the general hospital faces a similar situation and must be as highly technically qualified. Each patient, in addition to being a unique personality, is manifesting a disease condition unique to his individual characteristics, and, in addition, has specified for him a course of treatment peculiar to the individual evaluation of his physician. While the product in each case is dissimilar from any other case and the specified productive techniques are totally unrelated, the process itself, from a structural and managerial point of view, is quite similar. In each case it would be expected that an organic form of organization and mangement would be present, and, in fact, such is found to be true.

In many respects the unit production industries reported by Woodward are quite unsophisticated as compared to the typical general hospital although they both adhere to the organic form of structure. For example, Scott, reporting on the unit production method firms, noted that, because of the small size of the job order shop, the technical staff usually is not large; the staff has not usurped the foreman's prerogatives; and the functions of planning organizing, and controlling still devolve on the foreman to a great extent. 71 As will be demonstrated, the hospital is

70 William G. Scott, Organization Theory: A Behavioral Approach, p. 345. 71 ibid. 
quite different in these specific respects. It would therefore appear that the technological process itself is determining of the organic nature of the appropriate organizational structure.

It will be hypothesized that the hospital organization provides a prototype for large and complex organizations devoted to the tasks of unit production. It will be further hypothesized that the hospital organization is descriptive of the organic forms of management associated with such organizations, and that, as Woodward describes it, a technological continuum exists along which the fundamentals of the management process and its associated techniques are transferable. It will also be suggested that the prevalent trend is toward a reduction of emphasis upon the production of products in the manner conducive to assembly line techniques and a growing emphasis upon unit and process methods of production. 72 In that both of these latter technologies of production employ organic methods of management and organization the hospital will provide a model of successful accommodation as well as of problems yet to be resolved.

Bell has described a discretionary model of organization. ${ }^{73}$ His position is that three independent variables are associated with the

72 The arguments advanced by Marshall McLuhan, in Understanding Media: The Extensions of Man (New York: The New American Library, 1964), PP. 281-282, are perhaps representative of the cultural implications involved in the reduced employment of mass production techniques and an increased emphasis upon unit production methods.

73 Gerald D. Bell, Organizations and Human Behavior (Englewood Cliffs, N.J.: Prentice-Hall, Inc., 1967). 
degree in which an employee of the organization can render judgment and exercise discretion in the performance of his assigned tasks. 74 Bell's dependent variable is therefore the degree of discretion provided the employee. If extended to the organization as a whole one can see the similarity with the organic structure described by Woodward. 75 Bell provides that the three independent variables which determine discretion are the predictability of work, management control, and professionalization. 76 The individual will have relatively more discretion in the accomplishment of his tasks if: the work assigned is relatively ill-structured in respect to its patterned flow and the method to be applied; management chooses to exercise loose control over the employee, and; he is a professional by training. 77 Bell further believes that the independent variable, management control, can be considered related, or mutually determined, by the variables: predictability and professionalization. 78 Blau and Scott also shed insight on the relative laxness of management controls when the two factors of unpredictability and professionalization are operative by referring to the schema of Parsons which allows for clean-cut breaks between the technical and management levels of the hierarchy in such situation. 79

\section{4 ibid., p. 99.}

75 Woodward, p. 23. Note that Bell's work and authorities are entirely independent of the research conducted by Woodward in England.

76 Bell, pp. 99-100.

77 lbid. 78 lbid., p. 99.

79 Blau and Scott, p. 39. 
Predictability, as expressed by Bell, is comparable to the industrial examples presented by Woodward as the unit production technology. The essence of unit production is uniqueness--that which could not be predicted from past experience--the one-of-a-kind task demand, totally unrelated to the work performed in the past, or that which will be performed in the future. Bell is obviously describing a broader phenomenon than the limited industrial example of Woodward.

It is, therefore, these two variables which are selected as representative of the influences which suggest the hospital as a prototype of organizational structure. It will be maintained that the hospital demonstrates a ready example of the influence of these two variables when they are expressed in their most exaggerated form. Hospitals can be considered as epitomizing the influence of professionalization of the work force upon the organization structure. Hospitals represent the furthest extent toward which unit methods of technological production have been carried. If each of these factors can be considered as representative of a trend within our society then one could expect that the tospital would provide a model of the universal organization in transition.

It must be acknowledged that these two variables of interest are not independent of one another except as a conceptual method of providing explanation of the phenomenon evidenced by the organic structure of organization. Bell admits a relationship between the skills required to master the unpredictable work assignment and the techniques associated with the professional employee. 80 Woodward remarks on a resemblance 801bid., pp. 99-100. 
between the unit and process production firms in addition to their organic structure, that being the degree in which each employs a large number of skilled workers in contrast tc the batch and mass production firms. 81 Vollmer and Mills also note the link between technological advance toward sophisiticated techniques and rapid increase in professionalization. $^{82}$ it could also be argued that the link between the two is not in the single direction of first, unit production technology and then professionalization. Increased degrees of professionalization may supply the value system which demands the treatment of the productive act as a unique experience only amenable to unit production methods. However one would approach this linkage between professionalization and the individualized product within the organic organization is not of the essence of the argument being presented. They can be treated in their separate entities as suggested earlier or as a blend of manifest phenomena in the manner related above. It is even possible to relate additional factors such as increasing levels of education to reinforce the dynamic process of cultural change which is shifting the universal organization along the continuum toward an organic structure. Of more practical importance is the availability of a prototype which will assist in the understanding of the organizational processes involved in the shift from mechanistic to organic structures.

\footnotetext{
81 Woodward, p. 61.

82 vollmer and Mills, p. 22.
} 
Other writers have suggested within a similar context the prototype possibilities inherent in the hospital organizational structure. Bennis allows that hospitals along with universities and research and development organizations appear to mark the trend along which other organizations are traveling, and he advises investigation of the problems and attributes of these organizations for their prototype possibilities. ${ }^{83}$ Perrow alludes to a natural history of organizational change and suggests that profit-making organizations could look to hospitals and other voluntary service organizations for possibilities in the areas of tasks, authority, and goals. ${ }^{84}$ Freidson suggests that the study of industrial sociology might benefit from study of the hospital organization in regard to service industry relations with consumers. ${ }^{85}$ And, Hughes provides that:

- . the organizations in which professions work show patterns of authority and interaction which, according to earlier theories of organization, could not possibly work. They are, in general, organizations with more staff than line; their special importance for the study of social organizations is that they give us new models to work on just when business organizations, which students have been inclined to take as the prototype of rational organization, are themselves becoming so cluttered by staff advisors (of various old and new professions) that the line is scarcely distinguishable, and this is very frustrating. The

83

Warren G. Bennis, "Organizational Developments and the Fate of Bureaucracy," Industrial Management Review (Spring, 1966), p. 51.

${ }^{84}$ Charles Perrow, "The Analysis of Goals in Complex Organizations," Readings in Organization Theory: A Behavioral Approach, eds. Walter A. Hill and Douglas M. Egan (Boston: Allyn and Bacon, Inc., 1966), p. 143.

${ }^{85}$ Eiot Freidson, "Review Essay: Health Factories, The New Industrial Sociology," Social Problems, XIV (Spring, 1967), 493. 
newer generation of businessmen, instead of proposing that universities, hospital, and government agencies (in which the efforts of professional people are somewhat coordinated) be run in a business-like fashion, may turn to these madhouses for ideas on how to organize their own enterprises; for the staff people, insofar as they are really professional, have another loyalty than that to their employers; they belong to professions which have some sense of solidarity and autonomy. 86

If the hospital is accepted as a prototype and it can be demonstrated that it lies on a continuum along which the universal organization can be described then the means of transference of management principles from the modal organization to the prototype can be facilitated. 87 More important, it will be possible to consider the acceptability of these principles in the prototype organization on the basis of their relationship to the structure of organization. If a continuity of structure does exist it may well be that new lessons learned in the prototype can be transferred to the modal organization to ease the pains of passage.

${ }^{86}$ Everett $C$. Hughes, "The Professions in Society," Canadian Journal of Economics and Political Science, XXVI (February, 1960), 58-59.

87 For a discussion of the concept of principles of management and their association with "principles of organization," see Terry, pp. 1617; or, Hutchinson's summary of the management principles, p. 103. The link between the principles of management and the universal organization is outlined by Ralph Currier Davis, in The Fundamentals of Top Management (New York: Harper and Row, Publishers, 1951), p. l. For the concept of application of these principles within the nursing function of hospitals see: Thora Kron, Nursing Team Leadership (Philadelphia: W.B. Saunders Co., 1961), p. v. Woodward, pp. 245-246, comments upon the impact of her research on the accepted principles of management and the reaction of the management community in this regard. 
New interest is being generated in regard to the solution of social problems using the techniques of business management. Zalaznick reports in a recent article the trend in university schools of business to broaden their scope to encompass diverse administrative problem areas, including the health care field, in recognition of the broad transferability of managerial techniques. 88 Much of the success of this attempt, as noble as its aim, will be dependent upon a proper appreciation of the organizational structure involved. As Cyert and March have stated:

When we leave the area of the firm, we are likely to hear with impressive frequency that the structure, position, task, or history of a certain organization is unique. What we tend to forget is that the uniqueness in this sense is not an attribute of the organization alone; it is an attribute of the organization and our theory of organization. An organization is unique when we have failed to develop a theory that will make it nonunique. This uniqueness is less a bar to future theoretical success than a confession of past theoretical failure. 89

This study will attempt to relate the methods of dynamic organizational analysis which underlie the management process to the hospital structure. The two factors of relative professionalization and sophisticated unit production technology will be considered as the elements of concern in the dynamic process. The Appendix to this report will relate the substance of the dynamic analysis and its place within the variety of

${ }^{88}$ Sheidon Zalaznick, "The M.B.A.: the Man, the Myth, and the Method," Fortune, LXXVI1 (May, 1968), 168-171, 200,202, and 206.

${ }^{89}$ Richard M. Cyert and James G. March, A Behavioral Theory of the Firm (Englewood Cliffs, N.J.: Prentice-Hall, Inc., 1963), p. 287. 
topics labeled as organization theory. The structure of hospital organization will be briefly sketched in a form amenable to the dynamic analysis--that is, the question of objectives will be investigated and the structural elements of 1 ine and staff presented. With these established it will be possible to investigate the anomalies of hospital organization which have been reported by the authorities and which support the allegation of a dichotomy of structure. The prototype organization will then be described in terms of those characteristics which are unique to this form of organization and as they relate to the dynamic process itself. In conclusion the report will attempt to describe the management process as it must cope with the most salient of the prototype characteristics from the coordinative point of view. 
CHAPTER II

\section{ORGANIZATIONAL OBJECTIVES}

The concept of formal organization implies a grouping of human participants for the purpose of achieving specific objectives. Mooney expresses this concept as follows: "Organization is the form of every human association for the attainment of a common purpose." Although many aspects of formal arganization can be debated these two elements of a multiple of participants and specific objectives are accepted by all reporters as the fundamental characteristics of this form of social unit. This expression of formal organization is a narrower construction than the concept of social organization. ${ }^{2}$ Blau and Scott denote the broader idea by the elements of human participation and a shared value system. 3 This shared value system may be construed as providing objectives to the social grouping; however, these values are accepted as

1 James $D$. Mooney, The Princioles of Organization (Revised Edition; New York: Harper and Brothers, Publishers, 1947), P. 1.

${ }^{2}$ The following writers are representative of this view of formal organizations. Rocco Carzo, Jr. and John N. Yanouzas, in Formal Organizations: A Systems Approach (Homewood, 111.: Richard D. Irwin, Inc., 1967), p. 11, provide that: "Formal organizations are different from other social institutions in that they are designed to accomplish an explicit purpose." Talcott Parsons, in "Suggestions for a Sociological Approach to the Theory of Organizations--1," Administrative Sciences Quarterly, I (Septembe:. 1956), 64, notes that: ". . .primacy of orientation to the attainment of a specified goal is used as the defining characteristic of an organization which distinguishes it from other types of social systems."

3 Peter M. Blau and W. Richard Scott, Formal Organization (San Francisco: Chandler Publishing Co), pp. 1-5. 
residing in the culture of which the individual group member is a part. 4 Formal organizations, on the other hand, are characterized by objectives which are formally selected for achievement. 5 This purpose implied in formal organizations when taken as its unique characteristic can be demonstrated to provide the essential elements of organizational design and, therefore, it is the source of the concept of universality of structure.

The use of the word objective for this essential purpose in formal organizations can be debated from a semantic point of view. In the literature of management the word is found interchanged with the word goal with no apparent resulting confusion; standard dictionaries imply that the words, objective and goal, can be used synonomously. Specific authorities usually define the words separately when they are to be used for purposes of exposition. Hutchinson, for example, provides that goals are guides for organizations while objectives are to the individual what goals are to the organization. 6 However, it would appear that the consensus in regard to usage contained in the literature concerning organizations relates the word objective to the common purpose implied in these structures. For purposes of this report the word objective will be used in a similar manner to denote the broad, overall purpose inherent in formal organizations. Where the usage of the terms cited from other sources in this regard conflicts with this intention the

4 lbid, pp. 4-5. $\quad 5$ lbid., p. 5.

6 John G. Hutchinson, Organizations: Theory and Classical Concepts (New York: Holt, Rinehart and Winston, i967), p. 39. 
meaning may be implied from the context in which it appears or the term will be suitably clarified.

This definition of formal organization does not imply that the objective of the organization is determined by the human participants in the organization itself, or by some selected segment of the participants. The objective of the organization is resident in the values and needs of the society which it serves--the management of the organization, at best, performs an interpretive function which recognizes the apparent, or incipient, desires of the society and develops the structure to service these values and needs. It is this vital link between the organization and society which is overlooked in many of the descriptive studies of organizational structure, al though in the practical affairs of man an error arising in the interpretive function should quickly be corrected by the nature of this link and the system by which it is supported.

Talcott Parsons speaks of this link between the organization and society as resident in the power which is a generalized societal resource allocated to the various organizations to act as an agent for the society in the attainment of its various objectives. 7 Davis clarifies the link between society and the business organization by visualizing this power in the expression of the right to private property and its interpretation under law. 8 in return for the authority granted by this institutionali-

7 Talcott Parsons, "Suggestions for a Sociological Approach to the Theory of Organization--11," Administrative Sciences Quarterly, 1 (December, 1956), 226.

${ }^{8}$ Ralph Currier Davis, The Fundamentals of Top Management (New York: Harper and Row, Publishers, 1951), p. 91. 
zation of society's power the business organization is expected to provide the values which society desires. 9 Dale simplifies this link in the case of business enterprises by noting that these organizations define their objective by determining what their customers are really paying them for rather than narrowly identifying their objective with a specific, and perhaps transient, product. 10 John Mee makes this same concept dynamic by noting the various environmental forces which cause a constant process of objective interpretation by an organization if it is to remain viable within the society which is the source of its authority. 11 While these latter authorities relate this concept of the source of business objectives in the values desired by society, the power link between all organizations and the society remain the same. In fact, it can be maintained that the link of the voluntary hospital organization to the society is typically through the mechanism of the right to private property as described by Davis, rather than through the more subtle mechanism of the right of association which determines the objectives of various political and purely social organizations.

This approach to the determination of the source of organizational objectives has been criticised as being too idealistic and at variance

\section{ibid.}

10 Ernest Dale, Organization (New York: American Management Association, 1967), p. 54 .

11 John F. Mee, Management Thought in a Dynamic Economy (New York: New York University Press, 1963), p. 94. 
with the true nature of the organizational process. Etzioni remarks that: "In practice, goals are often set in a complicated power play involving various individuals and groups within and without the organization, and by reference to values which govern behavior in general and the specific behavior of the relevant individuals and groups in a particular society."12 This difference in regard to the methods whereby power is employed in the establishment of objectives is explained by Parsons to be the result of the level of analysis which is employed by the researcher. 13 He suggests that the determination of objectives through individual power acts, as a theoretical design, has resulted from the role and group analyses which have been performed on a micro-organizational level, holding all other influences constant. 14 More realistic, he suggests, is an ackowledgment of the disciplinary powers of the larger, encompassing society. 15

Closely linked to the argument advanced by the proponents of the role and group behavior approach to the determination of objectives is the apparent diversity of objectives contained within any single organization. Etzioni considers this to be a phenomenon resulting from the perversion of the original objective of the organization derived from society's desires. 16 He maintains that once organizations are formed

${ }^{12}$ Amitai Etzioni, Modern Oraanizations (Englewood Cliffs, N.J.: Prentice-Hall, Inc., 1964), Pp. 7-8.

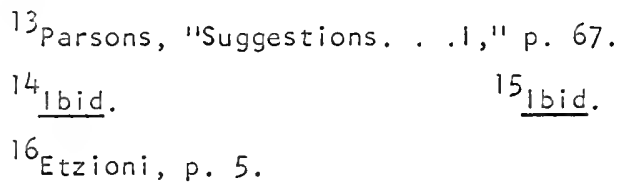


they acquire their own needs and these often become the masters of the organization. 17 Kast and Rosenzweig believe that traditional management theory was amiss in assuming a clear-cut objective which provided little insight into the multiple objectives of complex organizations. 18 These authors believe that systems theory will overcome this supposed deficiency of traditional theory; this belief is supported in a similar manner by Katz and Kahn. 19 The latter authors maintain that in spite of this oversight on the part of traditional theorists the stated objective as expressed in policy may be a starting point in organizational analysis. 20 These criticisms in regard to the multiple objectives found in organizations, negating the concept of a single objective inherent in the traditional theory, would be valid, for such are observed to exist, if traditional theory held such a point of view. However, such is not the case, as will be elaborated later.

What is maintained, in the mainstream of management thought, is the concept of the primacy of a single organizational objective--that objective which is derived from the values and needs of the society in its environmental context. This point is emphasized by fox in his

\section{1 bid.}

18Fremont E. Kast and James E. Rosenzweig, "Hospital Administration and Systems Concepts," Hospital Administration, XI (Fall, 1966), 27.

19 Daniel Katz and Robert L. Kahn, The Social Psychology of Organizations (New York: John Wiley and Sons, Inc., 1966), Pp. 15-16. 20 Ibid. 
reiteration of the primacy of this objective in regard to business enterprises:

The right to engage in private business stems from the right of private property, and this right may be modified, extended, or withdrawn as society desires. A firm must be concerned with formal goals--service to society--if it wishes to survive and prosper. . . For the success and sustained existence of such a firm in our society depends on its ability, relative to the ability of other producers, to meet the need of customers efficientiy. 21

This service to society--the salable values that the business plans to create and distribute--are defined as the primary service objectives of the organization. 22

This concept of the discipline of the market place is well accepted in economic theory as applied to the business organization. The apparent pleasure or displeasure of the society is often witnessed through the accountant's measure of profits gained or lost; however, first causes in these cases must be attributed to the link between the organization and the society as manifest in the primary service objective of the organization. Profits of a particular organization must ultimately be related to the finesse with which the management of the organization has performed its interpretive function.

The concept of profits as an organizational objective has often been used as a mark of separation between various organizations. Tnis has been

21 William McNair Fox, The Management Process (Homewood, 111.: Richard D. Irwin, (nc., 1963), p. $6 \overline{8}$.

22 bid., p. 69. 
expressed as the basic dichotomy between the hospital and business structures of organization by many commentators. Bloom considers the profit motive as the fundamental difference in objectives between the two forms of organization with the hospital substituting an orientation toward service to the community in place of the 'baser' motivation of the business organization. 23 Georgopoulos and Mann extend this concept even further by maintaining that the economic value of the hospital organization's objectives are secondary to their social and humanitarian values. 24 Undoubtedly this refers to some idea that the primary service objective of the business organization is the product itself rather than the utility which it provides to society. Yet this is at variance with the observations of management theorists who reiterate an emphasis upon the values provided to society in acknowledgment of the practical comments of analysts who emphasize the necessity of business organizations to define their objectives in terms of ultimate utilities rather than narrowly upon specific products which may soon be outdated. The nonprofit categorization of voluntary hospital neither removes the conflict among the internal membership of the organization in regard to the share of each in the sustaining values provided by the enterprise, nor does it eliminate the perverted emphasis upon the product itself rather than the utility provided which may be as prevalent in non-profit organizations as

${ }^{23}$ Samuel W. Bloom, The Doctor and His Patient (New York: The Free Press, 1963), p. 167.

24 Basil S. Georgopoulos and Floyd C. Mann, "The Hospital as an Organization," Hospital Administration, VII (Fall, 1962), 62. 
those which contain membership sustained by profit.

Even those authorities who recognize the role of profits as a measure of effectiveness unique to business organization fail to recognize that other measures of performance are equally as valid in the determination of the relative success with which the organization has served its primary service objective. The use of a measure other than profit does not remove the organization from the realm of economic performance. Rosenberger, however, appears to express the concept that the profit motive is determinant in the selection of management. 25 Nevertheless, it appears fallacious to argue that the selection of organization leaders would be based on anything less than the ultimate success of the organization in meeting its service objectives. Etzioni appears to be the originator of this particular argument. ${ }^{26}$ Although elsewhere he modifies this viewpoint to the extent that while both forms of organization are responsive to measures of effectiveness the business organization is able to facilitate this measurement through the availability of the profit gauge. 27 This concession to a similarity among all organizations is further extended by his recognition that the profit measure of private business must be qualified by the vagaries of cyclical econonic activity. 28

${ }^{25}$ Donald M. Rosenberger, "A New Look at Hospital Organizations," Hospitals, XXXVI (February 1, 1962), 44.

${ }^{26}$ Amitai Etzioni, "Authority Structure and Organizational Effectiveness, "Administrative Sciences Quarterly, IV (June, 1959), 49.

27 Etzioni, Modern Organizations, p. 9. 28 lbid. 
It is rare in management literature to find a statement which reflects profit as the objective of a business organization. This notion appears more frequently in the writings of those outside of the disciplines of management and economics where an attempt is being made to differentiate the various forms of organization. Actually, the terms profit organization and non-profit organization are lega? terms rather than some analytical device involved in the determination of the organizational and managerial process.

One sociologist who has taken cognizance of the relationship of the economic and social systems is Talcott Parsons. ${ }^{29}$ Based on his studies of the institutional structure of society he asserts that profit cannot be the primary organizational goal because profit-making is not by itself a function performed on behalf of the society as a system. 30 Mee makes the same point by asking two questions:

What is the primary purpose of business enterprise--to serve customers and provide employment or to utilize and increase the capital of owners? Is profit the end product, or is it a feedback means to provide more and better products and human satisfactions for more people? 31

Urwick's position taken at an earlier time is just as adamant in regard to the misconception in regard to profit and the objectives of the

${ }^{29}$ See particularly Talcott Parsons and Neil J. Smelser, Economy and Society (New York: The Free Press, 1956), for a structure of society which incorporates the economic system.

30 parsons, "Suggestions. . .1," p. 68.

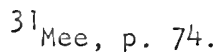


business organization. 32 He maintains that profit is a stimulus to individuals to participate in business activity, but, more important, it is also a measuring rod, a test of the success with which the real objectives of the business are being attained. 33 Davis provides that the objective of a business is service, while profit is a personal objective of a businessman. 34 A business will fail, Davis maintains, when any important group within it, whether capital, management, or labor, succeeds in subordinating the organization's primary service objective to its personal interests. 35 And, Terry incorporates the economic argument of profits being a residual resulting from the production and distribution of a product or service directed toward satisfaction of the organization's primary objective of service to the society. 36

It could be maintained that many of the above writers cited have a vested interest in emphasizing a primary objective of service to society because they are of the management school of thought and would be expected to support the transferability of the management process across organizational lines. Nevertheless, it is found that this same

32 L. Urwick, The Elements of Administration (New York: Harper and Row, Publishers, 1943$),$ P. 27.

33 ibid.

34 Davis, p. 104.

35 lbid., P. 105.

36 George R. Terry, Principles of Management (5th ed. rev.; Homewood, 111.: Richard D. Irwin, Inc., 1968), PP. 37-38. 
conclusion is being derived in other approaches to organization theory since the pioneering efforts of Parsons. The open-systems theory expounded by Katz and Kahn notes the appearance of intrinsic and extrinsic functions performed by all organizations. ${ }^{37}$ The intrinsic function is the transformation process which results in a product or service for society, while the extrinsic functions are the relationship of the organization in terms of inputs and outputs with its surrounding environment. 38 profit would be considered as an extrinsic link between the business organization and the providers of capital inputs as it is subsidiary to the primary transformation process. ${ }^{39}$ As they summarize this concept in terms of the efficiency at which the organization performs the transformation process and maintains its relationship with the surrounding environment it matters not whether the organization is specified as non-profit. 40 For:

The concept of efficiency does not have meaning only for business organizations, and the survival benefits of efficiency are not limited to profit-making organizations. These notions are inherent in the characteristics of human organizations as open systems. They remind us that the ultimate decision to give or withold the needed organizational inputs lies in the environment, and that the larger social environment in this way holds the power of life and death over every organization. 4 ?

The primary service objective of the hospital organization will only

37 Katz and Kahn, p. 62.

38 lbid. 39 1bid. 40 lbid. 41 lbid., p. 161. 
briefly be mentioned at this point for the concept best receives definition in its interplay with structural design. In fact, by reference to the various authorities it is obvious that little disagreement exists in regard to the primary service objective because it is stated in the most general nature as it regards the service provided to society. Ceorgopoulos maintains that little ambiguity exists in regard to the primary organizational objective of highquality care and service to the patient and the subordination of various functions such as teaching and research to this objective. 42 Elsewhere he modifies this slightly by providing that the primary objective of a hospital is to provide adequate care and treatment to its patients, recognizing that such care must be within the limits of medical knowledge and reasonable allocation of resources. 43 Although Wessen establishes a hierarchy of objectives for the hospital organization he awards the primary position to the giving of care to patients. 44 As will be seen the other objectives on his hierarchy can be included in the category of secondary and collateral service objectives. MacEachern also identifies the primary function of the hospital as being the care of the sick and injured. 45 It will be seen, however, that although

42 Basil S. Georgopoulos, "The Hospital System and Nursing: Some Basic Problems and Issues," Nursing Forum, V (1966), 8-11.

${ }^{43}$ Georgopoulos and Mann, p. 50.

44 Albert $F$. Wessen, "Hospital Ideology and Communications between Ward Personnel," Patients, Physicians and 11 lness, ed. E. Gartly Jaco (New York: The Free Press, 1958), pp. $458-459$.

45 Malcolm T. MacEachern, Hospital Organization and Management (Berwyn, 111.: Physicians' Record Company, 1962), p. 29. 
general agreement exists in regard to this statement of the primary service objective of the hospital organization there can be considerable disagreement in regard to the scope of this definition of objective when it is employed in the analysis of the structure of the hospital organization. This point will be further developed in the following chapter.

Additional insight is provided by this definition of primary service objective of the hospital organization as it is amplified by various other authors. Wessen remarks that the "heart" of any hospital is the patient ward, for it is here that the basic work, or primary service objective, of the organization is carried out. 46 A similar comment is made by MacEachern in his definition of the functions of the nursing service of the general hospital. 47 In each case the locus of the primary service objective of the hospital organization is found in the nursing service and the ancillary patient care functions. As Katz and Kahn would remark, it is here that the intrinsic functions of transformation are performed which result in the satisfaction of the primary objective of the organization.

It is maintained that the service provided by the hospital organization as detailed by these expressions of a primary service objective are identical in form with that provided by other organizations. The hospital organization's link with the larger society follows a pattern

\footnotetext{
46 Wessen, p. 448.

47 MacEachern, p. 512.
} 
described for other organizations which provide a tangible service to society. It is, therefore, not in the primary objective of the hospital organization that a separation between the hospital and the universal structure of organization will be discovered.

The importance of this point must be emphasized for it is with the statement of organizational objective that the analysis of organizational structure begins and it provides the thread of analysis throughout. The basis of this argument is, as Dale states, "Organization cannot be divorced from the idea of purpose. 148 He includes this point as the first of the classical principles of organization. 49 Carzo and Yanouzas also identify the classical concepts implied in this notion that the process of organization begins with objectives. 50 Before one can organize intelligently, Terry maintains, one must know the aims of an organization, and this objective statement helps determine the type and number of activities to be carried out, their relative importance, the type of people to include, and the social groups which will probably be formed. 51 Woodward states that the first step in building an organizational structure is to determine what purpose the organization has to serve. 52

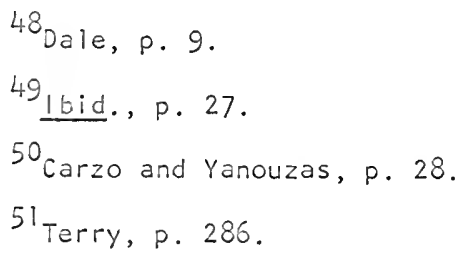


Davis concurs that, "The characteristics and requirements of functions and functional relationships are determined basically by the requirements for the satisfactory accomplishment of objectives. ${ }^{153}$

Davis describes the process whereby the structure of organization is developed from the organizational objective in his Principle of Functional Emergence. 54 He outlines the process of division of the objective of the organization into logical elements which are grouped on the basis of their functional similarity to provide for the most effective and economical attainment of this objective. ${ }^{55}$ In sum, the values demanded by the customers of the organization are the determinant of the structure which will be developed. 56

Simon's treatise on the decision-theory of organization described a similar process of specialization which follows functional lines derived from the object of the organization. 57 An important consideration in his argument is that this process implies the division and specialization of the overall organizational objective into sub-objectives which creates a hierarchy of objectives to match that of functions. 58 Simon demonstrates a comprehensive theory of decision-making based upon this fundamental process of organizing derived from functional differentiation.

53 Davis, p. 18

54 lbid., P. 328. 55 lbid. $\quad 56$ lbid., p. 330.

57 Herbert A. Simon, Administrative Behavior (2nd ed.; New York: The Free Press, 1957), p. 190.

58 Ibid. 
While each of these authorities who describe a process of functional differentiation flowing from the service objectives of the organization is identified with management theory, the same process is suggested by work on organization theory in other disciplines. One example is offered in Seeman and Evans report on an elaborate study to develop criteria of performance in the hospital setting. 59 Their study defined functional elements within the structure of the hospital which were related to specific sub-objectives of the overall organizational objectives and established that these were identifiable as basic organizational units. 60

In management theory perhaps the best summary of the process involved in organizing the activities of enterprise based upon organization objectives is provided by Koontz and 0'Donnell. 61 They describe the fundamental logic of organizing by the following seven sequential steps:

1. establishment of enterprise objectives;

2. formulation of derivative objectives, policies, and plans;

3. determination of activities necessary to execute these policies and plans;

4. enumeration and classification of these activities;

5. grouping of these activities in the light of human and material resources available and the best way of using them;

59 Melvin Seeman and John W. Evans, "The Objective Criteria of Performance," Medical Care: Readings in the Sociology of Medical Institutions, eds. W. Richard Scott and Edmund H. Volkart (New York: John Wiley and Sons, Inc., 1966), pp. 488-501.

60 1bid., pp. 489-491.

6l Harold Koontz and Cyril O'Donnell, Principles of Management (3rd Edition: New York: McGraw-Hill Book Co., 1964), pp. 212-213. 
6. assignment to each grouping, normally through its head, of of the authority necessary to perform the activities; and

7. tying these groupings together horizontally and vertically, through authority relationships and information systems.62

A recognition of the existence of a primary service objective in all organizations obviously does not answer the question as to the source of the variety of activities which are observed in every organization. These activities can ultimately be traced to the primary purpose of the organization, but their relationship to this objective is often tenuous and remote. It would neither be correct to ignore the multiplicity of unique goals which have been noted by observers, nor would it serve the purpose of the organizational analysis which is being attempted. It may already have been noted that the authorities cited have frequently pluralized the concept of objective, and this should now be explained.

Davis broadly separates the objectives of organizational activity into primary and secondary values to be supplied by organizational elements. 63 The primary values are those which have been defined as the primary service objectives of the organization as discussed above. Secondary values are those purposes which must be accomplished to discharge satisfactorily the primary service objective. 64 The secondary values which the organization is designed to supply may be broadly separated into the categories of purpose labeled by Davis as Collateral and

62 Ibid.

63 Davis, pp. 100-10!.

64 lbid. 
Secondary Service Objectives. ${ }^{65}$ As Fox has indicated:

Carefully formulated primary service objectives present a detailed enumeration of the salable values that a firm plans to create and distribute. They provide a frame of reference within which collateral and secondary objectives must be developed and within which organization structure should be designed. 66

This broadening of the objective base upon which the organization is constructed should not de-emphasize the concentration upon the purpose of the organization in relationship to the society it serves. Although the criticism is believed to be unjustified, scott has noted the possible overemphasis in traditional theory upon a singleness of purpose within organizations. ${ }^{67}$ He believes that this emphasis has tended to obscure the inner workings and internal purposes of the organization itself. 68 It will be maintained that the primacy of the objective of service is well taken as it bears upon the problems associated with organizational analysis; however, due recognition of the collateral and secondary service objectives must be included if this analysis is to be complete. Davis provides that the collateral service objectives are those values which the organization is expected to supply to groups that are a part of the organization. 69 While Davis extends this concept broadly to groups which are

65

lbid., pp. 102-106.

${ }^{66}$ Fox, pp. 69-70.

67 William G. Scott, Organization Theory: A Behavioral Analysis for Management (Homewood, 111.: Richard D. Irwin, Co., 1967), p. 107.

63 ibid.

69 Davis, p. 102 
associated with the organization and encompasses various social responsibilities of the enterprise, the essential internal participants are the owners and the workers. These collateral objectives are therefore the values and needs which the individual participants require to be satisfied in order to elicit their continued contribution toward the satisfaction of the primary service objective:

The secondary service objectives, as defined by Davis, include those values that are needed by the organization to enable it to accomplish its primary and collateral objectives with the required economy and effectiveness. 70 While this objective is subordinate to both the primary and collateral objectives it is the vital link between the two. This is apparent with the realization that in order to perform with satisfaction the requirements of both the primary and collateral objectives there must be a balance between the two, and this balance can only be obtained by satisfaction of the secondary service objective of performance with required economy and effectiveness. The roots of this concept are contained in the fundamental assumption of neo-classical economics which was elucidated by Alfred Marshall as the 'great' Principle of Substitution. 71 This principle assumed that the manager would always arrange his resources in the most efficient and effective manner technologically possible, for to do otherwise would reduce his competitive position. This optimal balance

70 lbid., p. 105.

71 Alfred Marshall, Principles of Economics (8th ed.; London: Macmillan and Company, Ltd., 1920), p. 550. 
of resources is rather more elaborate in economic terminology, but it implies the searching behavior of the manager who strives to discover the one best way to accomplish the primary objective of the organization and satisfy the demands placed upon the organization by its internal membership. While this principle can be assumed in economic theory it receives explicit recognition in management theory as the stated secondary service objective of the organization.

This same combinatorial arrangement of objectives in organizations is commented upon by other authorities who do not necessarily choose to use the same terminology employed above. Simon discusses the equilibrium of the organization in terms of the separate demands placed upon it by the owners, the customers, and the workers. ${ }^{72}$ Each of these parties to the activities of the organization has his individual needs which must be met if the organization is to survive, and the composite objective which can be obtained from this complex of needs is expressed as an organizational objective which is separate and distinct from those of the individual parties which remain as supplementary objectives. 73 He relates each of these objectives to inducements provided to the various participants and notes the variety of organizational forms which can be derived by siight modifications of these relationships of objectives. 74 Bennis performs a similar analys is of the organizational process through a

$$
\begin{aligned}
& 72 \text { Simon, pp. 16-18. } 74 \text { 1bid., pp. 110-112. } \\
& 73 \text { Ibid. }
\end{aligned}
$$


relationship of objectives which he equates to a system of reciprocity among the members of the organization and a system of adaptability to the internal and external environment. 75 The former, of course, is equivalent to the collateral service objectives while the latter is a complex included under the separate classifications of primary and secondary objectives.

It is in the collateral service objectives of the organization that the part played by profits in the business organization are clarified; however, it must be noted that profits are but one among many collateral objectives which must be satisfied if the organization is to succeed. Fox expresses this by noting: Mrimary service objectives are objectives of the organization; collateral objectives are those of the people associated with the firm, without whom primary objectives could never be attained. 76 Davis believes that collateral objectives are expected to be satisfied in some reasonable degree without any material or unnecessary sacrifice of the primary service objective. 77 These include good wages for employees, good salaries for executive employees, good dividends for investors, and other values, both tangible and intangible. 78 The intangible aspects involved in collateral service objectives will be

75 Warren G. Bennis, Changing Organizations (New York: McGraw-Hill Book Co., 1966), p. 7.

76 Fox, p. 70 .

77 Davis, P. 10.

78 1 bid. 
elaborated upon to some extent later in this study; however, it is sufficient to note that this concept encompasses the broad range of needs and values which participants in the organization will have apparent and which can be satisfied in the process of participation. Berelson and Steiner outline the ramifications of these intangibles in their expression of the objectives of the organization. 79

It is the relationship of this complex of primary, collateral, and secondary service goals which explain the behavior of organizations. The processes involved in the satisfaction of these objectives is the subject of extensive literature which is not relevant to the present study. However, there are certain aspects of this determining process which are interesting from the point of view of hospital organization and its comparison with the model of organization described in the management literature. Cyert and March provide that the goals of organization (which can be read as a sub-set of the complex of objectives) are a series of more or less independent constraints imposed on the organization through a process of bargaining among potential coalition members because the organization is a coalition of participants with disparate demands, changing foci of attention, and limiting ability to attend to all organizational demands simultaneously. 80 They also maintain that this coalition, or bargaining process is not unique to the business organization

79 Bernard Berelson and Gary A. Steiner, Human Behavior: Shorter Edition (New York: Harcourt, Brace, and World, inc., 1967), pp. 54-55.

80 Richard M. Cyert and James G. March, A Behavioral Theory of the Firm (Englewood Cliffs, N.J.: Prentice-Hall, Inc., 1963), P. 43. 
but it is manifest in all organizations although the effect is not as apparent in those enterprises which do not have the profit device of measurement. 81 Simon, however, maintains that the non-profit organization may not have as complicated a bargaining process, and conflict will be much reduced allowing a more firm emphasis upon the primary and secondary service objectives. 82

It is apparent that the range of objectives described in the management literature can also be described as operative in the hospital situation. While the hospital is generally a non-profit institution the needs of its individual participants are diverse and often in conflict with the primary and secondary service objectives. Rather than finding itself in conflict with the dividend claims of shareholders which is manifest in business organizations, the hospital must cope with the needs expressed by its unique form of owrership, the community as a whole. These needs may often be in addition to the values which the society has in regard to health care and which are expressed in the primary service objective of care of the sick and injured. Many of the subsidiary activities of the hospital organization may be directed toward the satisfaction of collateral needs expressed by this community ownership. The justification for such activities as the provision of parking lots for visitors, cafeterias and gift shops which cater to persons

$$
\begin{aligned}
& 81 \text { lbid., p. } 285 . \\
& { }^{82} \text { simon, P. } 121 .
\end{aligned}
$$


other than staff and patients, many of the public relations activities of the administrator, and the support of volunteer associations, can only be accepted under the concept of collateral values supplied to ownership. These needs of ownership are expressed, and the refusal of satisfaction on the part of management could have the same result as a refusal of dividends to shareholders of a business organization. Undoubtedly the hospital administrator would welcome the clear-cut demands of the profit seeker in preference to the diverse demands which ownership places upon the limited resources of the hospital organization, and which is often difficult to legitimize to other internal participants. In the following two chapters the concepts of objectives developed in this chapter will be employed to explain the structure of organization which exists in general hospitals. As has been noted the structure of organization can be explained by relating organizational elements to the objectives which they serve. It will be found that as described in management literature the hospital conforms to the principle that the line of the organization has responsibility for the primary service objectives while the broad concept of staff elements serve the collateral and secondary service objectives inkerent in all organized forms of activity. 83

${ }^{83}$ Davis, p. 100-101. 


\section{CHAPTER $\| /$}

\section{THE LINE ORGANIZATION}

The line of an organization refers to the chain of authority and responsibility which exists in an organization and provides for a specialization of the tasks associated with the creation and distribution of the primary service values which the organization has chosen to identify as its primary service objective. Each element in this "primary chain-of-command" is unalterably identified with the process involved in the creation and distribution of this primary service value. The removal of any element of this structure of tasks would result directly in the failure to satisfy the primary service objective.'

The line of an organization is created by a process of devolution of authority and responsibility for specific aspects of the work associated with the satisfaction of the primary service objective. This process results in a hierarchy of organizational elements extending from the head of the organization to the operative performers responsible for the tasks which create the value that is the objective of the organization. These elements are often identified as to their level in this hierarchy of authority and responsibility by such designation as units, departments, and divisions which imply that a lesser unit is subordinate to the superior department, and so on. ${ }^{2}$ In the line of

'Ralph Currier Davis, The Fundamentals of Top Management (New York: Harper and Row, Publishers, 1951), pp. 333-338.

2 bid., pp. $338-340$. 
the hospital organization the comparable elements may be designated as teams, units, wards, and departments with much the same implication as to a differentiation of the tasks to be accomplished and a necessary subordination of one level to another.

The elements of the line hierarchy are considered organic to the purpose of the organization. That is, these functional elements must be contained in the body of the organization in some form. The definition of the organic nature of a function is an attribute of its relationship to the primary service objective of the organization. In the business manufacturing organization these organic functions are considered to be production and distribution. 3 In the case of the hospital organization with the primary service objective of care and treatment of the sick and injured the organic functions would be such care and treatment. Those facilities directly involved in care and treatment, such as the nursing service and the ancillary services, would be a portion of the chain-of-command. 4 The complete removal of any one of these functions from the hospital organization would mean the failure of satisfaction of this objective although the function may be undifferentiated and contained within another unit at some particular point in time.

3William McNair Fox, The Management Process (Homewood, 111.: Richard D. Irwin, Inc., 1963), p. 77 .

While this is not a complete list the ancillary services include laboratories, x-ray, physiotherapy, occupational therapy, surgery, etc. Note, that by definition of organic functions this would not include such accepted hospital units as central supply and pharmacy which are auxilliary to the primary service objective of care and treatment. 

returning his patient to health--in the respect that a hospital is a sub-function directly employed in the cure of disease but not alone capable of performing this function, it is an organic element of the heaith care system. However, it must be emphasized that it is the physician who has the primary objective of cure while the hospital has but an element of this objective in its charge--care and treatment of the patient under the physician's charge.

This point is quite straightforward and accepted when the process of organizational analysis is performed. It only becomes confused when the elements of the health care system are studied in their individual parts and synthesis from this level upward is attempted. Any study of the scope of facilities provided in the modern hospital would conclude that the range of care and treatment feasible is quite extensive, however, the actual contribution of the hospital organization to the system objective of cure and prevention of disease is limited by the nature of the system and $i$ ts connection of interrelated parts. This is not meant in any way to disparage the contribution of the hospital to the overall system of health care, but is directed toward an appreciation of the basis upon which many studies of hospital organization have been made and the results which have been reported. 5

To argue that the hospital is anomalous in regard to the structure

5observations such as reported by Basil s. Georgopoulos, in "The Hospital System and Nursing: Some Basic Problems and issues," Nursing Forum, $V(1966), 3-35$, that the hospital exercises more control over nurses than doctors, lose much of their import when analysis rather than synthesis is employed in organizational study. 
of the health care system is to take a position in regard to alternative methods of delivering health care to society. 6 Many of these same arguments could be made in regard to the "feeder" plants of industry which play their part in the production and delivery of goods to society in a similarly complex manner. To provide that these plants ought to be integrated with the companies which they serve is merely to observe that alzernative methods of providing for the needs and wants of society are feasibie. The actual choice among alternative methods must be based upon principles of selection which go beyond the relative complexity of an existing system. Although complexity of structure is acknowledged to have its attendent costs, simplicity of structure gives no assurance of being less expensive. Each must be evaluated in terms of the objective to be served rather than on the basis of ease of comprehension. The points of duplication within the health care system which are commented upon by the Somers are undoubtedly valid, and the gaps which exist in the system are we!l known; however, the remedy to these discrepancies, including the comprehensive planning system suggested by these authors, may well remain an unacceptable, and therefore an unevaluated, alternative. 7

In describing the Iine organization which exists in the voluntary seneral hospital and its relationship to the primary service objective

GHerman Mi ies Somers and Anne Ramsay Somers, Medicare and the Hospi: 7 ibid. 
of the organization the following chain-of-command can be described. The upermost level in this chain is the board of trustees, the final internal authority in regard to the purpose established for the hospital organization and the link with the ownership maintained by the community. One of the most important functions of the board, as in any corporation, is the selection of the operating executive. It is in this act of designating the head of the organization that the first devolution of line authority is accomplished, and the initial link in the primary chain-ofcommand is created. The functions of the administrator of the hospital as the operating executive are those responsibilities designated by the board of trustees. The process of selection of the hospital administrator and the delegation of authority to this executive have been well discussed and do not require extensive comment at this point. ${ }^{8}$ An interesting discussion of the characteristics of these operating executives is provided by Etzioni, who identifies three types of hospital administrators. 9 These he classifies as the physician-administrator; the semiexpert administrator, who may be a physician with administrative training or a trained hospital administrator; and, the lay administrator, who is neither a physician nor a professional hospital administrator, but a person with management training or experience in another field. 10

8 Raymond P. Sloan, in Today's Hospital (New York: Harper and Row, Publishers, 1966), pp. 119-139, provides an excellent description of these processes.

9 Amitai Etzioni, "Authority Structure and Organizational Effectiveness, Administrative Sciences Quarterly, IV (June, 1959), 53-59.

10 bid. 
Etzioni's position in regard to the relative effectiveness of each of these types of operating executives will be considered later as the major propositions in regard to the anomalies of hospital organization are treated in some detail.

Directly under the hospital administrator the line of the hospital organization devolves upon the nursing and ancillary services. As mentioned before the chain within these organic elements is described in terms of departments, wards or units, and teams or stations, down to the primary operative performers. There may be an intervening level between the administrator and the head of the nursing or ancillary department designated as associate or assistant administrator, but this level of the hierarchy will be discussed below as a separate topic.

The director of nursing and the ancillary department heads derive their authority from the hospital administrator and assume responsibility to this official for the accomplishment of their assigned duties. 11 The use of the term director of nursing services connotes the often found grouping of both line and staff elements at the department level beneath a single superior responsible for this major component of the organizational activities. Examples of such arrangements would be the grouping of various wards under departmental service classifications such as medical, surgical, and pediatrics, along with the line element of surgery and the staff element of central surgical supply all in a

$11_{\text {Malcolm T. MacEachern, Hospital Organization and Management }}$ (Berwyn, 111.: Physicians' Record Company, 1962), p. 518. 
direct chain of responsibility to the director of nursing. These separations of elements reflect a differentiation of the tasks to be performed based upon product in the case of the medical specialty wards and the process to be facilitated in the case of surgery. This basis for differentiation of the organic function is typically found in the universal structure along with other possible methods described by Davis. 12

There seems to be no question of the identification of the nursing function as an organic element of the hospital organization. Wilson provides that the nurse is the full-time symbol of the atmosphere of the organization--that is, care and treatment. ${ }^{13}$ He also emphasizes this identification by noting that the nurse is, in effect, the day-today decision maker in regard to the functions carried out in the organization. 14 Georgopoulos comments that the nurses comprise the only group in the hospital that is always present at the center of work and the major group through which the organization can insure continuity of work

12 Davis, p. 343, provides for elemental differentiation by: product, commodity, or service; process or method; equipment or other dominant physical factors; and, physical dispersion of activities on some geographical basis. Each of these bases, in addition to the fundamental functional differentiation, are represented in hospital organization at the various levels of the line. Even geographical differentiation occurs in respect to wing arrangements on the hospital wards which facilitate a logical separation of areas which are too large for primary supervision.

13 Robert N. Wilson, "The Social Structure of a General Hospital," Annals of the American Academy of Political and Social Science, No. 346 (March, 1963), p. 67.

14 1bid., p. 72 . 
over time. 15 The nursing service is described by Brown as the right arm of the hospital administrator in the carrying out of the vital functions of the organization. 16 And, if the subtle point often referred to in the management literature as an identification of the line is employed, it is discovered that the nurse is the initiator of action in the hospital organization. 17

At the operative level of the line nursing organization there appear two basic forms within which the segmentation of tasks takes place.

These two forms are case assignment and a specialization of work in some functionalized manner. Brown remarks on the extensive degree of specialization and task functionalization which has taken place in the hospital organization and which has produced an extended line chain-of-command below the registered nurse. 18 Christman and Jelinek suggest that this specialization has been wasteful of nursing personnel and recommend a shortening of the chain-of-command to put registered and practical nurses back in direct contact with the patient. 19 The benefits and disadvantages involved in extended chains-of-command with extensive specialization of

15 Georgopoulos, p. 14.

16 Esther Lucile Brown, Newer Dimensions of Patient Care: Part 2; Improving Staff Motivation and Competence in the General Hospital (New York: Russell Sage Foundation, 1962), p. 61 .

17 Eleanor C. Lambertson, in "Reorganize Nursing to Re-Emphasize Care," Modern Hospital, CVIII (January, 1967), 68, remarks: "Since the patient is housed in a unit supervised by the nursing department, the therapeutic and institutional services are generally initiated, coordinated, facilitated or referred by the nurse in charge."

18 Brown, p. 63.

19 Luther P. Christman and Richard C. Jelinek, "Old Patterns Waste Half the Nursing Hours," Modern Hospital, CVIII (January, 1967), 78. 
the primary operative functions versus shortened chains with tasks more enlarged and generalized are discussed by Georgopoulos in a manner familiar to the management student concerned with the operation of business enterprises. 20 These matters will be discussed more fully in their relationship to the prototype characteristics of the hospital organization and have only been mentioned at this point to illustrate the extension of the primary chain-of-command in the hospital situation.

The ancillary departments of the hospital organization are similar to the nursing departments in their extension of the line of command to primary operative specialization. In large part these departments are differentiated one from another on the basis of process or method employed in satisfaction of their contribution to the primary service objective. The purely therapy departments are a process specialization of the organic function of treatment while the laboratories and $x-$ ray have a functional differentiation between diagnosis and treatment beneath the department level. A brief listing of these ancillary functions and their organization arrangement is provided by Brown. 2

The designation of associate and assistant administrators along with assistants-to the administrator has become more and more popular in hospital organizations. The classification of these officers in regard to their relationship to the line organization is as varied as are the functions which are assigned to these positions. In many cases, when

\footnotetext{
${ }^{20}$ Georgopoulos, p. 26.

21 Brown, pp. 56-60.
} 
they are subjected to analysis, these designations are only substitute titles for departmental positions which are inherent in the organization. in other cases it would appear that minor service levels are being developed which are separate from the major service levels discussed above. $^{22}$ Under these circumstances the minor service level created under the position of the administrator would be considered to provide no basic differentiation of the task of administration in spite of the designation which is assigned to the position. The relationship between the administrator as the operating executive of the organization and the functionally or process differentiated department head remains essentially undisturbed if the line is to remain intact.

A particularly favorite assistant designating mechanism at the present time is to group the various operating departments into the classification of professional and administrative (or business). In respect to the observation that these are artificial classifications without organic meaning beyond an approximate separation of primary and secondary/collateral objectives of the organization they must be considered as staff positions to the administrator, as outlined by Litterer. ${ }^{23}$ In many cases the siaff nature of these roles is borne out by the qualifications of the incumbents, those recruited for these positions being

${ }^{22}$ Davis, pp. 352-353, declares that major service levels represent broad, basic differences in the kind of service, either operative or executive, that is required by an organization. The levels and grades within a major service level are designated as minor service levels.

23 Joseph A. Litterer, The Analysis of Organizations (New York: John Wiley and Sons, Inc., 1965), Pp. 340-342. 
largely recent graduates of programs in hospital administration with generalized training rather than a specialized background in the functions which appear to have been subordinated to these positions. This is not to say that such staff roles will not facilitate the training of these individuals for greater responsibility.

Another variation on this same approach of interposing an executive level between the administrator and the operating department heads is discussed by Davis as the development of a "fractional" service level. 24 In essence this provides for the designation of a department head as assistant to the administrator to allow for a staff relationship between the specialist and the administrator in addition to the primary relationship which already exists. Again, any line connotation which is implied by this arrangement is at best artificial, and it should not be expected to solve the operating problems which called the arrangement into being.

The designation of an associate administrator is perhaps representative of a line accommodation in the structure of the primary chain of command, when such designation is in the singular. An associate administrator interposed between the administrator and the operating department heads provides for an often necessary separation between the internal and external duties of an administrator. In these cases the associate administrator becomes the operating executive, responsible to the administrator for all internal matters including the coordination of the functions assigned to the department heads. 25

$$
\begin{aligned}
& 24 \text { Davis, p. } 362 . \\
& 25 \text { lbid., pp. } 361-363 .
\end{aligned}
$$


The role of the physician in the hospital structure is most ambigwous and remains an issue in every discussion of hospital organization. This position of the physician in the hospital can only be understood by reflecting upon the historical perspective provided by the health care system in this country. Bloom discusses this perspective in terms of the developing role which the hospital has played in the system in response to the changing needs and goals of society. 26 From a refuge for the pauper and the friendless, the hospital has evolved into a center containing the complex tools of medicine provided by an advanced technology. However, the physician has retained his independence from this structure which provides the wherewithal for the practice of his craft. ${ }^{28}$ Bloom believes that this historic fact may be lost sight of as a blending of the duties of the profession with the mission of the hospital becomes more pronounced. 29

This same evolution of the role of the hospital is traced by Freidson, who notes that the impetus for this changing role was the physician rather than the lay clientele. 30 The conscious demand for these new facilities stemmed from the physician rather than the client who had

${ }^{26}$ Samuel W. Bloom, The Doctor and His Patient (New York: The Free Press, 1963), pp. 145-147.

\section{7} lbid. 28 ibid. 29 ibid.

30 Eliot Freidson, "Client Control and Medical Practice," Medical Care: Readings in the Sociology of Medical Institutions, eds. W. Richard Scott and Edmund Volkart (New York: John Wiley and Sons, Inc., i 966), p. 448. 
these new services imposed upon him. 31 Freidson believes that it is questionable to designate the patient as the customer of the hospital for under these circumstances the layman, while he pays for the services, has little control over their use. 32 Wilson views the physician as having been the guest of the hospital with very special prerogatives that allowed him to dominate many aspects of the situation which usually are reserved to the owners. 33 This same point is taken by Bloom, who regards this phenomenon as a result of the potency of the physician's role in the healing process, although his dependence upon the facilities provided by the hospital and the increasing competence of the nurse have served to balance the effect of the physician's apparently dominating influence as a guest. 34

These authorities, however, see the evolutionary process as incomplete. Bloom views the physician's interests as blending with those of the hospital thus leading to a new sense of ownership and responsibility on the part of the doctor. 35 Guzzardi believes that changing circumstances make a broader responsibility on the part of the physician inevitable. $^{36}$ Rayack sees the physician as increasingly becoming an

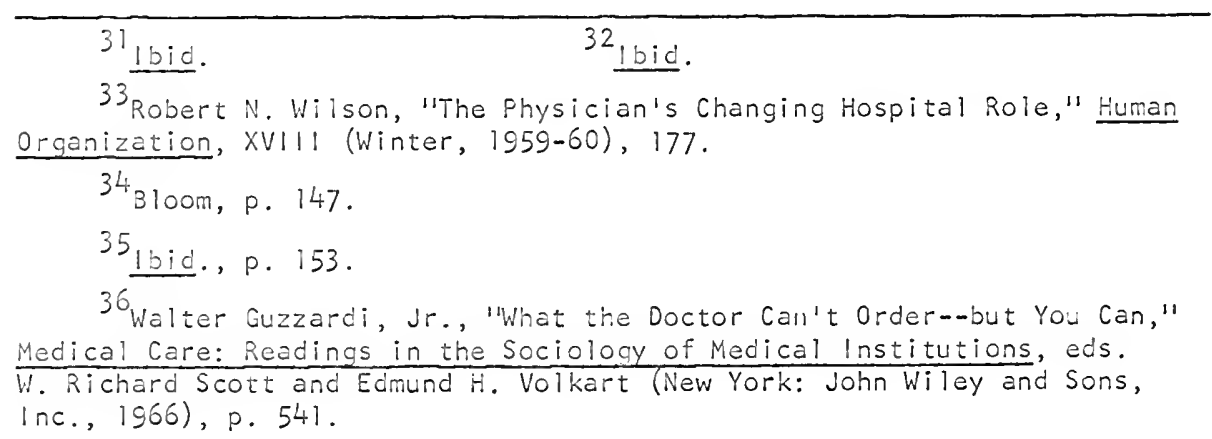


organization man dependent upon a host of institutions to perform his work and through this process losing his traditional independence of responsibility for the management of these institutions. 37 However, these comments are essentially speculation as to what the future holds for organized medicine and the health care system. Of immediate importance in defining the line of the hospltal organization is the determination of the present role, if any, of the physician in this structure. One prevalent approach to the role of the physician is obtained by enlarging the scope of the hospital primary service objective to include the accomplished healing of the patient. If this approach is taken the place of the physician becomes quite ambiguous if it is maintained that he is not a member of the organization. MacEachern appears to straddle the fence in this regard, maintaining that the hospital's mission is healing but then not adequately relating the physician to the process of organization involved, and finally providing for the delegation of authority to the nebulous "medical staff" and allowing for certain parallel line authority. ${ }^{38} \mathrm{c}$. Wright Mills allows that this ambiguity of roles describes a new entrepreneur attached to but not a part of the hospital. ${ }^{39}$ And, Sloan, who also maintains that the hospital must have

37Elton Rayack Professional Power and American Medicine: The Economics of the American Medical Association (Cleveland, Ohio: The World Pubiishing Co., 1967), pp. 39-40.

38 MacEachern, pp. 157-158.

39. Wright Mills, White Collar: The American Middle Class (New York: Oxford University Press, 1956), p. 116. 
some finality to its purpose beyond a mere contribution to the well-being of society, provides a unique role for the physician which defies description as employee or consultant but may perhaps be categorized as an independent contractor. 40 in each case the conundrum is provided by the expanded primary service objective awarded to the hospital organization.

From the legal point of view the position of the physician in the hospital has been quite clear in maintaining an essential customer-enterprise relationship. MacEachern appears to recognize this by noting that the law does not require a corporation to furnish its services to everyone who applies. 41 The courts have followed a quite consistent position in this regard by maintaining the right of the private hospital organization to select those persons who will be welcome to use it facilities. 42 This customer relationship of the physician to the hospital is reinforced by the substantive rights to practice awarded to the physician by the courts when the hospital is owned by the public. 43 This continuing trend toward a customer interpretation is reinforced by even more recent

40 sioan, p. 11 .

41 MacEachern, p. 162.

42 John F. Horty, Nathan Hershey, Eric W. Springer, and Donald M. Stocks, Student's Guide to Hospital Law (2nd Edition; Pittsburgh, Pa.: Health Law Center, Graduate School of Public Health, University of Pittsburgh, 1962), p. 138.

43 1bid. 
decisions of the courts. 44

But, perhaps, the most telling argument for the customer role of the physician is provided by the attitude of the doctors themselves. As sloom notes, the physician traditionally does not take responsibility for the organization and management, which are the essential line functions of the hospital. 45 And MacEachern's dictum that the board should pass the responsibilities for the treatment and care prescribed within the hospital to the practicing physicians appears less as a line delegation and more like a recognition of a fait accompli, for the physician can have it no other way. 46 However, the large degree of power which the doctor wields within the hospital organization, and which is well noted, cannot be denied. 47

Undoubtedly the most popular view taken of the hospital by the physician is to regard these facilities as his "workshop," a place where he can obtain extra care for his patients and receive a combined consultation beyond that which he could obtain by referring his patient to a specialist. 48 This concept of the hospital as a tool of the physician

${ }^{44}$ Arthur H. Bernstein, "Medical Staff Appointments, Pro and Con," Hospitals, ILII (May, 1968), 99.

${ }^{45}$ Bloom, p. 150.

46 MacEachern, P. 158.

47 oswald Hall, "Some Problems in the Provision of Medical Services," Canadian Journal of Economics and Political Science, XX (1954), 461.

48 Albert F. Wessen, "Hospital Ideology and Communication betwisen Ward Personnel," Patients, Physicans and Illness, ed. E. Gartly Jaco (New York: The Free Press, 1958), p. 461. 
which mantains the essential cuscomor reletionship between the two is nuted by Perrow, who believes that zhe physician will use that hospital which provides the best facilities for the care of the patient. 49 The administrator's duties as the operating line executive, as outlined by MacEachern, is the provisior of those facilities necessary to the physician tor the proper treatrare ci pazients; this statement is perhaps as complete a summary of the furction and purpose of the hospital organization as can de macie. 50 While no comparisons are attempted, Etzioni implies that this arangement is not dissimilar from that which exists in other segments of the service incsiry. 5 !

This independence of the physician from interna? responsibiitty and managenent of the nospital appears to de a unique American approach to the organization of healin care. 52 Aithough Wilson believes this to be a passing phenotienon he agrees that wat the American physician has had was a workshop designed for his convenience. 53 This aura of convenience appears to have been dictated by the physician's definition of his own

${ }^{49}$ Charles per row, "Organizational Prestige: Some Functions and Dysfunctions," Medica! Gare: Readincs in the Sociology of Medical !nstizutions, eds. W. Richard Scort and Ecmund H. Volkart (New York: John Wiley and Sons, lnc. 1966 ), p. 563.

50 MacEachern, P. i02.

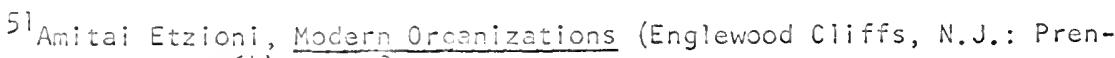
tice-Hall, Inc., 1964i, P. 78.

52 Rou: Tunley, Fe American Health Scandal (New York: Dell Publishing Co., 1966$)$.

53ilson, "The Physician's Vianging tiospital Role," p. 178. 
role and the support he expected to be provided by the hospital. 54 Tunley, for one, believes that this peculiar arrangement of free passage in and out of the hospital organization by the physician without responsibility to the organization being exacted, is part of what he describes as the scandal of American health care when it is compared with the system in operation in other countries. 55 Georgopoulos, however, believes that this concept of the hospital providing a doctor's workshop is gradually passing from the scene; ${ }^{56}$ while wilson indicates that the physician is undergoing a shift from his older charismatic role in the hospital setting to a more nearly bureaucratic niche within the structure. 57 However much the present situation of the physician's role within the hospital organization is deplored, it still remains descriptive to provide that the doctor is not typically of the hospital, but, instead, is a customer of these facilities provided by the community for his use.

This transition of the hospital to a position as a major segment of the health care system with its employment as a facility for the use of the physician appears to have placed the patient himself in an undefined role in regard to the hospital. Undoubtedly the immediate impact

${ }^{54} \mathrm{Hall}, \mathrm{P} .460$.

${ }^{55}$ Tunley.

56 Basil S. Georgopoulos, Hospital Organization and Administration: Prospects and Perspectives," Hospltal Administration, IX (Summer, 1964), 30.

57 Wilson, "The Social Structure of a General Hospital," p. 67. 
upon the patient is the loosening of the ties which traditionally held between the physician and the person who sought his care. Simmons and Wolff note that while the physician profits from the specific economies and conveniences of the workshop his patient experiences a widening of the social distance between himself and the person with which he has contracted for care. 58 The patient has undoubtedly taken second place in this present arrangement although most people believe that the hospitals exist primarily for the benefit of the sick person. 59 Flores maintains that while it is true that the patients are the recipients of whatever care is provided the hospital really exists to make it possible for the physician to practice medicine in the most effective manner provided by that science. 60 Wilson has remarked that the two most important actors in the hospital plot, the physician and the patient, are both only guests on the scene. 6 ?

While Blau provides that there is a marked difference between the customer of a business enterprise and that of a customer of a service industry it is stiil difficult to ascribe a customer role to the patient in the hospital. 62 The patient finds that his life is ruled in both

58 Leo W. Simmons and Harold G. Wolff, "Hospital Practice in Social Science Perspective," Medical Care: Readings in the Sociology of Medical institutions, eds. W. Richard Scott and Edmund H. Volkart (New York: John Wiley and Sons, $1 \mathrm{nc} .$, 1966), p. 477.

59 Florence Flores, "Role of the Graduate Nurse Today," The New Enaland Journal of Medicine, CCLXII (September 6, 1962), 487-491. 60 ibid.

6lWilson, "The Social Structure of a General Hospital," p. 70.

62 peter M. Blau and $W$. Richard Scott, Formal Organizations (San Francisco: Chandler Publishing Co., 1962), p. 59. 
minor and major detail in the hospital by total strangers. 63 simmons and Wolff observe that:

In the hospital the patient is "admitted" and "discharged" and all the visitors are under rules, while at home the physician is "on call" and can be "changed," and the nurse is "hired" and can be "fired." In the home "prescriptions" are requested and filled out, but in the hospital "orders" are written and must be enforced. 64

As Parsons has noted, a customer relationship can only exist when there is some shared basis of knowledge between the customer and the party being dealt with. 65 While Parsons attributes some special relationship between the patient and the physician, it is difficult to see any basis for bridging the gulf which exists between the patient and the hospital. Perrow remarks that this communications gap renders the patient incapabie of judging the care which is rendered or interpreting the hospital experience in its totality. ${ }^{66}$ If the patient is to be considered as a customer of the hospital organization then his knowledge of the service received can only extend to the most superficial aspects of the institutional care provided, which is unlikely to compare favorably with the size of the bill which is tendered. 67

63 simmons and Wolff, pp. 482-483.

64 ibid., pp. $483-484$.

${ }^{65}$ Talcott Parsons, The Social System (New York: The Free Press, 1951), p. 447 .

66 perrow, "Organizational prestige," p. 563.

67 ibid. 
To argue that both the physician and the patient are the customers of the hospital would be to deny the basic orientation of the various hospital personnel to the demands levied against the organization by the doctor in attendance. 68 on the other hand to maintain that the patient is the customer while the physician acts as a control agent in the customer's activities within the organization, as Etzioni argues, is to reduce the role of customer to the perfunctory paying of bills which is hardly the economic function implied in the term--customer. 69 This conception of the role of the patient also provides little in the way of significance for organizational analysis. Perhaps the best analysis of the part which the patient plays in the hospital organization is provided by Wessen. 70 He maintains that:

- . the patients are not so much a part of their social system [the members of the hospital organization] as a vital reference group in the midst of which the personnel operate, which they serve, and toward which they orient many of their actions and attitudes.7]

If it were not for the human quality involved it would be quite easy to

68 Donald M. Rosenberger, in "A New Look at Hospital Organizations," Hospitals, XXXVI (February, 1962), 43, considers the various categories within which the physician and pacient could be placed in regard to the hospital organization and arrives at the conclusion that both are customers.

${ }^{69}$ Amitai Etzioni, "Administration and the Consumer," Administrative Sciences Quarterly, 111 (September, 1958), 253.

70 Wessen, p. 253.

71 lbid. 
equate this statement to the orientation of the worker in industry toward the raw material of production and the product in its various stages of completion. Such of course is not entirely the case; however, in spite of the special characteristics involved, the orientation of management, in its control over the worker in the production process and the emphasis placed upon the primary service objective, will be much the same in both the hospital and the manufacturing concern.

There can be no doubt that a profound change occurs in the individual when he assumes the sick role in American society, particularly when this role involves hospitalization. Freidson has described this role in terms of an hour-glass description of society with the waist of the figure denoting a point where the patient passes from his normal reference group to a new role with the health care system. ${ }^{72}$ Freidson's essay is mainly concerned with the passing of the patient from his physician, by consultation, to a specialist as providing the waist of the two systems. ${ }^{73}$ At this point the patient no longer controls the relationships which exist; he is then the object of the process involved no matter how humane the considerations which are provided. ${ }^{74}$ In like manner it can be recognized that the patient's role in the hospital organization is as a portion of the process which the structure has been

72 Eliot Freidson, "Specialties Without Roots: The Utilization of New Services," Medical Care: Readinas in the Sociology of Medical Institutions, eds. W. Richard Scott and Edmund H. Volkart (New York: John Wiley and Sons, Inc., 1966), pp. 455-457.

73 libid. 74 ibid. 
designed to facilitate. To maintain a customer orientation for the patient would be a futile exercise in semantics.

It is in these two unusual roles, the patient and the physician, that we discover the root of the discrepancy of description between the hospital and the universal organization. The only present parallels that can be cited between the role of the patient as the article in process and situations of a like nature in organizations which are described to be of the universal character would involve children being processed under the customer oriented direction of a parent. In each case where the party in process is an adult with the ordinary customer control exercised by an authorized agent the anomalous nature of the organization is cited, although this particular arrangement has little, if any, structural connotation to the internal organization. The problem undoubtedly does not rest with the human characteristics of the client, but, rather, with professional characteristics of the agent. This point must be amplified for it is here that the confusion arises which appears to attribute an internal, line role to the agent rather than the customer role outlined above.

The power of the physician to affect the internal workings of the hospital organization is not the authority provided by organization theory to internal membership. Rosenberger has described the physician as not only a customer and a beneficiary of the hospital organization but also as an informal partner in an informal joint venture; ${ }^{75}$ while

${ }^{75}$ Rosenberger, pp. $43-44$. 
Gordon detects a negotiated relationship based upon a power and control relationship that is constantly being subjected to renegotiation. 76 The root of this power or informal authority as it is variously described can be considered to rest in the prestige associated with the medical profession as it applies in the peculiar hospital situation. Brown sees the basis for the part which this occupational prestige plays as residing in the evolutionary development of medicine and the health services which allowed the physician to precede the other professional groups in their development as the primary guardian of health. 77 In addition to this longer tradition the physician is favored by longer periods of training and study, legal precedent, and a particularly fortunate socio-economic position. 78 Brown remarks: "As a consequence of all these factors, physicians have had and continue to have the greatest authority, the highest status, and the largest prestige of any group within the hospital." 79 Significantly, Wessen notes that this respect for the doctor's prestige is systematically indoctrinated in hospital personnel, and it finds its greatest strength among those second in prestige--the nurses. 80 Even the advent of "team medicine" has not loosened the physician's prestigious position. 81

76 paul J. Gordon, "The Top Management Triangle in Voluntary Hospitals (11)," Academy of Management Journal, V (April, 1962), 72.

$77_{\text {Brown, p. } 66 .}$

78 ibid. 79 bid.

80 Wessen, p. 454.

8! Bloom, p. 167. 
But, as some authorities have noted, this power which stems from the charismatic prestige of the physician cannot be solely explained by the factors considered above; it appears also to be a function of the autonomous role which the physician plays in his association with the hospital organization. 82 The physician's autonomy has been laden with the power, expressed as both explicit and implicit authority, to direct the course of the organization. ${ }^{83}$ while the other professional groups associated with the enterprise do not hold the same degree of prestige as the physician their seeming inability to influence hospital policy appears to be more a function of their internal membership in the organizarion. 84

The possibility of a misinterpretation of the role of the physician as the presiding figure in the healing process to include the concept that he is of the organization, rather than the customer, can have its disastrous effects upon the management of the institution. Confusion in regard to the objective of the hospital can lead to the executive of the organization being held accountable for results over which he holds no effective decision-making authority. ${ }^{85}$ If the description, held by many, of the physician as an internal member of the organization, were correct, then the right to command held by the administrator

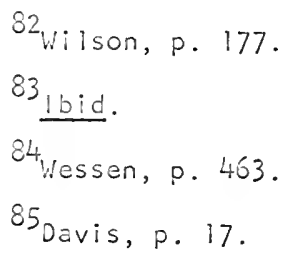


would not exist and his position would disappear. ${ }^{86}$ The situation would be as Gordon has described it, where on a day-to-day basis the corporation and its executives have no legal or organizational means to control the service which the hospizal has been set up to render. ${ }^{87}$ Rather, it is from the surrounding organizations which make up the environment of the hospital that the primary service objective of the organization is determined. 88 One of these organizations which is primarily involved in the determination of the hospital's objectives on a dynamic basis is the membership of practicing physicians--the customers of the hospital organization. This process of interaction involves the surrender of certain sovereignty on the part of both organizations but it does not mean an incorporation of the two parties or a modification of the structure for administration. 89

Much of the dilemma in regard to the position of the physician in the structure of the general hospital has arisen from the nature of the studies which have explored this issue. Those accounts which subscribe an internal role to the physician have been largely sociological in origin, but there also appears to have been considerable feedback into management studies. 90

$86_{\text {Koontz and O'Donnell, p. } 66 .}$

87 Gordon, p. 72 .

88 Blau and Scott, pp. 196-197.

89 ibid.

90 The concern in hospital administrative literature with the issue of finding a basis for management participation on the part of the privileged physician is indicative of the dilemma arising when the doctor is 
As Blau and Scott have remarked the objective of social science studies is the explanation of various aspects of social organization and the orderly structure of social life. 91 This depends in the modern lexicon, as Katz and Kahn describe it, upon the concept of open systems studies which link the various subsystems, systems, and supersystems, depending upon their degree of autonomy, into a total social system. 92 The approach of open-systems theory is in contrast to traditional organizational theories which tend to view the human organization as a closed system and disregard the nature of organizational dependency on its environment. 93 katz and Kahn believe that the traditional approach

awarded an undefined, internal role in the hospital organization. The present suggestions, and practices, include the utilization of various committee arrangements which practice remains essentially unevaluated at this point. If organization theory were to suggest any resolution of this contrived situation it would provide for complete incorporation of the practicing physicians into the structure of the organization on a salaried basis. There appears to be some trend in this direction with a subsequent modification of the hospital primary service objective to include the broader healing goal inherent in the work of the physician.

This aspect of the dynamics of the health care system toward a centralization of the healing function is a major issue in American medicine. Tradition and the ethics of the medical profession are actively resistant to a modification of the present doctor-patient relationship which would allow the suggestion of an authority superior to that of the physician in the healing process. It could also be suggested that the physician has little interest in the management responsibilities associated with internal membership. Much like American labor, the physician sees little to gain in disturbing the favorable advantage which he presently holds in the negotiated order of the system.

91 Blau and Scott, p. 1.

92 Daniel Katz and Robert L.Kahn, The Social Psychology of Organizations (New York: John Wiley and Sons, Inc., 1966), p. 58.

93 lbid., p. 29. 
has lead to an overconcentration on principles of internal functioning of organizations which ignores the feedback from the environment which is essential for organizational survival. 94 This opening of the boundaries of organizations has allowed the analyst to redefine the structure of the organization and the nature of participation to serve his particular purpose, which is accepted as his prerogative; however, the user of these results must be on guard against employing a descriptive analysis which is supported by a purpose at variance with that of the user. 95

The problem of the boundary to be enclosed in a particular study is well recognized in open-systems theory. Blau and Scott refer to this as the fundamental methodological dilemma in the study of social organizations. 96 Argyris, in establishing the boundaries for his studies prescribes the philosophy of extending the boundary of the segment under analysis to the extent that influences from the environment are neutralized. 97 Katz and Kahn describe the analytical problems, and the sociological implications, involved in the concept of partial inclusion where

94 libid.

95Litterer, pp. 6-9. The work of Amitai Etzioni, in A Comparative Analvsis of Complex Organizacions (New York: The Free Press, 1961), pp. 18-21, is illustrative of the careful outlining of boundary positions in the open-systems approach, here directed toward developing of compliance structures. This outline should forewarn the management student of indiscriminate adaptation of the conclusions derived to broader areas of concern.

$96_{\text {Blau and }}$ Scott, p. 222.

97 Chris Argyris, Integrating the Individual and the Organization (New York: John Wiley and Sons, Inc., 1964), p. 122. 
a participant is "ofll two or more organizations at a boundary position. 98 This is the dilemma of the salaried nurse and her professional association, or the worker and his union, which creates competing crosspressures upon the individuals and the organizations. 99 Sociological literature would describe the physician as being in this dilemma of partial inclusion in the hospital and in his profession; however, a truer approximation of the situation when the doctor is a privileged physician would be to describe his allegiance as solely to his profession. If a sufficient isolation of the phenomenon of the physician as a customer of the hospital organization is accomplished it is relatively easy to describe a unique situation in light of the degree of control exercised by the doctor in his transactions with the organization. 100

The position of management literature in regard to the boundary positions of organizations is we?l established. This issue was reopened by Barnard in his attempt to synthesize many of the concepts of the informal organizational theorists with the traditional constructions of management theory. 101 He considered the concept of the customer as a "member" of the organization to demonstrate the freedom of management

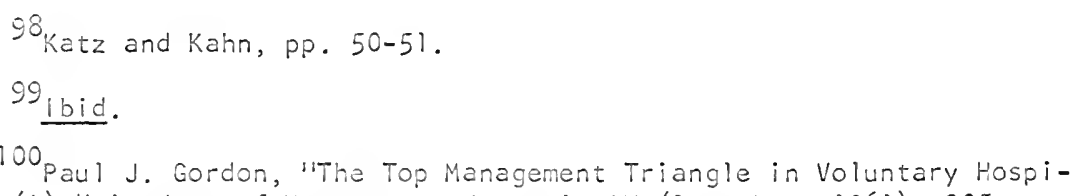
tals (1)," Academy of Manacement Journa?, IV (December, 1961) 205.

${ }^{101}$ Chester 1. Barnard, The Functions of the Executive (Cambridge, Mass.: Harvard University Press, 1938). 
theory from that of economics; however, his conclusions derived from the theory of organization as a coordinative process was to exclude the acts of consumers even though they were contemporaneous and closely linked with many of the actions of management. 102 His analysis had demonstrated that the inclusion of "persons" as such in the structure of organizations would unnecessarily limit the concept of "organization," and, therefore, it was more proper to consider them in the perspective of their roles as determined by the structure itself. 103 This point in management theory is amplified by Davis in his reiteration of the term "personnel" to include only those persons who have accepted an obligation for the performance of certain assigned functions. 104 Davis also points out that those responsibilities are determined by the characteristics of the values that must be created for the accompiishment of the organizational objective. 105 This definition of the boundaries of the organization being prescribed by the goals of the organization is explicitly stated by Parsons, who notes that it is through goals, not persons per se, that organizations are defined. 106

The specific purposes of the numerous sociological studies of the hospital organization are varied. Much of the information provided can be of interest to hospital managers if the purpose of the study is

$$
\begin{aligned}
& 102 \text { lbid., pp. } 70-71 . \\
& 104 \text { Davis, pp. 15-16. } \\
& 105 \text { bid. } \\
& 106 \text { palcott parsons, "Suggestions for a Sociological Approach to the }
\end{aligned}
$$
Theory of Organizations--1," Administrative Sciences Quarterly, 1 (September, 1956), 64-67. 
understood as it provides insight into the total system of which the hospital is a part. The cited study by Freidson provides considerable understanding of the role which is played by the patient in the health care process and should generate a more favorable perspective in dealing with the patient on a day-to-day basis. 107 other reports which tend to encourage the concept of the physician as a "team" member because of his peripheral association with the hospital membership are unlikely to provide reasonable guidance for the hospital manager. 108 Still another report suggests that the potential for a take-over of the hospital by the physicians is apparent. 109 such concepts of the structure of the hospital organization serve little purpose for the executives responsible for the management of the organization and could actually be harmful to the individual manager who attempted to exercise a measure of control over the physician other than that normally associazed with a customer.

The extent to which sociological studies can distort the structure of organizations beyond the point where they can be of assistance to management is exemplified by the normative compliance structure described by Etzioni as representative of the hospital organization. 111 He sees no

107 Freidson, "client Control," pp. 259-271.

108 3100m, pp. 160-161.

109perrow, "The Analysis of Goals in Complex Organizations," p. 135.

110 David B. Starkweather, in "The Classicists Revisited," Hospital Administration, $\times 11$ (Summer, 1967), 69-80, makes many of the same comments in regard to sociologically based studies.

11 Etzioni, Comparative Analysis, p. 21. 
reason why privates should be included in the organizational structure of the army when patients are not included as the lower level in the hierarchy of the hospital. 112 By so including the patients as members of the hospital organization he is then able to demonstrate that they comply through normative measures while other organizations including those of an economic variety insure compliance of the lower levels of the hierarchy by remunerative devices. 113 it is through this simple device of arbitrary boundaries that his comparative analysis derives the conclusion that the business and hospital organization are dissimilar. A similar position is taken by Bloom, who maintains that patients are a part of the social structure where long-term illness is involved. 114 Freidson, however, in his essay which suggests the hospital as a prototype organization, has taken exception to those studies which attempt to include the patient as a member of the hospital organization. 115

It is well accepted that sociological studies have their place in management theory. 116 Quite early in the development of this theory, Barnard noted that the single explanation of organizational behavior provided by economic theory was insufficient by itself to provide the insight necessary to explain the functioning of the executive. 117 He utilized the
112 lbid.
113 lbid., P. 42.
114 3100m, p. 161.

115 Eliot Freidson, "Review Essay: Health Factories, The New Industrial Sociology," Social Problems, XIV (Spring, 1967), 495.

116 Koontz and O'Donnell, p. 32.

117 Chester 1. Barnard, Organization and Manacement (Cambridge, Mass.: Harvard University Press, i948), PP. 112-125. 
method of varying the boundaries of the organization to gain broader insight into the organizational process for management purposes. 118 However, as Koontz and O'Donnel? note, there are various organization theories, each serving its own purpose. 119 The organization theory required for management purposes must concern itself with the authorityactivity structure of an enterprise and the goal-seeking process which takos place within this structure as well as with the problems of human relations. 120

This extensive argument which has been presented in support of the physician as the customer of the hospital organization rather than as an internal member of the hierarchical structure has not been made at the expense of those physicians who can by definition be included in such membership. These are the salaried or contract physicians who have internal roles in the organization and are of the line organization, usually at some management level in the structure. This category of lime physician would also include the residents in training and the interns on more transient line assignments who are found in the larger training hospitals. It is obvious that in these cases where physicians are directly responsible for organic functions other than the ancillary departments the primary service objective will more broadly contain the healing assumption.

118 Barnard, The Functions of the Executive, p. 69.

119 Koontz and O'Donnel1, p. 203.

1201 id 
It has been noted by a number of authorities that a tendency appears to exist in American society toward greater internal membership in the hospital organization by physicians. Guzzardi cites the Ford Hospital in Detroit as providing a model of the organization with all physicians on a salaried basis. ${ }^{121}$ He believes that as more new physicians become accustomed to earning a salary from the hospital during their training periods they will be less reluctant to continue the same arrangement on a permanent basis. ${ }^{122}$ Gilb recognizes that this tendency is already prevalent and notes that this raises new structural problems for the hospital in light of the traditionally independent character of the profession. ${ }^{123}$ She believes that the accommodation that will come about may possibly resemble the position of the faculty in a university setting. 124

In those hospital institutions which are fortunate enough to have a complete staff of physicians, Brown notes, these doctors are responsible to the administrator for the areas which would otherwise by under the jurisdiction of the nursing staff. ${ }^{125}$ However, it should be noted that while these physicians are of the line, responsible to the head operating executive, there is usually a medical director at an

121 Guzzardi, p. 542.

122 ibid.

${ }^{123}$ Corinne L. Gilb, Hidden Hierarchies (New York: Harper and Row Publishers, 1966), p. 102.

124

Ibid.

${ }^{125}$ Brown, p. 62. 
intervening level with considerable decentralized authority for the purely medical functions, much as the nursing director intervenes in the typical organization with an appreciable degree of decentralized authority. Again, while the tendency may be toward the fusing of the hospital organization and the medical profession into a single structure, the more typical organization is not of this variety at present, and, therefore, this variation will not be of major concern in this report.

The general hospital considered as a business organization serving a clientele may broadly be classified as a member of the amorphous service industry. In various ways the hospital has unique characteristics as a member of this industry. As Etzioni, and others, have noted the hospital is one of a group of service organizations which can be classified as predominated by professional participants. ${ }^{126}$ The conclusions reached by the authorities who make this observation, however, are at variance with what has been presented in this paper. Etzioni remarks that the intervention of the professional, as the operative performer in the organization, between the service provided and the consumer, allows for a separation of the consumption-control sequence found in normal market operations. ${ }^{127}$ While this separation may be true for the patient-physician relationship it is hardly so for that which exists between the physician and the hospital when the physician is

$$
\begin{aligned}
& { }^{126} \text { Etzioni, Comparative Analysis, p. } 51 . \\
& 127 \text { Etzioni, Modern Orqanizations, p. } 97 .
\end{aligned}
$$


accepted as the customer of the hospital; the physician as consumer of the services provided by the hospital is most knowledgeable of the product being provided and has a large measure of control in the exchange process. Rosenberger's description of the relationship between the physician as the customer and the nurse as the operative performer in the hospital is quite clear on this point. 128

In one other respect the hospital is unusual in the practices of the service industries although, perhaps, not remarkably so. This is in the control exercised by the organization over whom shall be allowed to make themselves available to the services provided. The hospital accepts a responsibility to the ownership of the facility that the customers shall be qualified in the employment of the services provided. This is essentially a further extension of society's concern with whom shall be allowed to practice medicine and to what degree they are competent in various segments of the profession. 129 If the physician's control in the exchange process is said to be balanced by control exercised by the organization it would be in respect to this initial selection of those physicians who will be granted privileges in the hospital. This same selection process is exercised by any business organization but on a much less formal basis, and like the business organization, the hospital has the right to terminate the relationship as specified in the contractual agreement.

128 Rosenberger, p. 44. 129 Freidson, "Review Essay," p. 493. 
As in the other service industries the operative performers of the hospital organization come into close contact with the customers; as a consequence the customer is able to direct or attempt to direct the worker at his tasks. 130 In fact, as Parsons expresses it, this is a prerequisite for the service classification. 131 MacEachern details this customer control in the hospital as a function of medical authority, although the word authority has a special meaning in organizational terminology and might better be expressed as a control relationship. 132 Woodward notes the interconnection between the service and production industries in the unit-production case where the desires of the customer largely provide the immediate direction for the operative performers. 133 The fine line of distinction between the service and production industries provided by a distribution function is obscured when this function is a part of the production process as in the case of the hospital organization.

This relationship between the customer being served and the organization providing the service may be an important result of the prototype

130 Howard S. Becker, "The Professional Dance Musician and His Audience," Professionalization, eds. Howard M. Vollmer and Donald L. Mills (Englewood Cliffs, N.J.: Prentice-Hall, Inc., 1966), pp. $212-213$.

13! Talcott Parsons, "Suggestions for a Sociological Approach to the Theory of Organizations--1," Administrative Sciences Quarterly, I (September, 1956), 71 .

132 MacEachern, p. 528.

133 Joan Woodward, Industrial Organization: Theory and Practice (London: Oxford University Press, 1965), P. 158. 
characteristics of the hospital organization, and it should be explored further now that it is considered as a customer-organization relationship rather than a phenomenon explained by informal authority. Perhaps the most unusual aspect of the hospital as a representative of the service industries concerned with unit-production is the extent to which the physician as a customer interacts with participants throughout the organization. 134 While there are areas of the organization with which he is not concerned the physician goes beyond what would be considered as the normal points of entry for a customer. It could be said that the physician traverses the organization both vertically and horizontally to insure that each facet of the care and treatment being rendered to his patient is to his specification. He is undoubtedly accepted as the expert on how the care and treatment is to be provided and he intends to insure that the specification is accomplished much as any service customer who cannot rely on the control device of final rejection of the product. 135 The doctor is unwilling to accept the formal relationship which might be prescribed by the organization to control his relationship with the established structure. His frequent encounters with the operative performers of the organization develop the semblance of an informal relationship that may make many of his specifications of an implied category. 136 Many of these specifications both implied and

$$
\begin{aligned}
& 134 \text { Blau and scott, p. } 60 . \\
& 135 \text { Freidson, "Review Essay," p. } 497 . \\
& 136_{\mathrm{Hall}} \text {, P. } 460 .
\end{aligned}
$$


explicit can be interpreted by either the physician or the operative performer as emergency in nature. 137 Although the operative performers who are in contact with the customer-physician are usually classified as professionals they must hold their professional judgment in abeyance when they are playing this complicated role, or they must learn to exercise this judgment with a discretion developed through constant association with the physician. ${ }^{138}$ But servicing the values of the customer is but one part of the operative performer's tasks in the hospital organization; in addition there are a variety of functions which are responsive to the internal maintenance function of the organization. ${ }^{139}$ It has only been quite recently that nurses as operative performers in the hospital organization have begun to define the internal aspects of their role to any great extent, and it remains questionable as to what the exact nature of this definition will be or to what extent this will modify the physician-hospital relationship. 140 If the "team nursing" concept continues to be received with favor, the professional nurse in her line supervisory role in the hospital organization will undoubtedly reinforce her position as coordinator and system integrator through her role as the intermediary between the organization and the physician much

\section{1bid., p. 462 .}

138 Lyle Saunders, "The Changing Role of Nurses," Issues in Nursing, ed. Bonnie Bullough and Vern Bullough (New York: Springer Publishing Co., Inc., 1966), p. 120.

$$
\begin{aligned}
& 139 \text { Brown, p. } 62 . \\
& 140 \text { Flores, pp. } 487-491 .
\end{aligned}
$$


as the salesman has served to regularize the relationship between the customer and the operative performer in unit-production firms of industry. 147

This latter point is perhaps the greatest insight that can be obtained by this digression into the part which the physician plays in the operations of the hospital organization. To separate the doctor from the internal membership of the organization is not simply an academic exercise, but, rather, a mechanism which suggests a course of action for the managers of hospital enterprises. It is believed that too much effort has been expended in attempting to regularize an authority relationship which does not exist. The failings of management theory to supply the answers recuired in the hospital situation is not the result of the inappropriateness of this theory to the particular organization, but, rather, the failure has been in the attempt to apply the portions of this theory concerned with internal authority relationships between superiors and subordinates to what is essentially a customer relationship. Given this situation it is not surprising to find that physicians will not submit to the line authority of the hospital executive since no basis for this authority exists. Within this context the most successful administrators have been those who have subscribed to the philosophy that authority has been decentralized to the physician, although they would be quite unwilling to demonstrate a retraction of

147 M. M. Johnson and H. W. Martin, "A Sociological Analysis of the Nurse Role," Professionalization, eds. Howard M. Vollmer and Donald $L$. Mills (Englewood Cliffs, N.J.: Prentice-Hall, Inc., 1966), pp. 206-2li. 
this authority given the proper emergency situation.

Social forces may someday provide an internal role for the physician in the hospital organization on a scale which makes this the mode for the industry. Management theory must then be re-examined for insight on how the authority relationships should be constructed with observation of those hospital organizations which presently conform to that model. Although authorities have been cited who predict this incopporation of the physician, traditional patterns and the active resistance of the physicians must first be overcome. It would therefore be recommended that the present pattern of organization be accepted as that which must be accomodated by sound management theory.

In large respect what has remained unrecognized at the administrative management levels has been accepted on the more practical operative management levels of the hospital organization and the necessary accommodation by nurses and other operative performers has traditionally been accomplished. Dale's recommendation in regard to the designation of customer coordinators to supplement the work of sales representatives when the product or service is of a particularly complex variety could be extended to the ancillary departments and consolidated at a higher level in the nursing service. 142 Woodward's work specifically addresses itself to the customer-organization coordination problem in the unit production firm. 143 Again, many of her observations in regard to the "organic"

$$
\begin{aligned}
& \text { 1420ale, p. } 181 . \\
& 143 \text { Woodward, P. } 158 .
\end{aligned}
$$


organization have been implemented by the hospital organization in recognition of the necessity to survive, rather than through an understanding of the management process involved. What is probably lacking in the hospital organization is the broader organizational efficiencies which serve to make up for the technical inefficiencies which are intrinsic to special order production and management. 144 Her observations were that unit-production firms were most successful in terms of efficiency when overall management controls were de-emphasized and selfcontrol by individual operative employees was encouraged by management. 145 To a large extent, and again by default, these are the practices found in the successful hospital organizations. The necessity for accommodation to the physician-customer are best accomplished at the operative level of the organization; however, the management of the organization must be supportive of the efforts of the workers to perform thase accommodations and insure that these numerous deviations are coordinated throughout the organization.

Perrow also suggests two areas within which top administrative management can provide the necessary conditions for operative performance self-control which are conducive to the organic organization necessary under unit-production conditions, although he does not appear to recognize the true organizational situation. He recommends the promoting of an independent basis for judging competence on the part of the operative performers in lieu of maintaining close supervision over their work. 146

144 bid. 145 1 bid.

146 perrow, "The Analysis of Goals," p. 136. 
In addition to this he provides that top executive management in the hospital must support the operative performers and the intervening levels of the hierarchy in the conflicts which arise with the physicians as customers. 147 The hospital should also be most careful in the selection of its clientele, the physicians to be awarded practicing privileges, to insure that the demands of these customers are not beyond the resources or competence of the hospital. 148

It should be obvious that the executive's use of management theory in this new context of the organizational structure of hospitals must be judicious. There is a great deal of management lore which has been accumulated in regard to the marketing management function, only some of which will be useful in the particular situation, largely because of the dictates of unit-production. Management rules such as, iThe customer is always right," are neatly balanced with such admonitions as expressed by Urwick that: "To allow the individual idiosyncracies of a wide range of customers to drive administration away from the principles on which it can manufacture most economically, is suicidal."149 Actually, as can be noted as a theme throughout this essay, it is expected that as much can be learned to the benefit of management theory from the structure of the hospital, once it is placed in proper perspective, as hospital management can learn from management theory. Those hospitals which can be observed

147 Ibid.

148 perrow, "Organizational Prestige," pp. 564-565.

149. Urwick, The Elements of Administration (New York: Harper and Row, Publishers, 1943$),$ p. 29. 
are viable institutions which have made the necessary, but not necessarily the best, accomodations to the situations which they face, however unmanaged these accommodations may originally have been. 


\section{THE STAFF ORGANIZATION}

The line of an organization may be thought of as complete unto itself in terms of its ability to provide satisfaction of the primary service objectives of the organization. In the hospital organization the structure which has been discussed as the line, the nursing and ancillary departments, is all that is really necassary to provide for the care and treatment of the sick and injured as specified by a practicing physician. The devolution of the line which was discussed in the previous chapter and which appears as departments, wards or units, and sections and teams, emanating from the authority and responsibility held by the administrator as the operating executive designated by the board of trustees, and culminating $i$ the operative performers as the lowest line element in the organization, reflects a specialization of the tasks associated with the creation and distribum tion of the values for which the hospital organization was established. It is this portion of the organization which is vital to its existence, and, therefore, it is awarded a primacy of regard in all matters of organizational concern.

However, these line elements of the organization are but a part of the organization which is observed in practice. There are many organizational elements which are not involved in the creation and distribution of the primary service element but which support the 
line structure of the organization by attendence upon the collateral and secondary service objectives of the enterprise whether the organization is that of the hospital or any other except the most rudimentary of structures.' These eiements of the organizational structure are generally referred to as the staff of the organization.

The concept of a staff structure contained within an organization has had a varied history in management literature and is only now beginning to take on a resemblance in theory to the structure which exists in actuality. The original conceptions of a staff element separate from the line were in recognition that not all elements of the organization were directly involved in the creation and distribution of the values which made up the primary service objective. ${ }^{2}$ it is from this basic point of departure that staff elements of an organization are defined as containing those functions which are directed toward the satisfaction of collateral objectives of providing for the values desired by the members of the organization and the secondary service objectives of providing the primary and collateral objectives in an economical and effective manner. ${ }^{3}$ This leads to the contention

John G. Hutchinson, in Organizations: Theory and Classical Concepts (New York: Holt, Rinehart and Winston, 1967), p. 65, asserts that the line-staff structure is the only organizational form capable of meeting the diverse requirements of modern organizations.

${ }^{K}$ Keith Davis, Human Relations at Work (3rd ed. rev.; New York: MeGraw-Hill Eook Co., 1967):, p. 174.

3 Ralph Currier Davis, The Fundamentals of Top Management (New York: Harper and Row Publishers, 195i), p. 372 . 
that the staff of an organization does no work and therefore contributes no basic values that the line would not otherwise create if there were no staff. ${ }^{4}$ The organization must provide for the coilateral and secondary service objectives in any case, so the development of staff elements is a specialization of these functions and a separation of these specialized elements out of the line functions concerned with the primary service objective.

In the purest sense the functions performed by the staff of an organization are managerial in origin and retain the nature of this characteristic in practice. It is therefore a part of managerial work that an executive assigns to someone outside the line chain-of-command. 5 It is a delegation of managerial work to people who do not supervise line operations. ${ }^{6}$ in this same context Mooney considers the staff as an expansion of the personality of the executive in recognition of the limited amount of time avallable to the single line manager and the requirement to have specialized knowledge available to the executive while still retaining the final right of decision-making with the line chain-of-command of the organization. 7 The growth of an organization

\section{4libid.}

5William H. Newman, Charles E. Summer, and E. Kirby Warren, The Process of Management (2nd ed. rev.; Englewood Cliffs, N.J.: PrenticeHal], (nc., 1967), p. 101.

6lbid., p. 103.

7 James D. Mooney, The Principles of Organization (Revised Edition; New York: Harper and Brothers, Publishers, 1947), P. 41. 
resulting from an increased demand for the primary service values can be accommodated by a devolution of the line tasks leading to greater specialization of the primary operative tasks and a spreading of the load of managerial work, but this makes little provision for the specialization of managerial tasks. ${ }^{8}$ As the 1 ine devolves with growth the chain-of-command becomes extended requiring an expansion of the managerial functions of planning, organizing, and controlling at each level of the line hierarchy. ${ }^{9}$ If this growth of the line continues without the development of a staff structure to support it, there is a tendency for the organization to resort to highly centralized controls at the upper reaches of the hierarchy. 10 However, in addition to the managerial burden which is placed upon the line executive under these circumstances, it is more than likely that the individual managers in the chain of line authority are essentially oriented toward the operative aspects of the tasks associated with the primary values of the organization. 11 The executive, by training and experience, will be knowledgeable about these areas of the enterprise and therefore tend to emphasize these values to the neglect of the supporting objectives which require an expertise beyond

\footnotetext{
8. C. Davis, p. 363 .

9lbid., p. 373.

10 ibid., p. 364.

11 bid.
} 
that held by the line executive in the complex organization. 12 For this variety of reasons the development of a staff organization can be predicted; under the circumstances of a growing organization the coordinative problems which will be amassed cannot be solved through further devolutions of the line structure without subjecting the organization to the threat of strangulation under highly centralized controls. ${ }^{3}$ To properly decentralize managerial control the line executives along the hierarchy of the primary chain-of-command must be provided with the assistance of the various areas of technical knowledge supplied by a staff organization. ${ }^{14}$

In this relatively pure conception of the relationship of the staff structure to that of the line the staff is said to evolve out of the duties and tasks associated with the line managerial levels of the organization. 15 The staff is a specialization of the managerial tasks of planning, organizing, and controlling--the coordinative activities required in any organized endeavor. ${ }^{16}$ In addition to the expertise associated with these organic management functions, the staff provides a specialization of the tasks associated with the accomplishment

\footnotetext{
12 ibid.

33 lbid., p. 366 .

14 ibid.

15 lbid., p. 370.

16 lbid.
} 
of the collateral and secondary service objectives which are subsidiary to the line activities directed toward satisfaction of the primary service objectives. 17 This separating out of the managerial tasks can be considered as a phased process dependent upon the volume of activity to which the organization is subjected in the creation of the primary values and the relative importance of the individual staff functions in the support of this activity. 18

Davis sumarizes the factors which lead to this separation of the staff from the line in his principle of functional emergence which outlines the impetus behind the differentiation and independent grouping of the staff functions. 19 This principle will be applied in discussion of the prototype characteristics of the hospital organization in a later chapter.

Davis provides for tests of the staff nature of various functions as an assistance in the analysis of organizations, 20 Essentially, these are related to the nature of the objectives which the particular organizational element are designed to serve. Just as the line segments of the organization devolve to provide a specialization in the creation of the primary values supplied by the enterprise, the staff elements go through a secondary devolution to provide an operative specialization in the creation of the collateral and secondary service values of the
17 bid., p. 791.
18 ibid., p. 375 .
19 !bic.
20 lbid., pp. 388-389. 
organization required by toth $l$ ine and other staff elements. 21 Therefore, if an organizational element does not directly participate in the creation or distribution of primary service values it is probably a staff segment of the organization and its devolution from a separate, evolved managerial eiement can be traced. 22

As mentioned before, this is the basis for the pure theory of Staff organization in the line-staff form of structure. In practice, however, the elements associated with organizational structure are not as cleariy defined as theory would allow. Many organizational elements appear to combine both line and staff characteristics, while many of the units within an organization which are clearly supportive of the line structure do not neatly fit into the classification which has been provided for staff organization. In the expanded theory of organization, therefore, further sub-classifications of staff eiements are proviced which retain the purity of the 7 ine concept but cloud the issue in regard to the staff.

This phenomenon of a complexity of staff elements was noted by Barnard, who alleged that the executive portions of an organization were made up of many individuals who were not involved in the management functions of the enterprise. 23 The only basis for grouping this large component of the individuals associated with the organization was therefore the fact that the work they performed was not of the

$2 ! \underline{1 b i c}$.

$2216: 0 .$, p. 791 .

23 thester 1. Barnard, The Functions of the Executive (Cambridge, Mass.: Harvard University press, 1938), p. 215. 
organization, but rather the specialized work of maintaining the organization in operation. 24 While he would categorize these members as of the executive group they would not all be considered as performing management within the organization. 25 Again, this only serves to reiterate the function which the broad category of staff serves in support of the collateral and secondary service objectives of the organization but now it is recognized that many of the functions performed are only indirectly associated with the tasks of planning, organizing, and controlling the operations of the enterprise.

Litterer notes this disparity between theory and practice and marks the development of new theoretical concepts to accommodate the real world. 26 The bulk of elements found in organizations, which cannot be identified directly with the creation and distribution of the primary service values, can be classified as either pure staff elements associated directly with the management functions in the traditional mode of thinking or as auxiliary departments which perform functions for the entire organization. 27 pure staff elements, therefore, can be identified by their association with particular line management positions while auxiliary elements are global in their assistance to the line

\section{4 ibid.}

25 ibid.

26 Joseph A. Litterer, The Analysis of Organizations (New York: John Wiley and Sons, Inc., 1965), pp. 334-335.

27 lbid. 
and other staff units. 28 Litterer further sub-classifies these auxiliary elements into specialized staffs which perform managerial work, or serve as advice giving units across the organization and operating service units Which serve the organization in a physicai sense.29 However, he procedes to note that many staff entities may combine these functions to some degree. 30

While R.C. Davis primarily discussed the purely managerial role of the staff elements he also recognizes the facilitating functions performed by many of these organizational units, 31 His method of analysis providas that all staff units can be identified as being of either a coordinative or a technical variety; coordinative staffs provide a specialization of the managerial functions of control while technical staffs are associated with the specialization of the manageria? planning functions.32 Within this scheme of analysis he notes that the technical staffs frequentiy perform facilitating functions for the entire organization in addition to the planning tasks which have evolved from line management. 33 However, it might be noted that in most cases which are cited by Davis, the planning functions performed by these technical staff units are subsidiary to their

28 lbid., pp. $340-345$.

29 1bid.

30 inid.

3]R. C. Davis, pp. $402-405$.

32 isid.

331 bid. 
major facilitating tasks carried out by these segments of the organization. His particular citation of the typical personnel department as representative of a technical staff is indicative of the primacy of the supportive role of this form of organization. 34

While it is true that the functions performed by these specialized units would be performed by the line organization if the staff elements were not provided it is difficult to associate these facilitative tasks with the management function directly. It is interesting to note that the categorization of staff units by Davis into the coordinative and tech nical groupings inciudes but two of the three traditionally discussed organic management functions. He provides that the third of the management functions -- organizing -n remains largely undifferentiaced from Iine management itself, and, therefore, evolution of this function to staff elements has not taken place. 35

Other authors who discuss the role of staff elements within the structure of organizations provide various classifications of the different types of units which occur in practice. Hutchinson identifies personal and general staff units with the former associated with individwal line managers and the latter performing tasks in a particular functional area which are available to any individual or group in need of assistance. 36 Dale uses the term general staff to refer to those elements which are concerned with managerial functions while specialized

$$
\begin{aligned}
& 34 \text { ibid., p. } 402 . \\
& 35 \text { lbid., p. } 685 . \\
& 36 \text { Hutchinson, p. } 66
\end{aligned}
$$


stoff departments is a term reserved for those units which perform auxillary work, relieving line executives of these burdens and allowing them to concentrate on their primary task of management. 37 Keith Davis refers to a trichotomy of the staff elements into advisory, service, and control categories with the first involved as specialized counsel to managemant, the second performing the facilitating functions, and the third supporting management in its coordinative tasks. 38 Carzo and Yanouzas look to the highly ceveloped staffs which exist in military organizations to note the parallel in any organizational forms of the advisory and service categories of staff. 39

Perhaps, the most comprehensive discussion of the peculiarities associated with the facilitating functions performed within organizations is provided by koontz and 0'Donnel1.40 The facilitating elements, which they label as service departments, are separate from both staff and line in their association with other elements of the organization. 41 staff and line connote organizational relationships while service departments

37 Ernest Dale, Organizations (New York: American Management Association, 1967), P.81.

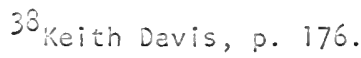

39rocco Carzo, Jr., and John N. Yanouzas, Formal Organizations: A systems Approach (Homewood, II! inois: Richard D. Trwin, Inc., 1967), P. 54.

4OHarold Koontz and Cyril O'Domell, Principles of Management (3rd Edition; New York: MeGraw-hil? Book Co., 1964), pp. 264-265. $4 i$ ibid. 

chapters.

Because service departments reflect a consolidation of tasks performed throughout the organization an issue arises as to the degree to which this centralization of activities should be carried. 46 once a centralization of functions is suggested the decision must be ren dered as to the organizational location of the service element. 47 When the service provided is diffused throughout the organization the question is never raised as to what good organizational practice might be in regard to these units. 48 Each line or staff manager is able to decide how and when these functions may be performed in support of his unit. With centralization these prerogatives are removed from the individual manager's control.

In particularly large enterprises the calculus which determines the relative benefits which will accrue from the differentiation and centralization of service units will weigh heavily in favor of such specialization. 49 The opportunities for such centralization will be greatly increased under these circumstances. However, the larger the organization, the more remote the particular activity will become from any individual management unit. 50

46 ibid., p. 303 .

47 ibid.

$4816 i c$.

491 bid.

501 bid. 
It is, therefore, necessary to balance the economies and efficiencies which such service departments may provide with the diseconomies and inefficiencies resulting from the loss of control over these activities by the operating executives. 51

One of the problems involved in utilizing this more modern analys is of organizations which provides for service elements is in the distinction of the form of authority which these elements contain. Within the more traditional concept the question of whether these elements have line or staff authority must be asked. Mooney recognized this problem in reference to organizational units which appeared to have both line and staff characteristics, but offered no solution. 52 McGregor appears to classify the service departments as line elements of the organization because they emphasize the generalized managerial skills rather than specialized professional skills normally associated with staff officials. 53 Koontz and O'Donne!, who have contributed the most to this form of analysis appear to beg the question through their categorization of service departments as groupings of activities rather than managerial roles. 54 It would appear that in the sense in which the service departments represent the bringing together of the tasks associated with operative perfor mance in both 1 ine and staff departments and the creation of a managerial

51 lbid., p. 311.

52 Mooney, p. 36.

530ouglas McGregor. The Human Side of Enterprise (New York; McGrawHill B ook Co., Inc., 1960$)$, P. 171 .

54 Koontz and O'Donne?1, p. 296. 
unit to coordinate these activities the authortty which it employs must be considered as distinct and subject to specific analysis in each particular case.

$\therefore$ is remarkable to observe that in the case of the typical hospital organization the pure staff elements are relatively unevolved and remain contained within the managerial eiements of the organization. On the other hand, the service elements appear to be well differentiated and separated from the parent line organization. This may well be a result of the relatively small size of hospitals as compared to business organi: zations which manifest the development of staff elements as a function of growth in the volume of business. 55 However, the degree to which the service department concept has been employed in hospitals has no ready explanation, and, therefore, this provides the possibility for discussion of this phenomenon as a prototype characteristic of these organizations, According to Davis, the failure of evolution of staff elements merely reflects the accomplishment of the managerial functions in the ine executive positions. 56 In the hospital organizations, however, the extensive development of service components appears to have diffused the line management functions throughout the organization on an apparently functional basis. This, of course, accounts for the relatively large span-of-control which the administrator exercises in the hospital organization when compared with American business. 57 It will remain the

55R.C. Davis, p. 420

56 lbid., p. 425.

57 Dale, p. 95. 
subject of analysis to determine whether this characteristic of the hospital organization is amenable to explanation in the manner suggested by Dale, who believes that either status aspirations or a sense of the importance of a particular function of the unit causes extended spans of management, or whether other factors are involved. 58

As previously discussed, many hospital organizations provide a separation of the functional departments into professional and business segments by a level of administrative management intervening between the administrator and the functional area managers. If the purely staff advisory services which are rendered by the service departments were considered alone it would be possible to detect a separation by this mechanism of the line departments and the rudimentary staff functions. The executive in charge of the business functions would then fit the classification of chief-of-staff provided in the military organization. However, more than staff elements are involved in these service departa ments in the hospital organization an many of the managerial functions of the line have been devolved rather than evolved to these units. By the same token there are elements within the organizational segment under the professional classification which contain similar advisory functions to line management which would be excluded from the staff grouping suggested. It would therefore appear, as outlined by Rosenberger, that no logical basis exists for this broad dichotomy of the hospital organization. 59

$$
58 \text { ibid., p. } 94 .
$$

5900 ald M. Rosenberger, "A New Look at Hospital Organizations," Hospitals, XXXVl (February 1, 1962), 45-46. 
Various outlines of the structural organizations of general hospitals are provided in the literature with associated functional statements concerning the duties assigned to the various elements. 60 Perhaps the most authoritative of these out lines is that provided by MacEachern.6l Utilizing this outline it is possible to categorize the various hospital departments into five segments based upon the functions which they are assigned; these are: Iine, staff, service departments, line and service departments, and staff and service departments. In the first category, as discussed in the previous chapter, are the nursing and ancillary departments. Among the elements discussed by MacEachern, only one, the public relations director, can conceivably be classified as being a pure staff function; however, this function cannot be cone sidered as a differentiated unit in the typical hospital.

There are numerous differentiated hospital departments which can be conceived of as typically service departments. These would include the medical library and the admission unit on the before mentioned professional side of the house and the utilities and maintenance department in the category mentioned as business affairs, along with housekeeping, laundry, and information. Both the accounting-purchasing-supply elements and the personnel department would be considered as combined staff and service

60 Representative of these outlines are: Esther Lucile Brown, Newer Dimensions of Patient Care: Part 2 (New York: Russell Sage Founcation, 1962), Pp. 57-60; and, American Hospital Association, Uniform Chart of Accounts and Definitions for Hospitals (Chicago: American hospital Association, 1959).

6l. Malco3m T. MacEachern, Hospita? Organization and Management (Berwyn, 111inois: Physicians' Record Company, 1962). 
depertments. One department, food service, could be included as being both a line and service department in nature, if it is recognized that this department is directly involved in the primary service objective to the extent to which it provides special diets as ordered by a physician.

Both of the combined staff and service departments found in the zypical hospital organization contain the potential for the separation of the advisory and activity aspects of their function. In American business the personnel department as a service activity is often found separated from the staff advisory service of industrial relations. This is often a reflection of the increased managerial attention required when the work force is organized as a bargaining unit. Likewise, the routine physical functions of accounting are more likely to be a service activity with the advisory control staff as a separate element in the organization. When this separation is accomplished the staff elements are normally located as an advisory area of top management allowing the service activities to direct their routine activities at a lower level, perhaps, on a more decentralized basis throughout the organization. Undoubtedly there is a factor of size which it would seem prevents such separation in the typical hospital organization; however, as the magnitude of the problems associated with personnel planning and managenent control become more aggravated, which situation appears to be developing in the case of American hospitals today, such staff elements may be indicated.

Such an arrangement will permit the hospital administrator to 
maintain the uniquely large span-ofmcontrol which allows for direct interaction between the top executive and the operating departments. As outlined in the previous chapter, the present arrangement which introduces the assistant administrator as an intervening level between the administrator and the various department organizations provides a poor substitute for a more typical staff arrangement. Creating an artificial separation between the business and professional areas of the hospital organization is in reverse of the coordinative requirements which are apparently needed between them. The hospital is comparable to a village or a ship which is complete unto itself -- to splinter the cooperating entities into segments which then group unlike functions has little to commend $i t$. The rush toward professional administration in American hospitals undoubtedly created a gap in the availability of trained and experienced persons to fill these positions; however, this situation has been alleviated to a great extent, and to continue the practice of utilizing what should be valuable staff positions as a training ground for inexperienced "generalists" is in wasteful ignorance of the real problems which the hospital faces. The American health care system has gained the time, or if not it must, to provide a career based upon well-rounded experience throughout the various hospital departments and meaningful staff positions for its future administrators much in the same manner as business managers are developed in American industry.

This chapter and the previous two have attempted to provide a perspective of hospital organization. With this basis it is now possible 
to investigate a few of the salient arguments which have been advanced in regard to the anomalous nature of these organizations, and to look at these contentions from a modified point of view which adheres more closely to the universal organization. It will then be possible to analyze the hospital organization for its prototype characteristics and investigate the ramifications of these characteristics as items of managerial concern. 


\section{CHAPTER V}

\section{AN ANOMALY: LINE IS STAFF AND STAFF IS LINE}

Amitai Etzioni has argued that the hospital organization is basically dissimilar from that of the universal organization described in the management literature. ' He asserts that in the universal structure the line of the organization, the executives, are identified as managers while the staff are experts. The staff has no direct authority, but, rather they act as advisors to the line or have limited authority over specified, functional areas. ${ }^{2}$ Managers, because they direct the major goal activities of the organization, are awarded line authority, while experts deal only with the secondary activities which are means to the organizational goals and therefore are limited in the authority which they can exercise. 3 Etzioni further insists that the role of the expert is the creation and institutionalization of knowledge while the manager's role is the integration of organizational systems directed toward the major goal activities of the organization. 4 Because of these differences in roles the expert and the manager will differ in their type of personalities. The expert will have a limited perspective and will be

TAmitai Etzioni, "Authority Structure and Organizational Effectiveness," Administrative Sciences Quarterly, 11 (June, 1959), 43-67.

2 ibid., p. 45.

3 ibid.

4ibid., pp. 45-46. 
committed to abstract ideas and therefore will be less practical. 5 The managers, on the other hand, will have an extensive, though limited knowledge of many areas, and with this broader perspective will tend to be more skilled in human relations. 6 overall, the manager will be a generalist while the staff man will be a specialist.

As a consequence of these factors the manager will tend to identify with the goals of the organization and obtain his personal values from the organization itself. The expert will have internalized the values of his specialized field and identify himself with others of his specialty outside of the particular organization. As a consequence the expert will be more transient to the organization while the manager will view his career as within the particular organization. 7 it is therefore not surprising to note that managers rather than experts will rise to the top executive position, and so appear, in nost organizations. 8

This phenomenon is most frequently found in American business organizations because of the nature of the profit objective in these institutions. 9 As long as the objective of the organization is not the service or utility created and with which the expert can identify then no other structure can produce the results desired. Profit accrues from the

5lbid., p. 46 .

6 ibid.

7 libid., pp. $46-47$

8 lbid., p. 48 .

glbid., p. 49. 
success of the integrative efforts of the manager; his ability to coordinate the effots of many experts in the production of a product or service in the most successful manner. 10 When the expert attempts to lead the enterprise the values of his specialized field intrude upon the economic values of the organization." "Manager orientations and the institutional goals of private business seem to match."12 "When an expert orientation dominates, this is dysfunctional to the organizational purpose. 113

Etzioni sums up the salient characteristics of the structure of business organizations by stating that: "Managers direct the major goal activities and have the major authority; experts deal with means and are in minor and subordinated authority positions."14 He questions the universality of this concept of organization beyond the business enterprise and suggests that although political and religious organizations appear to conform to this structure it is by adaptation, and, therefore, it is ill-suited to the situation. 15 However, other organizations clearly deviate from this mode of structure and conform to an organizational arrangement more nearly suited to their purpose. These he identifies as professional organizations. 16

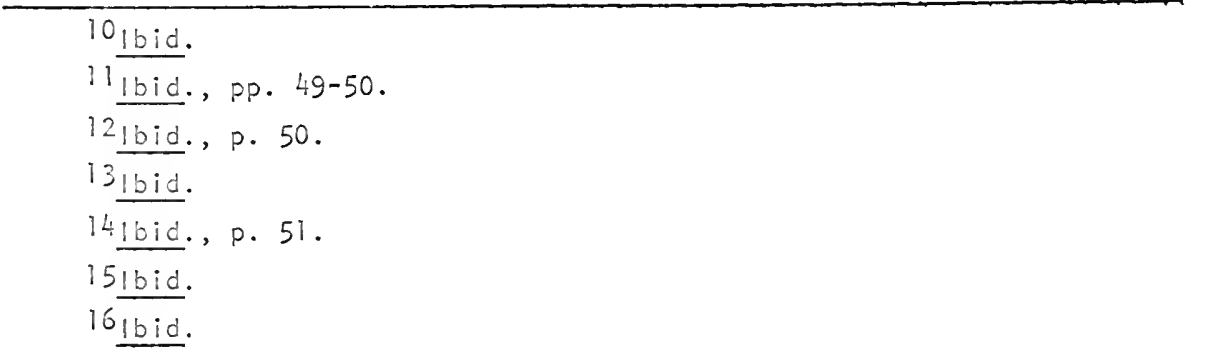


Professional organizations have as their major goal the creation and institutionalization of knowledge. 17 These organizations would inciude various research institutions, universities, schools, and hospitals which contain these values as their primary goals. 18 Research institututesand universities are concerned with the creation of knowledge, universities and schools with the spreading of knowledge, and hospitals with the application of knowledge. 19

In these professional organizations the roles prescribed for the universal structure appear to be reversed. 20 The major goal activity of these organizations is expertness, while managers in these structures are mainly concerned with the secondary activities. ${ }^{21}$ While Etzioni questions the concepts of line and staff in these structures, if such exist, the roles have become exchanged in these organizations. ${ }^{22}$ Managers in professional organizations provide advice about the economic and administrative implications of various proposed actions, but the expert, the professional, through the specialized knowledge of the objective of the organization, decides what action will be taken. 23

Etzioni notes that many of the objections leveled against experts

17 ibid.

18 lbid., pp. 5i-52.

19 lbid.

20 bid., p. 52.

21 ibid.

22 !bid.

23 ibid. 
in private business are also manifest against administrators in professional organizations. 24 The specialist in the business organization is accused of having a limited perspective and trained incapacity. In the professional organization the administrator is criticized for holding the values of economy and efficiency over that of the primary objectives of the organization. ${ }^{25}$ In the business organization an overinfluence on the part of experts threatens both the organizational objective and even the existence of the firm. ${ }^{26}$ in professional organizations over-influence by administration undermines the goals of the organization and inhibits the conditions for the creation and application of knowledge. 27

These arguments of Etzioni are reiterated and to some extent amplified in his later writings. 28 other earlier authorities have suggested various aspects of this same thesis. Parsons has commented upon this phenomenon of reversed roles in regard to the university organization. 29

24 ibid.

25 ibid.

26 bid., p. 53 .

27 lbid.

$28_{\text {Amitai Etzioni, A Comparative Analysis of Complex Organizations }}$ (New York: The Free Press, 1961); and, Modern Organizations (Englewood Cliffs, N.J.: Prentice-Hali, Inc., 1964) .

${ }^{29}$ Talcott Parsons, "Suggestions for a Sociological Approach to the Theory of Organizations -- 11," Administrative Sciences Quarterly, I (December, 1956), 236. 
Hall has commented upon the predominance of technical personnel in the hospital organization as an anomaly of these structures. 30 Brown, in essential agreement with Etzioni, concludes that this manifestation within hospital organizations is basically part of the argument concerning the existence of two lines of authority which will be considered in the next chaper. 31 Gordon, while considering this thesis has contested the argument in regard to specialists and generalists by arguing that the parties involved in hospital organizations often defy these categorizations. 32

While much of Etzioni's argument is based upon the role of the physician in the hospital organization a simple reiteration of the argument presented in Chapter 111 will not dispel the implications provided by this thesis when the overall participation of professionals in these organizations is recognized. Many of the present occupants of positions within the hospital organization are professionals at the present time and many other groups are actively seeking such recognition by the development of the value system and science-based background usually associated with the specialist. Although Etzioni indicates that the

30 oswald Hal1, "Some Problems in the Provision of Medical Service," Canadian Journal of Economics and Political Science, XX (1954), 458.

31 Esther Lucile Brown, Newer Dimensions of Patient Care: Part 2 (New York: Russell Sage Foundation, 1962).

32 paul J. Gordon, "The Top Management Triangle in Voluntary Hospitals (11)," Academy of Management Journal, V (April, 1962), 74. 
organizational situation is different when the line is composed of semi-professionals the tendency is toward the emergence of full professionalization for these groups. 33

This drive for professionalization by internal members of the hospital organization is related in many accounts; one of these, which first appeared as an editorial, has been included by Vollmer and Mills in their work and recounts the striving for such status by the occupational grouping which has come to take the title of medical technologist. 34 Goode questions the feasibility of realization of the aspirations of many of these groups including the nurses and the pharmacists; however, he maintains that the final decision rests with the public which is served by these individuals. 35 It would appear that as long as these occupations remain free to define themselves and to take the steps which lead to professional recognition the possibility for public acceptance of the desired status exists. 36 The main block to recognition of the aspiration of these occupations could either come from the organization which

33 Etzioni, Modern Organizations, p. 87.

34 Medical Technology," Professionalization, eds. Howard M. Vollmer and Donald L. Milis (Englewood Cliffs, N.J.: Prentice-Hall, Inc., 1966), p. 20.

35William J. Goode, "Community Within a Community: The Professions," American Sociological Review, XXII (April, 1957), 36.

36 ibid. 
utilizes their skills or the customers of these organizations as comprising their public. Bloom maintains that the physician as the customer of the hospital organization appears to encourage the aspirations for professional status on the part of the nurses by more and more acceeding to the contention that the body of knowledge which is nursing may be separate from that of medicine, and the physician is increasingly relying on the nurse and other skilled persons within the hospital organization to perform their tasks independent of the doctor's direction. 37 If this tendency continues these occupations may well gain the monopoly of judgment which Greenwood ascribes to the professional.38

It cannot be denied that the line of the hospital organization consists of specialists. Georgopoulos has outlined the degree to which nursing has gained an expertise beyond that which had traditionally applied, and he maintains that nursing, like many other professions, is continuing on a trend toward sub-specialization along with many other of the occupations employed in the hospital organization. 39 However, the employment of experts in the line organization as managers is not unique to the category of structure which Etzioni has labeled as professional.

37 Samuel W. Bloom, The Doctor and His Patient (New York: The Free Press, 1963), p. 91.

38Ernest Greenwood, "Attributes of a Profession," Professionalization, eds. Howard M. Vollmer and Donald L. Mills (EngTewood Cliffs, N.J.: Prentice-Hall, Inc., 1966), p. 12.

39 Basil S. Georgopoulos, "The Hospital System and Nursing: Some Basic Problems and Issues," Nursing Forum, V (1966), 26. 
Woodward has noted that specialists often have line roles in the business organization. 40 she maintains that no matter how specialized an executive might be from a knowledge and skill point of view, he remains a line manager if he is responsible for specific end results. 41 Litterer has indicated a similar conclusion by emphasizing that a line or staff designation is not dependent upon any inherent characteristics or unique properties of the position or the individual, but, rather, such designation is determined by the relation of the position to organization goals. 42 Just as the line designation is not a result of a characteristic generalist background in the case of the line executive, the staff member must not necessarily have a specialist point of view. R. C. Davis has remarked that while it is true that technical staffs are generally composed of specialists the higher reaches of these branches are often composed of executives with a much broader perspective. 43 In the case of the coordinative staff executives, they are most likely to have a generalist's orientation toward the organization. 44 The executive concerned with organizational control will have characteristics and a viewpoint which is

40 Joan Woodward, Industrial Organization: Theory and Practice (London: Oxford University Press, 1965), p. 100.

47 lbid.

42 Joseph A. Litterer, The Analysis of Organizations (New York: John Wiley and Sons, Inc., 1965), p. 338.

43Ralph Currier Davis, The Fundamentals of Top Management (New York: Harper and Row, Publishers, 1951), p. 394.

44 lbid. 
closely akin to that of the line. 45

It would appear redundant to again attack the profit objective which is a point in Etzioni's argument for this has already been well treated. However, if this primary profit objective of business organizations were accepted it would only be changed so that in non-profit organizations the line would be directed by other objective motivations. ${ }^{46}$ While Dale maintains that this motivation would be the welfare of the public served, this could be amplified to state the highest quality and quantity of welfare at the lowest possible cost. 47 It would still be necessary for the ine executives to perform the integrative functions necessary to coordinate the total endeavor in satisfaction of this objective.

Professionalism has its impact upon the structure of organizations in a way more subtle than that described by Etzioni. The specialization which he describes as typical of staff in the universal organization is a result of the increased complexity of the line management functions of planning, organizing, and controlling and the need for the specialist's expertise in these areas. The use of staff is but a special way of dividing up managerial work. ${ }^{48}$ To some degree there are alternatives provided for

45 ibid., p. 410 .

46 Ernest Dale, Organizations (New York: American Management Association, 1967), p. 61.

\section{7 ibid.}

48 Will iam H. Newman, Charles E. Summer, and E. Kirby Warren, The Process of Management (2nd ed. rev.; Englewood Cliffs, N.J.: Prentice-Hall, inc., 1967), p. 10]. 
overcoming the obvious complexities of the management function as are discussed in the previous chapter. Devolution of line authority should obviously be considered in these situations. Newman, et al., warn that staff and service units, while relieving the complexities of management, are tributary to the mainstream of management, and inevitably complicate an organization structure. ${ }^{49}$ A manager should see a clear advantage in utilizing staff elements, for simplicity is a virtue in organizing an enterprise. 50 The criterion by which an auxiliary unit is justified is basically the assurance that adequate attention will be provided to a secondary operation by establishing a technical competence outside the specialty of the operating executive through such a unit, thereby, relieving the busy executive from minor chores that otherwise would be a nuisance. 51

All of this is relatively straightforward. There are alternative arrangements of structure which will insure the satisfaction of the primary objective and it remains to management to make such selection. The real question, however, is the determination of the point where the chores of management become so onerous that they detract from the primary service values of the organization. It would appear that the hospital organization provides some special insight on this topic for it appears

$$
\begin{aligned}
& 49 \text { lbid., p. } 126 . \\
& 50 \text { lbid. } \\
& 51 \text { bid. }
\end{aligned}
$$


that a heavy specialization in the line organization, and more accurately -- advanced professionalization, has created a unique application of the principles involved.

Etzioni has remarked within a different context from the argument Which is now being discussed, that when people with strong professional orientations take over managerial roles, a conflict between these roles and their professional orientation usually occurs. 52 As the nurses and ancillary personnel strengthen their professional identification using the ever apparent physician as their model they tend to pattern their regard for the managerial tasks associated with their roles as somehow detracting from their status much in the same manner of the doctor. 53 This disinclination to accept the chores of management is usually expressed as a desire to emphasize the clinical work and the direct patient functions which is the heart of their professional identification. 54 Various schemes have been derived to relieve the nurses, for one, of the tasks of management. 55 The evolution of the managerial functions to staff and the devolution and separation of the auxiliary management tasks in the case of the hospital organization can be considered as a function of the

52 Etzioni, Modern Organizations, p. 79 .

53 Hall, P. 461 .

54 Basil S. Georgopoulos, "Hospital Organization and Administration: Prospects and Perspectives." Hospital Administration, $1 \mathrm{X}$ (Summer, 1964), 31.

55Luther P. Christman and Richard C. Jelinek, "0ld Patterns Waste Half the Nursing Hours," Modern Hospital, CVIII (January, 1967), 78-81. 
limited managerial orientation of the line executiyes which is typically found in the professional organization. Complexity of the managerial functions would be expected to occur at an earlier stage in these organizations due to this orientation of the managerial incumbents away from managerial concern. Evolution of staff elements and devolution and separation of service elements would both appear earlier than in the universal organization and be deeper in structure at any point in the growth of comparable organizations. Woodward supports this contention by noting the same phenomenon in what she describes as the organic organizations which were identified in her investigations of industrial organizations. 56 she has remarked that under these circumstances the line of the organization appears to be disintegrating as executive responsibilities are more extensively being conferred upon specialist staffs. 57

Pure staff evolution, however, should not provide the manifestation of formal authority exercised by the staff which would be central to the thesis advanced by Etzioni, that roles have become reversed. Apparently the observations of Etzioni are directed toward the functional authority exercised by the service departments exclusive of their staff roles. Staff elements of an organization may gain some degree of informal authority by the nature of their specialized knowledge or their location in association with higher level executives; however, this is relatively easy

56 Woodward, p. 65.

57 Ibid. 
to recognize and rectify where necessary. 58 The functional authority of the service unit, however, is of the line variety through its devolution from a line function as an operative management task. 59 Staff and service elements because of their frequent combination are often confused as to the type of authority which they exercise. 60 Again, Koontz and 0 'Donnell are referred to for their clarification of staff as an organizational relationship and service departments as an activity of organizations.61

The creation of the service department entity is a process of devolving line authority for specific managerial tasks and separating it from the line of the organization for independent grouping and accomplishment under the imperatives imposed by the secondary service objectives of efficiency and economy. 62 Woodward has remarked on the non-staff characteristics of these service elements and their impact upon the coordinative

58 Douglas McGregor, The Human Side of Enterprise (New York; McGrawHill Book Co., Inc., 1960 , P. 30 .

59rocco Carzo, Jr., and John N. Yanouzas, Formal Organizations: A Systems Approach (Homewood, 111 inois: Richard D. (rwin, Inc., 1967), p. 55 .

$60_{\text {Newman, et al. }}$ p. 116.

61 Harold Koontz and Cyril O'Donnell, Principles of Management (3rd edition; New York: McGraw-Hill Book Co., 1964), p. 292.

62 John G. Hutchinson, Organizations: Theory and Classical concepts (New York: Holt, Rinehart and Winston, 1967), p. 94. 
process in the industrial organization. 63 it appears obvious to the service department specialist that he should have control, and therefore authority, over the functions for which he is responsible. ${ }^{64}$ However, this allocation of authority is not without its consequences. Scott indicates that such grants of authority are clearly not envisioned by traditional theory which maintains the concept of unit of command which appears to be violated by functional authority. 65 In the business operan tion the splitting off of management tasks is usually viewed with concern by $l$ ine managers for they see their authority being removed while they are still largely held responsible for results. 66 Line managers find themselves remote from vital functions necessary for their operations. 67

In the hospital organization the decision to specialize and differentiate some aspect of the managerial tasks of line executives is welcomed through its affinity to the professional role to which the line adheres. Yet the complaints which are exercised over specialist supervision and the difficulty involved in coordination of the line

63Woodward, pp. 166-167.

640avis, pp. 458-459.

65William G. Scott, Organization Theory: A Behavioral Analys is for Management (Homewood, 11 inois: Richard D. Irwin Co., 1967), p. 116.

$66_{\text {Koontz and 0'Donnell, p. } 310 .}$

67Newman, et al., p. 128. 
functions is much the same in the business organizations. 68 The logic of functionalization of managerial tasks is as clear as when first pronounced in the writing of F.W. Taylor. 69 To argue that these elements are staff in nature denies the apparent fact that the work of the service units is not advisory. 70 Keith Davis has commented that the benefits of functionalization are largely economic, but its disadvantages are primarily in human relations. 71 If these economic advantages are additionally weighted by the imperatives of professionalization the explanation of the intensive functionalization of managerial tasks in hospital organizations is understandable. It will remain for a later discussion of the prototype characteristics of the hospital organization to determine whether the human relations disadvantages of such structural elements are adequately counterbalanced.

It then appears that the reversal of roles which Etzioni notes in professional organization, particularly the hospital organization, is less a function of the specialist characteristic of the professional but more an acceleration of a structural process which is well recognized in the management literature. Rather than ascribing a line role to the

$68_{\text {Brown, p. } 71 .}$

${ }^{69}$ Carzo and Yanouzas, p. 54.

70 Woodward, p. 167.

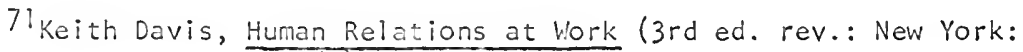
McGraw-Hill Book Co., (967), P. 173. 
staff elements, the service departments have developed with the necessary functional authority to perform their assigned tasks. As a body these staff elements may appear to encompass the generalist role but individually their perspective is limited to the specialists's tasks. As is indicated the concern over the devolution of functional authority to service elements is not peculiar to the professional organization. McGregor's significant work builds upon a theory of control which is essentially the domain of the staff and service groups in the business organization. ${ }^{72}$ His conclusions provide, in a manner dissimilar to Etzioni's argument, that a reversal of line and staff roles has occurred in the industrial organizations of this country. ${ }^{73}$ That is, the line -- the central and fundamental authoritative chain-ofcommand -- is becoming increasingly dependent upon the proliferating specialized staff groups. ${ }^{74}$ in an even stronger statement, Galbraith has taken the position that the government-industrial complex which dominates the American scene is ruled by the "technostructure" of these organizations. 75 Through analysis this "technostructure" is revealed as the staff and service element of these organizations. On this basis

72 MCGregor.

73 lbid., p. 155.

74 ibid.

75 John Kenneth Galbraith, The New Industrial State (Boston: Houghton Mifflin Company, 1967). 
alone it could be argued that Etzioni's thesis merely supports the contention that the hospital organization is of the universal structure.

In spite of this recognition of a changing organizational structure which these authors reveal it is apparent that the hospital has been influenced by this dynamic process to a more advanced degree than the modal organization. Woodward's studies of industrial organizations in England, while perhaps not representative of the American situation, indicate that the development of organic forms of organization with an adherence to a structure of functional authority are but the leading edge of all organizations.76 In the hospital organization the degree to which devolution and separation of managerial tasks has taken place is remarkable. However, it is questionable whether even advanced devolution of authority over these tasks, with separation and elevation of these functions within the organizational hierarchy, can develop a complex of functional authority which would outweigh the remaining operative management functions of the traditional line of the organization. 77 What is being observed in the hospital organization is a mode of line

$$
\begin{aligned}
& 76 \text { Woodward, p. } 65 . \\
& 77_{\text {R.C. Davis, pp. 14-15; provides that executive management is }}
\end{aligned}
$$
divisible into two categories: administrative and operative management. The latter is essentially the management of groups -- the face-to-face work of the manager as the leader in the accomplishment of the day-today tasks of the organization. Administrative management is the longerrange project tasks which must be undertaken by management. The contention is here that administrative management is more amenable to staff and service department separation. 
and staff-service department separation peculiar to advanced professionalization within an organization. To the degree in which other organizations experience the same influx of professionals this phenomenon is indicative of the tendency of the universal organization. The professional character of the contained occupations encourages this form of devolution and separation and the organistic nature of the hospital structure has not been restrictive of the tendency. In other forms of organization with more traditional outlooks this dispersion of the management functions has been more inhibited.

This explanation of the phenomenon observed by Etzioni, and in other respects by McGregor and Galbraith, is not beyond the pale of existing organization theory and its structural dynamics. It is mainn tained that the structure of the universal form of organization has been adapted in the professional organization along the lines suggested by this theory. The dynamic process has been extended beyond the bounds normally encountered in the typical organization but the logical extension is apparent. This raises new problems for the prototype organization, but it also suggests the success of the theory as a basis for the prinn ciples of management. 


\section{CHAPTER VI}

AN ANOMALY: TWO CHAINS OF COMMAND

The second major contention of an anomaly of hospital structure which sets this organization apart from the universal organization is what Harvey L. Smith has described as the basic duality of hospitals.l He maintains that two main lines of authority -- lay and professional mexist in the hospital. The one is that hierarchy which extends from the trustees through the administrator and the department heads to the various categories of hospital workers.2 While the second line of authority is composed of the various roles held by professional persons in the organization -- especially the physicians. 3 The physician, or anyone acting for the physician, can abrogate or countermand any directive or order which emanates from the administrative hierarchy. ${ }^{4}$ While the physician may have little formal authority in the organization his actual authority is very great indeed. 5

The physician and his agents including the nurses and other ward

i Harvey L. Smith, "Two Lines of Authority Are One Too Many," Modern Hospital, LXXXIV (March, 1955), 59-64.

2 lbid., p. 59.

3ibid.

4 bid.

5 lbid. 
personnei have the capability to exert power throughout the hospital structure. Some areas appear to be reserved for administrative rule, others are reserved for professional rule, while still other areas of the organization are best described as hybrids. It is in this last area that the many conflicts of jurisdiction arise. 6

This phenomenon of dual authority is not entirely unique to hospital organizations. Other human structures which contain professional competence appear to manifest many of these same features, with the university providing a ready example. 7 This situation is the result of attempting to handle two different principles of administration within one organization. The more typical organization functions through the exercise of bureaucratic authority -- which the management theorists would describe as formal authority. In the hospital organization, as typical of professional organizations, this authority is accompanied by a measure of charismatic authority in the hands of the professionals. ${ }^{8}$ The primary characteristic of charisma in the hospital organization is its defiance of administrative regulation. 9 These posessors of charisma resist being encompassed in the bureaucratic organization. 10 it is the special problem of the hospital that it is an administrative structure which must contain and regulate charismatic professional persons who are defiant of lay
6ibid.
7 Ibid.
8lbid., pp. 59-60.
9lbid., p. 60.
101 bid. 
regulation." Therefore, both the administrators and the professionals are authoritative figures but for different, and conflicting reasons. ${ }^{12}$

Smith recalls the observations of Barnard who provided that two types of status exist in all organizations. 13 Scalar status is that which is inherent in a position in view of its hierarchical rank. ${ }^{14}$ Functional status accrues, on the other hand, from the nature of the work performed which may not be limited to the particular organization. ${ }^{15}$ In organizations orders generally emanate from those who have higher status than the recipient. However, in the hospital organization a person may be subordinate to two or more individuals who have either higher scalar or functional authority. ${ }^{16}$ This duality of authority is matched by a basic duality of purpose within the organization itself a. that is, whether the objective of the organization is of a service or business variety. 17 Employees are therefore confused by the conflicting demands of "money" and "service" being issued in the forms of orders by persons with either scalar or functional authority.

On another basis of duality which Smith observes in the hospital structure he anticipates the argument presented by Etzioni which was the

$$
\begin{aligned}
& 11 \text { lbid. } \\
& 12 \text { lbid. } \\
& 13 \text { lbid. } \\
& 14 \text { lbid. } \\
& 15 \text { lbid. } \\
& 16 \text { lbid. }
\end{aligned}
$$


topic of discussion in the previous chapter. He notes that the physicians are referred to as the staff but their authority is not typically advisory. 18 While they are labeled as staff they intervene with authority of administrative rules and procedures. 19 And while they are staff they are responsible for the major goal activities of the organization. 20

While smith presents many of his arguments in terms of the physician's role in the hospital he does not limit the duality of structure which appears to exist to this group. He makes specific mention of the various professionals, or emerging professions, which play their part in the hospin tal structure, and he attributes to them the same characteristics of the physicians in regard to the appearance of two lines of authority. ${ }^{21}$ Each of these professional groups within the hospital structure manifests the charismatic behavior noted in the case of the physician. 22 Unlike the workers in industry who organize and express demands for money without altering the administrative authority structure the proto-professionals of the hospital organization develop professional group relationships which ask for changes in status and recognition which is the essence of the internal hierarchy of authority. ${ }^{23}$ It is therefore, as in the previous argument in regard to the anomalous structure of hospital organization,

181bid.

19 ibid.

20 lbid.

21 lbid., p. 63.

22 bid.

23 Ibid. 
impossible to dispel the contentions of this position held by Smith by reiterating the fact that physicians are not of the organization.

The arguments presented by Smith in his article have been well received and appear in many citations by other authorities. Wessen has carried this apparent structural anomaly down to the ward level of the organization but amplifies it to encompass the entire range of functional authority exercised in hospitals. ${ }^{24}$ Georgopoulos and Mann incorporate this argument as a basic factor in their work. 25 And Georgopoulos maintains the argument in his later work. ${ }^{26}$ As mentioned before, Etzioni has employed this argument in support of his contention that the line and staff roles are reversed in hospital and other professional organizations. 27 However, at a later point in time he appears to accept that what is being discussed, at least in the case of physicians, is essentially two parallel organizations. 28

${ }^{24}$ Albert F. Wessen, "Hospital Ideology and Communications between Ward Personnel," Patients, Physicians and 11 liness, ed. E. Gartly Jaco (New York: The Free Press, 1958), pp. 451-452.

25 Basil S. Georgopoulos and Floyd C. Mann, "The Hospital as an Organization," Hospital Administration, VII (Fall, 1962), 59

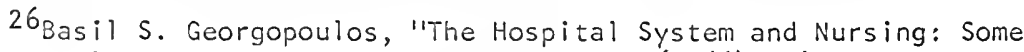
Basic Problems and Issues," Nursing Forum, V (1966), 14.

27 Amitai Etzioni, "Authority Structure and Organizational Effectiveness," Administrative Sciences Quarterly, Iv (June, 1959), 59.

28 Amitai Etzioni, A Comparative Analysis of Complex Organizations (New York: The Free Press, 1961), p. 225. 
Further citations of Smith's argument are made by other authors. Scott has used this thesis to advance the propostion that the amount of conflict between the professionals and administrators is reduced in those organizations which contain professionals of high versus low prestige. 29 And, Bloom, by adding a third, and separate, authority source to the situation, specifically the trustees, maintains that two of these power groups often enter into cooperative agreements to offset the relative power of the third authority. 30 Somers and Somers, employm ing Bloom's extension of the argument, incorporate the concept of an anomalous structure in voluntary general hospitals into their call for reform of the health care system. 31

The significance of Smith's argument is contained in the traditional edict of organization theory that there must be unity of command in an organization if the objective of the enterprise is to be attained. 32 Scott, in particular, addresses himself to this aspect of Smith's

29. Richard Scott, "Professionals in Bureaucracies - Areas of Conflict," Professionalization, eds. Howard M. Vollmer and Donald L. Mills (Englewood Cliffs, N.J.: Prentice-Hall, Inc., 1967), p. 275.

${ }^{30}$ Samuel W. Bloom, The Doctor and His Patient (New York: The Free Press, 1963), p. 162.

31 Herman Miles Somers and Anne Ramsay Somers, Medicare and the Hospitals: Issues and Prospects (Washington, D.C.: The Brookings Institute, 1967), p. 51 .

32 Henri Fayol, General and Industrial Management (London: Sir Isaac Pitman and Sons, Ltd., 1949), pp. 24-26. 
position. 33 While Carzo and Yanouzas discuss the obvious dissimilarity between the hospital organization and the universal structure in the same context, harking to many of the warnings expressed by traditional theory in this regard. 34

Starkweather is perhaps the only writer who has attempted to answer the argument from a managerial theory point of view. 35 He visualizes the two 1 ines of authority presented by Smith as being cooperative systems running on parallel tracks.36 The link between the two systems, much as in the case of railroad tracks, are ties which bind the lines together. 37 The ties which are common to all organizations and in this case to the two separate line organizations are the functions of management. Theren fore, in the case of the hospital organization the physicians and the administrators have a common objective of service and each is utilizing the functions of management to further that objective. 38 However, the two lines can be thought of as sharing the one set of management functions, just as the rails of a railroad share the common ties. 39

33William G. Scott, Organization Theory: A Behavioral Analys is for Management (Homewood, Tllinois; Richard D, Trwin Co., 1967), p. 108.

${ }^{34}$ Rocco Carzo, Jr., and John N. Yanouzas, Formal Organization: A Systems Approach (Homewood, lllinois: Richard D. Irwin, Inc., 1967), p. 44 .

35 David B. Starkweather, "The Classicists Revisited," Hospital Administration, XII (Summer, 1967), 69-80.

36 lbid., p. 70.

37 lbid., pp. 70-71.

38 lbid., p. 71 .

39 lbid., p. 73. 
In one area of the functions the physicians may command more of the decision-making area while in another, less. 40 The tendency will be for the two lines of administrative and medical staff power to balance off, one-with-the-other, in the exercising of the management elements. 41

Even if the doctors are accepted as a portion of the internal organization it would be unnecessary to defend the traditional concepts of unity of command in the eyes of many organizational theorists. Simon maintains that the unity of command described in the typical traditional theory has never existed in any administrative organization. 42 And, Dale describes various situations in the business organization which clearly are violations of the concept of unit of command yet which are considered as necessary for the effective functioning of particular organizations. 43 Even R. C. Davis constructs a similar concept for the universal structure in an organization having experienced extensive staff evolution with the creation of administrative and operative management 1 ines of authority. ${ }^{44}$ Another variation on the theme of two lines of authority contained

40 1 bid.

41 lbid., p. 78.

42 Herbert A. Simon, Administrative Behavior (2nd ed.; New York: The Free Press, 1957), p. 25.

43 Ernest Dale, Organization (New York: American Management

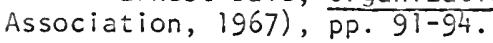

44 Ralph Currier Davis, The Fundamentals of Top Management (New York: Harper and Row, Publishers, 1951), pp. 439-443. 
within an organization is provided by Katz and Kahn. 45 They maintain that all social organizations contain an executive and a legislative function. 46 some organizations fuse the executive function concerned with the execution of policy and the legislative function concerned with the establishment through common consent, of this policy. ${ }^{47}$ In the business organization this is typically true. 48 In other organizations, for example, the university, these functions are separate. 49 The faculty determines policy and the administration executes it. Urwick has made the same observation, and has taken much the same position, at an earlier time. 50

It should be noted that an acceptance of the doctor as a part of the hospital organization is not a universally held concept, however, much that would affect the argument made in relationship to the two lines of authority in these organizations. Hall, for one, holds the view that the physicians are outside of the hospital organization; however, this does not make it any less necessary that cooperative behavior be exercised by

45 Daniel Katz and Robert L. Kahn, The Social Psychology of Organizations (New York: John Wiley and Sons, Inc., 1966), p. 45.

46 ibid.

47 bid.

48 ibid.

49 lbid.

50 L. Urwick, The Elements of Administration (New York: Harper and Row, Publishers, 1943), P. 54 . 
the parties to the healing process. 51 Lentz makes much the same point in indicating that the physician's prestige may be on the wane in regard to it providing him with the authority necessary to accomplish his tasks as an independent practioner. 52 Brown takes a position close to that of this essay that the physician is external to the hospital organization and, therefore, perhaps in a competing chain-of-command. 53

Whether the physician is excluded from the hospital structure, therefore attributing the power which he exercises in the organization to that expected of the customer, albeit a customer powerful in prestige, it is still necessary to accept that an authority is held by those professional persons who are legitimately described as of the hospital organization. However, before dealing directly with this subject it is necessary to consider scme aspects of the customer-organization relationship which exists when the physician is considered external to the organization. Etzioni in an earlier article noted that the hospital organization accommodated to the prestigious physician as a customer through a process which has been described by Selznick as co-optation. 54 Selznick argues that if an organization faces a power problem in its internal or

5l Oswald Hall, "Some Problems in the Provision of Medical Services," Carradian Journal of Economics and Political Science, XX (1954), 459.

52 Edith M. Lentz, "Hospital Administration -- One of a Species," Administrative Sciences Quarterly, I (March, 1957), 459-460.

53 Esther Lucile Brown, Newer Dimensions of Patient Care: Part 2 (New York: Russell Sage Foundation, 1962), p. 65.

54 Amitai Etzioni, "Administration and the Consumer," Administrative Sciences Quarterly, 111 (September, 1958), 260. 
external environment it will attempt to resolve the situation by incorporating the dissident element into the body of the organization to the degree necessary under the circumstances. 55 The hospital organization has attempted to modify the power relationship of the physician by instituting such measures as the joint conference committee which allows the pressure of the customer relationship to be directed into a more responsible outlet. 56 As Etzioni presents it, this is an alternative to the difficult process of indoctrinating the members of the hospital organization to the service role which they play in regard to the customer. 57 As discussed in Chapter 111, the reasoning behind the development of the joint conference committee and other mechanisms for gaining the cooperation of the physician has generally been misunderstood by the operating officials of the hospital organization. It has been accepted that this institutionalized role in the management of the organization was something which the physician should have been accommodating to before these measures. It might be better for hospital administrators to realize that a natural process of accommodation to the powerful role of the physician as customer has been at work. Those persons within the organization who directly serve the physician have been developing a status more nearly equal to the customer. 58 As the nurses and other

55philip Selznick, "Strengthening Leadership--Co-optation," hiuman Relations in Administration, ed. Robert Dubin (2nd Edition; Englewood Cliffs, N.J.: Prentice-Hall, Inc., 1961), pp. 360-362.

56Etzioni, "Administration and the Consumer," pp. 258-259. 57 ibid.

58 Robert N. Wilson, "The Social Structure of a General Hospital," Annals of the American Academy of Political and Social Science, No. 346 (March, 1963), p. 73 . 
ancillary department workers find a place in the professional sun, the doctor's aura is diffused and dimmed. 59 The monopoly of professional status, and its concomitant power in the customer-organization relationship has been broken with the rise of new professional groups within the organization and the increased dependence of the physician upon technical assistance in the healing process. ${ }^{60}$ Ryack has commented that the physician no longer finds himself as the prime mover in the health care process -- he must compete with many other occupations for the prestige associated with healing of the sick. ${ }^{61}$

The power relationship which develops under these circumstances cannot be said to be unique to the hospital organization. Any business organization which is dependent upon a single customer or a relatively small group of like customers will undoubtedly feel at a disadvantage in the relationship. In most of these situations the customer will more than likely have a technical capability equal to that within the organization which is directly in contact with the customer. The company will undoubtedly attempt to maintain a status relationship which is as nearly equal between the two as is possible under the particular circumstances. Katz and Kahn refer to this necessity for the business organization to maintain its autonomy and resist domination by its customer group when

59 Robert N. Wilson, "The Physician's Changing Hospital Role," Human Organization, XVIII (Winter, 1959-60), 181.

60 Bloom, p. 165.

${ }^{61}$ Elton Rayack, Professional Power and American Medicine: The Economics of the American Medical Asscciation (Cleveland, Ohio: The World Publishing (0., 1967), Pp. 62-63. 
this type of relationship exists. ${ }^{62}$ It cannot be said that the situation in the hospital organization is much different from these business examples; what is interesting, however, from a management point of view, is the observation of how the solution to this problem is evolving in the hospital organization. The hospital may always remain a unique case in respect to the fact that the customer is also professionally oriented; however, the individualized service which the organization of the future will be providing to its customers will make the customer-organization relationship quite as intimate as that exercised in the hospital setting. The degree to which the customer will be professionally oriented toward the product being consumed may well be as high in many less exceptional cases as the tempo of technology increases and provides the opportunities for external economies of scale and complete service department separation from the parent organization. The trend toward such service department separation appears to be on the increase as organizations begin to realize that purchased services have become more economical than providing such services internal to the organization. In each such case the relationship which develops between the serving organization and the corporate customer is of a power sort which is not easily explained by reference to the organization with many, relatively unsophisticated customers. Rather, in those organizations serving technically oriented clientele it would be expected that the personnel in contact with the customers would be of relatively high prestige within the organization.

${ }^{62}$ Katz and Kahn, pp. 58-59. 
There can be no doubt that much of the confusion in regard to the hospital organization has been caused by the distortion which resulted from attempting to force the description of the structure by including the physician as part of the line of the organization. Once this artificiality is removed the perspective becomes clear and a familiar organizational phenomenon becomes apparent. Smith employed the analysis of organizational status provided by Barnard. This analysis is a portion of Barnard's attempt to synthesize the formal and informal theories of management. 63 in fact, Smith is employing a portion of the informal theory of authority. He is maintaining the position that the authority held by an individual within an organization is sometimes different than that provided by the organization in its hierarchical scheme and that this informal authority may be dysfunctional to the organization purpose. However, in the case under consideration we discover that a very real purpose is served by the development of a functional status through the means of increased occupational prestige in the case of nursing and ancillary personnel -- mainly that this prestige is required to offset the prestigious position of the customer, the physician, and thereby maintain the stability of the organization with its surrounding environm ment.

The basis for the striving for prestige in the case of nursing and many other occupations contained in the ancillary groups of the hospital organization has often been expressed in a vague manner. Henderson

63 Chester 1. Barnard, Organization and Management (Cambridge, Mass.: Harvard University Press, 1948), Pp. 207-244. 
provides that medical care will never reach its fullest development until a peer-relationship is established among those in the health professions. ${ }^{64}$ ti would appear that organization theory and particularly its dynamic applications might be utilized to good advantage in explaining much of the phenomenon of increasing professionalization both in service organizations and industry. 65

It might be said that this blind reaction to one organizational problem creates a multiple of new problems for the enterprise. In providing a balance between the organization and its environment the internal balance between organizational elements is disturbed. Perhaps as in the case presented by Smith, two lines of authority or even more are being created through the organizational prestige accruing to the professional members. There is a real possibility that professionalization of more and more occupational groups will herald the separation of the executive and legislative functions in new organizational settings where traditionally they were fused. Kornhauser recounts one of the salient features of the professional outlook, the necessity for

${ }^{64}$ Virginia Henderson, The Nature of Nursing (New York: The Macmillan Company, 1966), p. 67.

65Burton R. Clark, in "Faculty Organization and Authority," Professionalization, eds. Howard M. Vollmer and Donald L. Mills (Englewood Cliffs, N.J.: Prentice-Hall, Inc., 1966), p. 287, describes this increasing tendency toward professionalization of occupational groups in various organizations, in addition to recounting many of the dysfunctional consequences. 
autonomy within the organization. ${ }^{66}$ However, there are other organizational accommodations which appear to be inherent in the professional attitude. In particular, the already noted tendency for professionals to evolve and devolve managerial functions and tasks to staff and service department echelons of the organization. Where professionalization gains the individual status through prestige and ultimately an increased measure of organizational authority, line authority is gained by service department groups in adequate counterbalance through the mechanism of functional authority. 67

66 William Kornhauser, "Scientists in Industry: Conflict and Accommodation," Professionalization, eds. Howard M. Vollmer and Donald L. Mills (Englewood Cliffs, N.J.: Prentice-Hall, Inc., 1966), p. 292.

67This point, and the entire concept of organizational balance, receives elaboration in a later chapter concerned with the prototype characteristics of hospital organization. 
AN ANOMALY: HOSPITALS ARE BECOMING MORE BUREAUCRATIC IN STRUCTURE

Edith Lentz describes the present organizational situation in American hospitals as one in which the structure is passing from a more traditional concept to that of the bureaucratic model. ' The traditional form of hospital organization provided for a highly centralized form of structure with strict authoritarian control exercised by the trustees over the business affairs of the organization and by the physicians over the professional activities carried out by the nursing personnel. 2 The trustees looked on the hospital as their feudal estate and visited it daily to give personal direction to the staff who were treated as the serfs of the estate both in regard to the subsistence wages provided and the paternalistic direction to which they were subjected. 3 The superintendent, who was the forerunner of today's administrator, was merely another of the workers who required constant supervision by the board in his conducting of the business type activities of the organization. 4

"Edith M. Lentz, "Mospital Administration -- One of a Species," Administrative Sciences Quarterly, I (March, 1957), 456-463.

2 lbid., pp. 456-457.

3 lbid.

4 bid., p. 457. 
The role of the physician was independent of the organization; however, as a guest to the estate of the trustees he was given powers to match his prestige in supervising the work of the employees of the hospital. 5 Much as the owner-entrepreneur might elicit the assistance of a works superintendent the board would invest the physician with the authority to oversee the endeavors of the paid employees. ${ }^{6}$ Under this relationship the physician would deal directly with the board, circumventing whatever authority structure that might exist in the organization.7 But to most extents the structure of the organization was loosely formed with many of the individual employees dealing directly with the members of the board in a manner typical of the rudimentary business organization. In terms of organization theory authority was centralized in the executive position with little if any devolution of authority and accountability for the management functions in spite of the differentiation of the operative functions.

The hospital today has undergone a metamorphoses which is similar to that which must have occurred in business as these organizations moved from the owner-entrepreneur form to the corporate structure. 8 As the structure of the organization became more complex with the introduction of

5lbid., pp. $458-459$.

6 ibid.

7 ibid.

8 lbid., p. 459. 
new professional personnel occasioned by the rapid advance in medical technology it was no longer possible to coordinate and control operations through the occasional supervisory activities of the separate members of the board. Even the more frequent supervision performed by the "guests" of the house was insufficient because their competence did not span the range of functions being accompiished. An active, day-to-day coordinator and controller of all of the functions of the establishment was required and the role of the hospital administrator became institutionalized in a manner similar to that of the professional manager in industry. 9

The advent of the professional administrator, however, brought with it the complex of structural rules and regulations which are the hallmark of the bureaucratic organization. 10 In order to make possible the orderly coordination of the activities of the hospital it was necessary to establish the lines of communication and control which makes this form of organization workable." No longer is it possible for the physician, who continues as a "guest" of the house, to make his end runs to the trustees if the activities of the enterprise are to remain coordinated. And to the extent that coordination of the entire range of activities of the hospital organization must be accomplished the physician must conform to the controls established for the proper operation of the

$$
\begin{aligned}
& 9 \text { lbid. } \\
& 10 \text { lbid. } \\
& 11 \text { lbid. }
\end{aligned}
$$


enterprise. ${ }^{12}$

However, the bureaucratic form of organization has not completely replaced the more traditional form. 13 The transition is not yet complete. What presently exists is a three part power structure consisting of the board, the physician, and the administrator. ${ }^{14}$ The physician finds it difficult to accommodate to the bureaucratic structure in the hospital phase of his activities. 15 The autonomy necessary for his functioning in the healing process is not easily susceptible to the submission required by the organization. 16 However, with the increase in technology and the availability of the specialized help provided within the hospital structure the physician finds that the bulk of his work still remains outside of the hospital organization. 17

The tasks of the administrator are complicated by this arrangement and it is difficult for him to manage the institution for which he holds responsibility. ${ }^{18}$ The prestige of the physician intrudes into many of

12 ibid.

13 lbid., pp. 459-460.

14 bid.

15 Ibid., p. 459.

16 Ibid.

17 lbid.

18 lbid., p. 460. 
the activities which the administrator is attempting to coordinate. Much of this same form of prestige is held by internal members of the organization upsetting the usual balance of positional authority which exists in the bureaucratic organization. 19 In addition, the professional identification of these internal members strengthens their desires for autonomous positions within the organization creating further control problems for the administrator and his staff. ${ }^{20}$ The administrator trained in the procedures of business management can only be frustrated by this situation leading to still further emphasis upon the logical process implied in the bureaucratic form of structure.

Much of this same argument is presented by Burling, Lentz, and Wilson in an earlier work. ${ }^{21}$ As elaborated therein, the problems associated with hospital structure are primarily a function of the stage within which the particular organization finds itself. Those organizations which still have a heavy element of the traditional structure find that the bureaucratic imperatives are quite painful. Those organizations which have successfully made the transition and become true bureaucracies find this structure quite compatible with the health care situation. ${ }^{22}$

19 lbid.

20 lbid., p. 461.

${ }^{21}$ Temple Burling, Edith M. Lentz, and Robert Wilson, The Give and Take in Hospitals (New York: G. P. Putnam's Sons, 1956), pp. 317-333. 22 lbid., pp. 331-332. 
Many other authorities note a trend toward bureaucratization of the hospital organization and other structures which have traditionally maintained the autonomy of the professional worker. Gilb has commented that an historic movement has existed which will lead to the wholesale bureaucratization of all work as predicted by Max Weber. 23 Wilson agrees with this contention to the point of maintaining that the bureaucratic mold is both logical and historically appropriate for the physician. $24 \mathrm{Ha}$ l], however, would disagree with Lentz in regard to the existence of a tendency toward the development of bureaucratic structures in hospital organizations. 25 in his viewpoint the hospital organization had its roots in the bureaucratic tradition, having historically been organized by religious orders and military and governmental establishments. 26 Each of these has added its own distinctive measure of bureaucratic structure to the present hospital organization. 27

Other authorities also agree on the occasion for the rise of the bureaucratic form of organization. Perrow is in agreement with Lentz in

23 Corinne L. Gilb, Hidden Hierarchies (New York: Harper and Row, 1966), p. 231.

$24^{2}$ obert N. Wilson, "The Physician's Changing Hospital Role," Human Organization, WIII (Winter, 1959-60), 179.

250 swald Hall, "Some Problems in the Provision of Medical Services," Canadian Journal of Economics and Political Science, XX (1954), 458.

26 ibid.

27 ibid. 
respect to the need for administrative coordination; however, he sees the cause in the concern of the various parties to the hospital organization becoming aware of the need for more efficient and economical operations in the face of a health care system which has become increasingly interdependent and specialized. ${ }^{28}$ Gilb concludes that the rise of the bureaucratic form of organization in the health care field is the result of technological advances in medicine, the bulk of new knowledge, the availability of capital, and socioeconomic changes that have made large-scale undertakings more feasible as well as necessary. 29 Blau and scott maintain that the development of the bureaucratic form for a particular organization is a natural consequence of the search for some routine and a stable means of economic support which all enterprises will experience at some point in their existence. 30 Gouldner suggests that the bureaucratic solution is advanced when the parties to an organization perceive some group within the enterprise failing to perform their role obligations. 31 "Bureaucratic measures are thus a response to

${ }^{28}$ Charles Perrow, "The Analysis of Goals in Complex Organizations," Readings in Organization Theory: A Behavioral Approach, ed Walter A. Hill and Douglas M. Egan (Boston: Allyn and Bacon, Inc., 1966), p. 136. $29_{\text {Gilb, p. } 98 .}$

30peter M. Blau and W. Richard Scott, Formal Organizations (San Francisco: Chandler Publishing Co., 1962), p. 31.

${ }^{31}$ Alvin W. Gouldner, Patterns of Industrial Bureaucracy (New York: The Free Press of Glencoe, 1954), P. 231. 
a breakdown in a social relationship; they are a defense against the tensions which arise when the expectations that two parties have of each other are no longer adequately meshed and complementary. ${ }^{1132}$

Within this context then the bureaucratic organization can be considered as an attempt to provide clearly marked lines of communication and authority through a formal status structure with stated goals and a system of explicit rules and regulations.33 Bennis dimensionalizes the bureaucratic structure by a division of labor based on specialization, a well-defined hierarchy of authority, a system of rules covering the rights and duties of employees, a system of procedures for dealing with work situations, an impersonality of interpersonal relations, and promotion and selection based on technical competence. 34 Gouldner sees the fruits of such forms of organization in the reduction of statuslocated tensions stemming from close supervision in addition to reducing tensions throughout the organization as a whole which stem from the interaction of persons with different value and belief systems, breaks in the chain-of-command, short circuited communications, and the challenge to the legitimacy of management, to mention a few. 35 However,

32 lbid.

33 Biau and scott, p. 14.

34 Warren G. Bennis, Changing Organizations (New York: McGraw-Hill Book Co., 1966), p. 4-5.

35 Gouldner, p. 240. 
the rationality of the bureaucratic model does not remain unquestioned with respect to overlooking the individual within the structure. 36 And, Georgopoulos and Mann specifically question its application as a structural form of organization when the individuals involved have professional characteristics. 37

The point which is raised in regard to the feasibility of the bureaucratic structure in the case of professional participants along with other aspects of this form of organization suggests many questions in regard to its application. Wessen remarks that it would hardly be applicable to describe the hospital as a bureaucracy when the caste system which prevails in these organizations is observed. 38 Blau and Scott would add that both the traditional and charismatic authority of the professionals, and the stability of social order which they provide, are unlikely to be easily upset. 39 Wilson, at a later point, sees no simple resolution of the juxtapositon of the professional with a rising tide of bureaucracy. $40^{\circ}$ The tendency to engineer the ambiguity

36 Joseph W. McGuire, Theories of Business Behavior (Englewood Cliffs, N.J.: Prentice-Hali, Inc., 1964), P. 29.

37 Basil S. Georgopoulos and Floyd C. Mann, "The Hospital as an Organization," Hospital Administration, VII (Fall, 1962), 19.

${ }^{38}$ Albert F. Wessen, "Hospital Ideology and Communication between Ward Personnel," Patients, Physicians and IIIness, ed. E. Gartly Jaco (New York: The Free Press, 1958), p. 450.

$39 \mathrm{Blau}$ and Scott, pp. 30-3i.

40 Robert N. Wilson, "The Social Structure of a General Hospital," Annals of the American Academy of Political and Social Science, No. 346 (March, 1963), p. 74. 
out of jobs which prevails in this form of structure does not fit the criteria of professional work. ${ }^{41}$ The professional's resistance to such forms of structure and the attendant consequences of their incorporation in this form of organization has been well summarized by scott. 42 In addition to the specific opposition of the professional to assuming a bureaucratic role there are many more generalized objections to the use of this model of organization. The work of Merton, and others, have outiined these commonly known objections to the dysfunctional aspects of the bureaucratic model. 43 perrow has commented in this vein by noting that if administrative dominance is based primarily on the complexity of basic hospital activities rather than the role of the hospital in the community then the operative orientation of the organization may be toward financial solvency, careful budget controls, efficiency, and minimal development of services. 44 Etzioni questions the entire concept of bureaucratization of the hospital

${ }^{41}$ Frederick Herzberg, Work and the Nature of Man (Cleveland, onio: The World Publishing Co., 1966), p. 65.

42 W. Richard Scott, "professionals in Bureaucracies - Areas of Conflict," Professionalization, eds. Howard M. Vollmer and Donald L. Mills (Englewood Cliffs, N.J.: Prentice-Hall, Inc., 1967), pp. 265-275

43 Robert K. Merton, "Bureaucratic Structure and Personality," Complex Organizations: A Sociological Reader, ed. Amitai Etzioni (New York: Holt, Rinehart and Winston, 1961)', pp. 48-61.

44perrow, pp. 136-137. 
organization if the uniqueness of each patient's case is accepted, which fact is in direct opposition to the concepts of routinization of service implied in the bureaucratic model. 45

The anomalous character of the contention that hospital organizations are becoming more bureaucratic in structure resides in the notion that the hospital is tending toward the universal structure as described in the sociological literature where bureaucracy is taken as the model organization. 46 Rather it is the purpose of this study to present the argument that the hospital organization is of the universal structure with notable characteristics which mark it as a prototype for the changing circumstances which all organizations must face in the future. In particular the two features common to hospital organizations, professionalization of internal members with the associated value placed upon autonomy, and unit-production techniques which defy routinization of procedure, appear to be antithetical to the bureaucratic model which is suggested as representative of the universal structure. It would therefore appear to be worthwhile briefly to investigate the degree to which the bureaucratic organization describes the present universal structure.

One of the most serious disabilities of the bureaucratic form of organization as described in the literature is the emphasis upon

${ }^{45}$ Amitai Etzioni, Modern Organizations (Englewood Cliffs, N.J.: Prentice-Hall, Inc., 1964), P. 53 .

$46_{3} 1$ au and scott, p. 32 . 
control. 47 However, the issue of control has no place in the traditional theory of the rational bureaucratic organization in spite of the admonitions that coordination and control are synonymous. 48 Dubin asserts that if all other systems in an organization were perfectly operative there would be no need for control. 49 Carzo has also remarked that Weber's model of bureaucracy is one of perfection much like the model of a machine without friction. 50 That the universal organization is not of the bureaucratic description can be attributed to the human inhabitants of these organizations. Scott provides that the "perfection assumption" of this classical theory requires an exact match between the capacity of the individual and the authority of the function. 51 March and Simon also comment on the assignment problem in organizations as being the root cause of the development of a theory of

47 Chris Argyris, Personality and Organization (New York: Harper and Row Publishers, 1957), p. 131.

48 Joseph A. Litterer, The Analys is of Organizations (New York: John Wiley and Sons, Inc., 1965), p. 233 .

49 Robert Dubin, Human Relations in Administration (Englewood Cliffs, N.J.: Prentice-Hall, Inc., 1961), P. 389.

50 Rocco Carzo, Jr., and John N. Yanouzas, Formal Organization: A Systems Approach (Homewood, 111 inois: Richard D. Irwin, Inc., 1967), p. 27 .

5lWilliam G. Scott, Organization Theory: A Behavioral Analysis for Management (Homewood, T11inois: Richard D. Irwin, C., 1967), p. 112. 


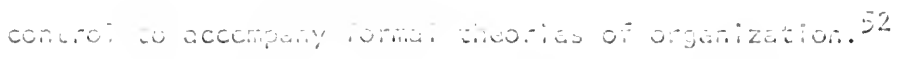

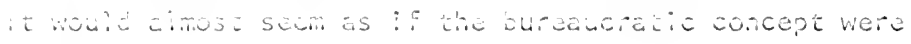
seif-defeating. The struchured ficio wich constitutes the bureauaratic organization provides the necd for control as an a?most inevitable psycholocical conseguene. or che pathologicaily described bureaverecy such as the displacement

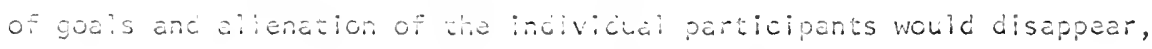
aiong with ine need for controis, if persona?ties cowla be shaped to

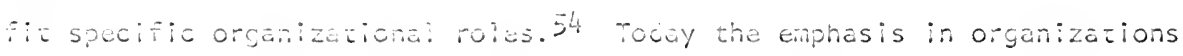
is piac_o upon the selection and ecuation of incividuais to flit roles within organizasions. 55 fis witi de secin in the procorype discussion of the hospizal organizazion thesi imperatives appan to be less and less critica? in these structures, since the imperacives which cause an active resistunce to the rationalizy of the seructurai organization are iess upparent in the hesizh care orsanizasion.

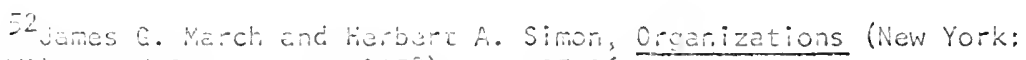

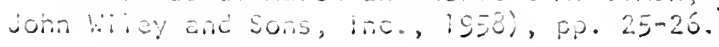

53victo: A. Thompson, "äreaucracy and innovation," Administrative sciences anderiv, $\times$ (June, isos), 20.

5 Etzioni, Moder orgenizations, p. 75.

5E: Dic. P. 68.

56 couldier, $p .236$, outlines the ractors which are involved in slich resisterce. 
While Georgopoulos maintains that a large segment of hospital administration clings to a concept of business administration which emphasizes the requirements for extensive control,57 it appears to be well recognized that this avenue affords little opportunity for the solution of the problems of hospital management. 58 Brown believes that hospital administrators when compared with managers of industry and business, have been lax in informing themselves about the recent findings in the social sciences. 59 Whether this is true or not there can be no doubt that management has made itself aware of the changing circumstances of organizational structure and in particular, the link between the requirement for coordination and the necessity for control. 60 This is particularly true in the case of those organizations which employ professional personnel. ${ }^{61}$ And it would appear to be most apparent in the hospital situation. ${ }^{62}$ It is becoming more apparent also

57 Basil S. Georgopoulos, "Hospital Organization and Administration: Prospects and Perspectives," Hospital Administration, IX (Summer, 1964), 25.

${ }^{58}$ Esther Lucile Brown, Newer Dimensions of Patient Care: Part 2 (New York: Russell Sage Foundation, 1962), p. 17.

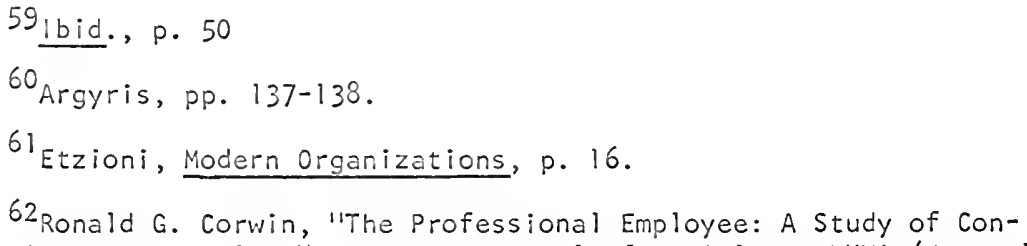
flict in Nursing Roles," American Journal of Sociology, LXVI (June, 1961), 66. 
in such cases as reported by Woodward where the increased efficiencies derived from rationalization of organization structure is minimal because of the uncertainty involved in the production processes and the probability of error in the setting of standards in the unit-production industries. 63

It would appear that the organization which Lentz is attempting to describe, and toward which she believes hospitals are tending, is less that of the bureaucratic form described in sociological literature, and more that of the modern business organization upon which the principles of management are based. It is regrettable that so much of the writings concerning hospital organization have emanated from a sociological background with its reliance upon the bureaucratic model. Even among sociologists the qualifications of this model which they present appear to have reduced the value of the original conception of a bureaucracy. Etzioni has remarked on the disadvantages of using the word bureaucracy as a synonym for organization. ${ }^{64}$ Blau and Scott reserve the term bureaucracy to connote a specific syndrome found in some organizations. ${ }^{65}$ Wilson separates bureaucracy from formal rational bureaucracy. ${ }^{66}$

63Joan Woodward, Industrial Organization: Theory and Practice (London: Oxford University Press, 1965), p. 178.

64 Etzioni, Modern Organization, p. 3.

$65 \mathrm{glau}$ and $\mathrm{Scott}, \mathrm{p} .208$.

66 Wilson, "The Physician's Changing Hospital Role," p. 177. 
Georgopoulos and Mann refer to hospitals as being quasi-bureaucracies. ${ }^{67}$ Thompson provides for the monocratic bureaucracy as distinct from other, less well-defined, forms of organizations. 68

Bureaucracy as a concept has now become a target for change, ${ }^{69}$ with Bennis predicting that bureaucracies, as such, will pass from the scene. 70 In the management oriented literature this is well documented. Dale has remarked that management process organization theory has long since passed beyond the bureaucratic model. ${ }^{71}$ Terry has noted the emphas is upon the individual and groups in organization theory and the de-emphasis of structural concepts of the bureaucratic variety. ${ }^{72}$ Litterer provides that bureaucratic descriptions of organization tend to resemble management descriptions but in most important ways they differ. ${ }^{73}$ Keith Davis maintains that the bureaucratic description must be reserved for governmental organizations for it would be entirely inapplicable in the business

67 Georgopoulos and Mann, p. 53.

68 Thompson, p. 4.

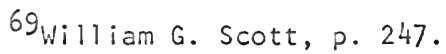

70 Warren G. Bennis, "Organizational Developments and the Fate of Bureaucracy," Industrial Management Review (Spring, 1966), pp. 41-55.

71 Ernest Dale, Organization (New York: American Managment Association, 1967), p. 35 .

72 George R. Terry, Principles of Management (5th ed. rev.; Homewood, illinois: Richard D. (rwin, Inc., 1968), p. 281.

73 Litterer, p. 12. 
situation where the imperatives of competition generally rule. 74 Koontz and O'Donnell suggest that the expression and phenomenon of bureaucracy may have some limited application in the description of business organizations particularly in the case of service department elements of the structure. ${ }^{75}$ it is highly possible that the phenomenon which Lentz is attempting to report in the case of the hospital is of this latter variety.

The structure of the business organization which can be taken as the universal model with its basis for the principles of management is of a more dynamic form than that provided by the bureaucratic description. It would be expected that hospital administrators who were students of management theory would be exposed to this dynamic model rather than the static bureaucratic formula. Also, therefore, it would be expected that this tendency which Lentz reports can be hoped to lead to logical conclusions provided by management theory and the accommodation of the structural form of organization to suit the hospital situation. This conclusion would recognize that the traditional bureaucratic model is not appropriate when applied to non-routine, "creative" decisions and activites. ${ }^{76}$ The apparent dependence of administrative superiors upon their operative subordinates in the hospital organization

74 Keith Davis, Human Relations at Work (3rd ed. rev.; New York: McGraw-Hill Book Co., 1967), p. 166.

75 Harold Koontz and Cyril O'Donnell, Principles of Management (3rd Edition; New York: McGraw-Hill Book Co., 1964), p. 312.

76 Fremont E. Kast and James E. Rosenzweig, "Hospital Administration and Systems Concepts," Hospital Administration, XI (Fall, 1966), 26. 
should make administrators aware that bureaucratic solutions are inapplicable. 77 The means of motivation of individuals is readily at hand in the hospital environment where the opportunities for individual achievement and a sense of recognition are available to the lowest level of operative performer, which will not remain unrecognized by the management-trained hospital administrator who holds the bureaucratic form of organization in $i$ ts correct perspective. 78

To be most beneficial to management theory, observations about hospital organization should not be cast within the descriptive model provided by the bureaucratic structure which has little application in the business situation. The accommodations in respect to organizational control which have been accomplished in hospital organizations concerned with unit-production and employing professional workers would be of particular benefit to general management theory and this can obviously not be accomplished within a bureaucratic model. The transfer of management techniques to the hospital situation will only be accomplished if both forms of organization are described in similar terms which ignore the artificialities of descriptive devices such as the bureaucratic structure. Woodward has commented on the inadequacies of organization theory to describe the organic structure typified by unit-production

$77_{\mathrm{Bl}}$ au and Scott, p. 232.

${ }^{78}$ Frederick Herzberg, Bernard Mausner, and Barbara Bloch Snyderman, The Motivation to Work (2nd Edition; New York: John Wiley and Sons, inc., 1959), p. 125 . 
techniques and professional participation -- it would appear that hospital organizations could make a significant contribution in this regard if the description of these organizations were related to the universal structure rather than the bureaucratic model.79

It should be recognized that hospital organizations are accomplishing a startling change in their structural form. Whether these changes began with what Lentz refers to as a "traditional" structure or, as Hall maintains, their traditional bureaucratic form, the item of interest is the structure which is evolving. Merely to pass this off as a new form of bureaucratic organization would be to miss the vast amount of data which analysis of this structure could provide. Woodward has noted that the problems which arise with the passage of an organization from batch methods of production to unit-production methods are insignificant when compared to the problems associated with an enterprise moving toward batch production. 80 if hospitals are becoming more bureaucratic, with routinization of productive activities in the batch-method format, then severe organizational problems should be expected. However, if instead hospitals are continuing unit-production methods, or are moving toward greater employment of these techniques this phenomenon should be reported as such, for the dissipation of organizational problems through this movement will be of immense value to managerial theory.

$$
\begin{aligned}
& 79_{\text {Woodward, p. } 181 .} \\
& 80 \text { bid., p. } 209 .
\end{aligned}
$$




\section{THE PROTOTYPE ORGANIZATION}

The anomalies of hospital organization which have been discussed are exclusively the result of sociological studies which attempt to describe the social structure of this organization. These attempts are not without success in noting that the description of the hospital organization departs from the concept of a modal structure in many significant respects; however, the purpose served by these departures is not well documented. To a large extent, as would be expected, these descriptions concentrate on the human element contained within the hospital organization. While it would serve little purpose to ignore this element, the human factors must be considered as a segment of a larger productive system containing imperatives of its own, and the whole as linked by a system of management designed to provide a coordinated enterprise.

The present chapter will attempt to consider these factors as a dynamic interaction which results in a unique application of structure to accomplish specific results--the purpose of the enterprise. While the model of hospital organization which is discussed is taken as typical of this form of structure it is necessarily a construction which ignores all but the points being considered and therefore is unrepresentative of any specific organization. Because it is a dynamic interpretation rather than a static description the various phases of 
organizational change are distinct from changes elsewhere in the structure except where these are of particular interest. The emphasis will constantly be upon the prototype characteristics of the hospital organization when it is subjected to this dynamic analysis provided by management theory.

Perhaps the most salient feature of the hospital organization is the marked organic nature of its structure when it is compared to more mechanistic structures which are amenable to human engineering. This concept of an overall separation of organizations into the nature of their basic structure was first developed by Burns and Stalker.' They view mechanistic structures as being conditioned by a situation of relative stability where the specification of functions can be accomplished and maintained over a significant period of time. ${ }^{2}$ The problems and tasks of the enterprise can be broken down and assigned to the various functional areas which are specified within the structure and the coordination of these elements can be accomplished through a routinization of organizational procedures. 3 These forms of organization are marked by a well established command hierarchy which is well understood throughout the enterprise. 4 In contrast the organic form of structure is adapted to unstable conditions where problems and requirements for action on the part of organizational participants cannot readily be broken down

Tom Burns and G. M. Stalker, "Mechanistic and Organic Systems,"

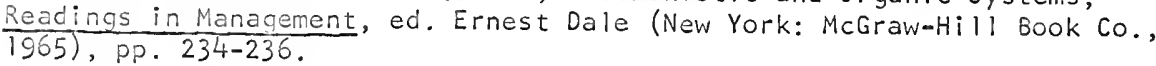
2 lbid., p. 234.
31 bid.
4 lbid. 
and distributed. 5 Because of this dynamic situation the organization is constantly subject to the definition of tasks and functions by the individual participants rather than through the command hierarchy. 6 Much of the communication exercised in this form of organization is lateral through the structure rather than vertical via a command hierarchy. 7 The proper functioning of this form of organization is heavily dependent upon the conception of purpose which each individual participant holds of the organization. 8

Burns and Stalker believe that the major determinant of the organic or mechanistic nature of a particular organization's structure is a function of the degree to which the various roles within an organization have had the opportunity to develop a traditional status relationship with one another. 9 Under the dynamic conditions of change in purpose and procedure this historic basis for relationships cannot develop; however, once developed the responsiveness of the organization to a change in circumstances will be severely limited. Much of the energies of the mechanistic organization will be expended upon the clash of participants over power and status if change is introduced. 10 Therefore, the viability of these forms of organizations must be subject to serious question when exposure to change, or the reduction of routinization is introduced upon the scene.

Woodward has used these definitions of two contrasting forms of

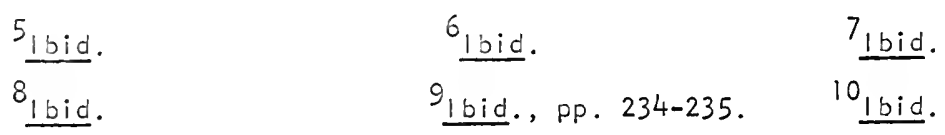


organizational structure in her studies. 11 The mechanistic organizations are characterized by a rigid breakdown into functional specialism, precise definition of duties, responsibilities and power, and a well developed command hierarchy through which information filters up and decisions and instructions flow down. ${ }^{i 2}$ The organic structures are more adaptable; jobs lose much of their formal definition, and communications up and down the hierarchy are more in the nature of consultation than of the passing up of information and the receiving of orders. 13 A large proportion of the firms she studied conformed to the organic structure to some degree, a fact which she attributes both to the locale of the study area, which contained many new and developing industries, and the viabi?ity factor--those firms which cannot adapt in a changing environment are less likely to provide surviving specimens. 14 However, when all organizations investigated were measured against a criterion of degrees of success those which more closely conformed to the model of the organic structure were significantly overrepresented in the highly successful category. 15 in addition, there was demonstrated a close correlation between success and the variables of type of structure and form of technology employed. 16 successful mass-production firms were more i ikely to have a mechanistic form of structure while the structure of the unit-production and process firms was more likely to be of the

13 Joan Woodward, Industrial Oroanization: Theory and Practice (London: Oxford University Press, 1965).
12 ibid., p. 23.
15 bid., p. 33.
13 bid.
14 lbid., p. 25.
16 1bid., pp. 68-72. 
organic variety. 17

The presence of characteristics of these two varieties of organizational structure has not gone unrecognized in this county; however, most of the observations have been subsumed, unfortunately, under the traditional controversy between the formal and informal schools of management theory. Generally the compromise has been made that both concepts apply in every organization while the link between the specific form and its predominance under particular technological conditions has gone unrecognized. It still remains to be seen whether these American theories can be sorted out to provide additional substance to the contention that specific technologies of production largely dictate the formality of organization structure. To some extent the present writings which direct themselves to such applications of organization theory still concentrate on the preference of one theory over another without specifying the circumstances. 18 However, excellent descriptions of the organic organization, such as that presented by Likert, are availalbe for application given the proper circumstances. 19

The ambiguities of organizational structure which have been presented as anomalies of hospital organization are essentially manifestations of

17 Ibid.

18 Fremont E. Kast and James E. Rosenzweig, "Hospital Administration and Systems Concepts," Hospital Administration, XI (Fal1, 1966), 26.

19 Rensis Likert, "A Motivational Approach to a Modified Theory of Organization and Management," Modern Orcanization Theory, ed. Mason Haire (New York: John Wiley and Sons, Inc., 1959), p. 186. 
the organic nature of the structures involved. The hospital lacks the mechanistic features of those organizations which are able to regularize their accommodations with the environment which they serve. The hospital must exist in an environment in which diverse and unique demands upon its capabilities are constantly being exercised to which it must respond in a spirit of service. Rigid regulation of its procedures which would allow for the reduction of the ambiguities which are involved and a clarification of the organizational structure is impossible under these circumstances.

This link between the organic organization which has been described and the methods employed in hospital organizations has been noted. Georgopoulos and Mann provide that the hospital when its organization is explored, is basically a human rather than a machine system. 20 In addition to the organization being composed of human participants the product itself is a composition of human reaction to the process employed. 21 The hospital organization must manifest a structure which permits a heavy reliance upon the members of the organization to coordinate their activities on a voluntary, informal and expedient basis which in turn accommodates the ambiguities of the human element. ${ }^{22}$ Elsewhere, Georgopoulos has noted that the concepts of mass production

20 Basil S. Georgopoulos and Floyd C. Mann, "The Hospital as an Organization," Hospital Administration, VII (Fall, 1962), 53.

21 Daniel Katz and Robert L. Kahn, The Social Psychology of Organizations (New York: John Wiley and Sons, Inc., 1966), p. 116.

${ }^{22}$ Georgopoulos and Mann, P. 53. 
and uniform products has only a very limited application, or acceptance, in the hospital situation. 23 Rosenberger has specifically identified the hospital of today as an "odd-lot" job shop, to use the language of industry. 24

In the literature of management the question of organic versus mechanistic structures is usually reduced to a discussion of the basic dilema which exists between providing invididual freedom and reaping the economic benefits of organizational efficiency and order, ${ }^{25}$ with consideration given to whether either system of organization will be the best overall in terms of some calculus which is yet to be derived. 26 However, there appears to be an increasing recognition that the question involved is only relevant to the productive circumstances involved. Keith Davis takes this point of view in his discussions of the imperatives which dictate the requirements for open communication and personal contacts across chains-of-command. 27 While Argyris acknowledges that whatever the benefits to be obtained in terms of human satisfaction from the organic form of organization, this structure is quite often determined

23 Basil S. Georgopoulos, "Hospital Organization and Administration: Prospects and Perspectives," Hospital Administration, IX (Summer, 1964),26.

${ }^{24}$ Donald M. Rosenberger, "A New Look at Hospital Organizations," Hospitals, XXXV! (February 1, 1962), 43 .

${ }^{25}$ George R. Terry, Principles of Management (5th ed. rev.; Homewood, 111.: Richard D. Irwin, Inc., 1968), P. 285.

26 ibid.

27 Keith Davis, Human Relations at Work (3rd ed. rev.; New York: McGraw-Hill Book Co., 1967), P. 182. 
by factors beyond the control of the humanistic inclinations of management. 28

Actual adaptations of the organic form of organizations have largely been of the accidental variety--creatures of circumstance--rather than of management design, at least until quite recently. As Bennis has noted, the essence of the organic structure is spontaneous adaptation to the needs of the system. ${ }^{29}$ It would require either an overwhelming ignorance of management theory or abject resignation in the face of overwhelming circumstances to avoid the imperatives of present theory which require management to function as the organizer of the enterprise and dictate the proper form of organization. More recently specific forms of organization have been developed in industry which incorporate the opportunities for organic determination of structure within a larger frame of enterprise organization. Bennis discribes these organic forms of structure as the project organization based upon "temporary systems" developed to handle specific problems to be solved in an adaptive and rapidly changing manner. 30 These temporary systems will consist of groupings of strangers with diverse skills who will be presented with a problem which in interaction with the technical capabilities of the participants will evolve a structured relationship among them which will satisfythe immediate situation. 31 once the problem is resolved, which ${ }^{28}$ Chris Argyris, Integrating the Individual and the organization (New York: John Wi ley and Sons, Inc., 1964), p. 185. 29 Warren G. Bennis, Changing Organizations (New York: McGraw-Hill Book Co., 1966), p. 8.
301bid., p. 12
31 Ibid. 
may be a matter of days or months, the structure will be abandoned for new groups with new problems.

This project, or "Task-force," form of organization is a reasonable adaptation of the organic concepts of organization when the "problem" is of major proportions and will command a significant amount of the enterprise's resources. This is not the essence of the matter in the hospital or other unit-production organization. While in the case of the hospital the service to be rendered to the patient may be lifesaving, and in that respect important, the problem situation may be one of a thousand experienced by the organization throughout a single day. Woodward reports that the unit-production firms included in her study which met the criterion of success were of the simple line variety. 32 Needless to say these firms were in no respect comparable in size to the typical hospital organization, nor were the technical requirements of the task beyond the capability of the "generalist" in this size firm. Significantly, however, two of the large process-production firms included in her study which also were measured by success were of a functional structure and operated as organic organizations calling upon the expertise of functional specialists to supervise and coordinate, as necessary, the multiple problem situations which arose during the course of the enterprise operations. 33 In addition, many of the "successful" batch-production firms which were intermediate between the unit-production and mass-production firms, while

\footnotetext{
32 woodward, p. 64. 33 lbid., p. $118-122$.
} 
appearing to conform to a line-staff organization, actually provided functional authority informally to the staff elements and operated in an organic manner. 34

Organization theory provides little descriptive leeway between the line-staff and functional forms of organization, and while the hospital organization is generally described in line-staff terminology it appears that through the extensive development of the service department concept and ancillary department functionalization a functional form of structure may be evolving. The success of this form of organization is entirely dependent upon an organic method of operation--there is little which can be routinized in this scheme of organization beyond the statement of broad areas of functional competence and the sense of dependence which must exist. The only purpose which this form of organization can serve is to provide the opportunity for interaction among the various areas and levels of competence on a problem-solving basis. However, in both the project form of organic organization reported by Bennis, 35 and the functional form of organic organization reported by Woodward, 36 an essential element of the structure is the role of coordinator, below, or on a parallel level of the organization with the functional elements. In the hospital organization this function would appear to be performed within the nursing staff if the functional form of organization holds

34 Ibid., pp. 102-122.

35 Bennis, p. 12 .

36 Woodward, p. 118 . 
the key to the organic description of the hospital organization. However, it would be premature to suggest such a conclusion without considering the other ramification of hospital organization which has been suggested as entering into the determination of the prototype characteristics of these structures.

The hospital organization is not alone in containing the charactersitic of unit-production technology although in terms of size and volume of activity which is directed toward such production it would be considered as unique. In addition, however, the hospital organization is marked by the degree to which it employs professional workers in the accomplishment of its unit-production tasks. Smith has commented that hospitals are a seed-bed of professionalization through the association which exists in these organizations with existing professional groups and the training activities to which the hospital is committed. 37 This concentration of professional workers must be considered as a unique attribute of the hospital organization. 38 it would therefore be expected that this unique manifestation of hospital organizations would lead to a variety of complicated issues in regard both to management and organization. 39

Perhaps the most significant ramification of professionalization and the root cause of many problems which it creates within organization is

37 Harvey L. Smith, "Two Lines of Authority are One Too Many," Modern Hospital, LXXXIV (March, 1955), 63.

38 Edith M. Lentz, "Hospital Administration--0ne of a Species," Administrative Sciences Quarterly, I (March, 1957), 461-462:

39 Basil S. Georgopoulos, "The Hospital System and Nursing: Some Basic Problems and Issues," Nursing Forum, V (1966), 14. 
the basic identification of these individuals with the supra-goals of their profession over the goals of the organization within which they are employed. 40 They tend to make poor organization men because their loyalties are divided between their professional values and organization demands. 41 The values of a professional group are its basic and fundamental beliefs, the unquestioned premises upon which its very existence rests. 42 Such an external identification prevents the development of the process of identification with organizational goals outlined by Simon as a prerequisite to satisfactory performance of an individual within the productive enterprise. 43 In return for professional identification with the values of this supra-organization the professional is insured of the protection of his rights as an organizational member through the cooperative efforts of this external organization. 44

This identification with the social values of the profession has a twofold effect upon the hospital organization. For one, the professional worker will be only partially involved in the activities of the organization as a life work, although his degree of involvement may have high

$$
\begin{aligned}
& 40 \text { Bennis, P. } 12 . \\
& 41 \text { lbid. } \\
& 42 \text { Ernest Greenwood, "Attributes of a Profession," Professionali- } \\
& \text { zation, eds. Howard M. Vollmer and Donald L. Mills (Englewood Cliffs, }
\end{aligned}
$$
N.J.: Prentice-Hall, Inc., 1966), p. 16.

43 Herbert A. Simon, Administrative Behavior (2nd Edition; New York: The Free Press, 1957), p. 205.

${ }^{44}$ Corinne L. Gilb, Hidden Hierarchies (New York: Harper and Row, Publishers, 1966), p. 53. 
potency. 45 When the value system of the professional is obtained within the organizational setting it would be expected that a high degree of compatability between professional and organizational values would exist. The professional worker obtains his value system through training and this training in the case of health care workers is largely provided within the institutional setting of the hospital organization. 46 However, the profession as such maintains control over the rules for admission of novices and the methods of training employed in the hospital as a training institution. 47 Even beyond the control exercised over training of these categories of workers the professional association exercises control of standards for operation of the hospital organization through their accreditation bodies. 48

The most salient outward manifestation of professionalization is the specialized competence of these employees and the authority which they command in regard to their field of knowledge. 49 Hall believes that this competence will direct the individual to command a functional area of the organization rather than to be simply satisfied with

\footnotetext{
${ }^{45}$ Katz and Kahn, p. 134.

46 W. Richard Scott, "Professionals in Bureaucracies--Areas of Conflict," Professionalization, eds. Howard M. Vollmer and Donald L. Mills (Englewood Cliffs, N.J.: Prentice-Hall, Inc., 1967), P. 271.

47 Lentz, pp. 460-461.

48 Paul $\downarrow$. Gordon, "The Top Management Triangle in Voluntary Hospitals (11),"Academy of Management Journal, V (April, 1962), 67.

${ }^{49}$ Davis, p. 292.
} 
providing a service. ${ }^{50}$ Although the professional may recognize the need for the integration of various functions within an organization, he believes that he should have considerable freedom to perform functions in his area as he thinks they should be done. 51 The key word in any discussion of the professional, and which may well be separate from the degree of competence which they hold, is autonomy. 52 "They want to have some choice about the kinds of projects on which they work and the ways that they approach problems." 53 Moreover, Hall believes, as has been demonstrated in the hospital organization, that as an occupation obtains professional status these workers will strive to escape administrative control and they will seek to be incorporated, on a policy-making basis, in the official system of authority of the organization. 54

The third manifestation associated with the professional worker, and which is closely associated with a high degree of competence and desire for autonomy, is the prestige which these employees command, or seek to elicit from their associates within the organization. Brown has specifically noted this ramification associated with the drive toward professionalization in the case of nursing and ancillary personnel in the hospital organization. 55 This prestige-seeking behavior in the case

50 oswald Hall, "Some Problems in the Provision of Medical Services," Canadian Journal of Economics and Political Science, XX (1954), $465^{\circ}$.

5 ? Davis, P. 292.

52 lbid., p. 289

53 1 bid.

55 Esther Lucile Brown, Newer Dimensions of Patient Care: Part 2

(New York: Russell Sage Foundation, 1962), P. 114. 
of the emerging professions will be demonstrated by an aggrandizement of the prestige-bearing aspects of their duties. ${ }^{56}$ "They will strive for parity with the established specialties within work institutions, while demanding positions superordinate to those of more recent invaders. ${ }^{1157}$ The tendency will be toward the deflection of menial and humble aspects of their work to lower breeds of workers. 58

The contrast between the professional employee and the other workers in the organizational setting is quite marked. The regular worker will be quite aware of his dependence upon the other parties to the enterprise while the professional will seek autonomy as the only reasonable 'method for the accomplishment of his tasks. ${ }^{59}$ In Simon's terms, the bounds to rationality of the professional worker will be less constrained and he will seek the authority of decision-making in broader areas. 60 Blau and Scott would tend to identify the professional worker as the "cosmopolitan" as against the "local" who finds his identity in the working situation and develops values which are in consonance with the organization. 61 The "cosmopolitan" on the other hand tends to obtain his recognition from his professional peer who accords with his value system and the organization is regarded as merely a vehicle which permits 56 Hall, P. 465.

57 ibid. 58 bid.

${ }^{59}$ Scott, pp. $269-270$.

60 Simon, p. 241.

61 Peter M. Blau and W. Richard Scott, Formal Organizations (San Francisco: Chandler Publishing Co., 1962), p. 64. 
him to pursue his professional goals. ${ }^{62}$ As Kron reports in the case of nursing peronnel, the transition of the worker to a professional categorization develops a sense of frustration with the administrative chores previously performed but now not central to the professional identification which has been developed. 63

Each of these features of the professional worker suggests the setting provided by the organic organization which has been described previously. Scott lists various areas of conflict which exist between the professional employee and his organizational employer within what he describes as the bureaucratic setting, but which can be interpreted as the modal organization complete with appropriate control machinery. 64 These are the professional's resistance to organization rules and standards and the supervision of deisgnated superiors, and the conditional loyalty which the professional awards to the organization. 65 This manifests itself in an independence of the professional from organizational pressures and demonstrates his inclination to serve the customers of the organization as his personal clientele in the manner of service normally associated with the free professional. 66

62 Davis, P. 288.

${ }^{63}$ Thora Kron, Nursing Team Leadership (Philadelphia: W.B. Saunders Company, 1961), p. 9 .

${ }^{64}$ scott, pp. 268-269.

65 bid.

6631 au and scott, p. 74 . 
It has been noted that these values of the professional which are antithetical to the usual forms of organization are highly regarded in what have come to be called "innovational" organizations, a term closely linked with the organic structure which is being considered. 67 Thompson has described the innovational organization as being characterized by a structural looseness, generally, with less emphasis on narrow, nonduplicating, non-overlapping definitions of duties and responsibilities-. the innovational organization is not as highly stratified as the modal organization. 68 In these innovational organizations, departmentalization must be arranged so as to keep parochialism to a minimum but with some overlapping and duplication permitted and with some vagueness about jurisdictions which will encourage a good deal of communication. 69 Thompson further notes, that in these forms of organization professional orientations and loyalties will be stronger than could possibly exist in more formal structures. 70

Whether by calculation or circumstance those organizations which contain an intensive participation on the part of professionals appear to have a characteristically more decentralized decision-making structure. 71 Hutchinson makes this observation in the case of hospitals by noting

67 Mason Haire, "Introduction--Recurrent Themes and General Issues in Organization Theory," Modern Organization Theory, ed. Mason Haire (New York: John Wiley and Sons, Inc., 1959), p. 5.

${ }^{68}$ Victor A. Thompson, "Bureaucracy and Innovation," Administrative Sciences Quarterly, X (June, 1965), 13.

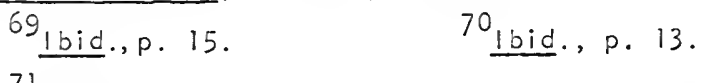

71 Howard M. Vollmer and Donald L. Mills, eds., Professionalization (Englewood Cliffs, N.J.: Prentice-Hall, Inc., 1966), p. 146. 
within the frame of reference of the "acceptance theory" that the zones of acceptance are much narrower in the lower reaches of these organizations than is typically found elsewhere. 72 This observation would be supported by the contentions of the professional's need for autonomy in the exercise of his skills and competence. In these forms of organization management's primary significance is no longer as the apex of the authority pyramid, but, rather, its central function is the design of impersonal mechanisms of control which become the substitute for the directives of superiors. 73 Furthermore in these situations the standards which become management's control are derived from the values held by the profession. 74 In the professional organization there must clearly be compatability among the measures of success provided by superiors, peers, and the public being served. 75

The values contained within the professional frame of reference provide the motivation of the professional worker within the organization. While this topic will be the subject of the final chapter of this essay, the professional organization provides a prototype of organizational structure designed to satisfy the higher-le needs of man through its

72 John G. Hutchinson, Organizations: Theory and Classical Concepts (New York: Holt, Rinehart and Winston, 1967), p. 79.

73 B iau and Scott, p. 185.

74 Joseph H. Fichter, "What Determines Success," Professionalization, eds. Howard M. Vollmer and Donald L. Mills (Englewood Cliffs, N.J.: Prentice-Hall, Inc., 1966), p. 146.

75 lbid. 
accommodation of the values of competence and autonomy. This factor has been commented upon by Scott. ${ }^{76}$ More traditional forms of organization at best can only provide for the satisfaction of lower and intermediate levels of human needs. ${ }^{77}$ As those needs become satiated within the familiar context of organization new forms of structure will be developed to accommodate the developing higher needs. Keith Davis sees this phenomenon as already on the scene and as a part of the growing tendency for professionalization of various occupations. ${ }^{78}$ The outlet for satisfaction of these emerging human needs is the organization that is devoted to intellectual and creative work. ${ }^{79}$ Thompson has commented that the form of organization which is conducive to these satisfactions may be impossible to value in terms of costs or benefits to society, but it will be innovational and, therefore, organic, which is a fair appraisal of the organizations of the future. 80

With these two factors of unit-production and advanced professionalization of the work force clearly in mind it is possible to investigate the dynamic process which is involved in the determination of this organic structure and to trace the development of the prototype organization

76 William G. Scott, Organization Theory: A Behavioral Analysis for Management (Homewood, 111.: Richard D. Irwin, Co., 1967), p. 78.

77 Abraham H. Maslow, Toward a Psychology of Being (Princeton, N.J.: Van Nostrand Co., Ind., 1962), pp. 31-33.

78 Davis, p. 291.

79 bid.

80 Thompson, p. 20. 
from its earlier stages where it more closely approximated the modal organization. The point of departure is provided by the discussions of the universal organization which appears in the literature. The prototype organization itself has been loosely described in terms of the organic organization. It would be hoped that this analysis will provide a firmer description, in organizational terminology, of the exact nature of the hospital structure and, thereby, the organic organization.

In spite of the pronouncements in regard to the decentralized nature of the innovational organization an investigation of the hospital organization would reveal the appearance of some tendency toward recentralization of authority. The traditional concept of the line operative performer in the hospital organization can be visualized as the nurse working directly with the physician in the care of the patient and having the full authority necessary to carry out her functions which spanned the requirements of the patient during hospitalization. Whether this concept of the nursing function ever existed, and Brown takes exception to this, the present arrangement is radically different. 81 The operative performers in this line activity today are often other than the professional nurse. 82 The professional nurse has devolved the responsibility for direct patient care and becomes an echelon of supervision over the operative performers of the organization bringing the authority

81 Esther Lucile Brown, "The Need for Differentiation of Nursing Service," Issues in Nursing, eds. Bonnie Bullough and Vern Bullough (New York: Springer Publishing Co., Inc., 1966), p. 107.

82 Ibid. 
of nursing up into the hierarchy of the hospital organization, and separating it from performance in satisfaction of the primary service values.

The concepts of centralization and decentralization are variously described in the management literature. Hutchinson describes decentralization as simply the exercise of authority as near as possible to the point where problems originate. ${ }^{83}$ Etzioni alleges that decentralization is relative to the kinds and degrees of authority which subordinates hold in the exercise of their assigned tasks. 84 The more broadly these tasks are expressed the greater the decentralization of authority at any particular level of the organization and the greater the autonomy of the individual in the accomplishment of his tasks. 85 simon provides for two methods of decentralization which have the same effect; the individual may not have operating rules specified for his activities leaving him free to make decisions as he sees necessary, or he is specifically delegated responsibility for designated decisions which must be made within the organization. 86 In either case the individual has the opportunity to weigh competing considerations, and he does not have to accept conclusions reached by others in the organization. 87

83 Hutchinson, p. 99.

${ }^{84}$ Amitai Etzioni, Modern Orqanizations (Englewood Cliffs, N.J.: Prentice-Hall, Inc., 1964), P. 28.

85 lbid.

${ }^{86}$ Simon, P. 234.

87 lbid. 
To place this concept within a context which can be considered in comparative terms to the phenomenon which exists in the hospital these simple definitions can be amplified. Simon provides, that for decentralization of authority to be meaningful the individual who is to exercise authority as an organizational decision-maker must have the means available to render these judgments--that is he must be provided with the organizational resources necessary to derive the premises upon which his decisions will be rendered. 88 This concept can be demonstrated by considering a level of the organization where decisions of some magnitude are to be rendered. Terry demonstrates the concept of feasible decentralization of authority by postulating a structure of organization where the authority holder has functionalized service elements reporting directly to him, and then he detaches these elements from the authority holder and places them at a higher level in the organization. 89 In the first case the authority holder is autonomous of the remainder of the organization to the extent that the functionalized services provide the resources necessary to exercise his authority. In the second case, although his authority may remain the same, he is dependent upon other organizational elements beyond his sphere of control. Only in the first case would Terry allow that decentralization of authority exists. 90 These considerations are separate from the pure notion of

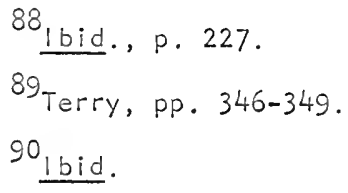


whether an individual in an organization should have a certain degree of authority. Various criteria for decentralization, or centralization, of authority exist which tend to ignore the feasibility of such an organization structure. Hutchinson allows that decentralization of authority is the wave of the future, because computer systems will allow the upper reaches of management to provide real-time control over the actions of their subordinates. 91 This supposes that control rather than the availability of organizational resources is the issue. R. C. Davis believes that the degree of decentralization of authority within an organization is dependent upon the degree of standardization of procedures which can be accomplished and the degree to which emergency situations must be accommodated within the organization..$^{92}$ By these criteria it would be expected that the unit-production hospital organization would be highly decentralized. Elsewhere Davis asserts that decentralization must have as $i$ ts prerequisite the availability of sufficient numbers of competent personnel. 93 Again, if this is accepted as a determining criterion, the hospital would be expected to be a decentralized form of organization, at least down to the professional nursing level suggested earlier. It appears, however, that these individual criteria must be weighed against the cost of making an administrative unit of the organization truly

$$
91 \text { Hutchinson, p. } 159 .
$$

92 Ralph Currier Davis, The Fundamentals of Top Management (New York: Harper and Row, Publishers, 1951), pp. 309-310.

$$
93 \text { lbid., p. } 315 .
$$


autonomous, as is suggested by Dale on the basis of his investigations which reveal a continuing tendency toward centralization of authority with increased economy and efficiency of operations. 94

The true nature of the hospital organization in regard to these concepts of centralization and decentralization of authority which are topics normally considered in terms of the mechanistic form of organization are revealed by a simple observation of any older hospital building and its architectural design. These facilities demonstrate, much as the fossil remains of a previous civilization uncovered by an archeologist, a culture which existed within the hospital at a previous time. Within these antedated structures there are complete diet kitchens on each ward, broom closets which could contain complete maintenance facilities, supply closets on each ward which in total provide more space than the storage facilities of the centralized supply service, medicine cabinets and narcotic lockers which out-space the modern pharmacy, and autoclaves and sterilizers, which if they exist at all in the modern hospital, are located in a central-surgical supply element of the organization. Instead of commenting that they built buildings differently in those days, the remark should be that they structured organizations in a dissimilar fashion in the past.

Brown recounts the previous organization which existed in American hospitals as providing anthropological evidence of the autonomous structure of organizational elements which had existed and of the centralization

94 Ernest Dale, Organization (New York: American Management Association, 1967), p. 119. 
of activities which has taken place. 95 This description matches that provided by Carzo and Yanouzas in regard to the autonomous administrative unit. 96 These units characteristically resemble a total organization, within which virtually all of the decisions and actions necessary to achieve a general purpose can be taken. 97

Therefore the organizational structure which exists in hosfitals today cannot be discussed in terms of centralization or decentralization, and the autonomy which the professional employee seeks defies remedy through the propositions provided by the mechanistic structure of organization even if this were the actual desire of the professional person. Professionalization is in essence, specialization and differentiation of spheres of interest and concern. 98 As Simon has noted, the problem of organization cannot be considered separately from that of employee specifications--position descriptions are less dictated by organization structure, as organizational structure is dictated by the characteristics of available manpower. 99 To decry the massive relocations of authority which has taken place in the hospital organizations is to deny the shift in professionalization which has manifest itself within these structures. The restructuring of the nursing role within the hospital organization

95 Brown, Newer Dimensions, p. 13.

96 Rocco Carzo, Jr., and John N. Yanouzas, Formal Organization: A Systems Approach (Homewood, 111. :Richard D. irwin, Inc., 1967), pp. 64-66. 97 lbid.

98 Gilb, p. 105.

${ }^{99}$ Simon, p. 228. 
which is presently taking place must be understood within this larger context.

The present issue in hospital organization is involved with the definition of the role of the professional nurse and the structure of the autonomous area within the organization which is her concern. While Litterer adheres to the terminology of centralization and decentralization which may not be appropriate to this situation he notes that there are different types of functionalization each of which provides different areas of autonomy. 100 He mentions management functions, business functions, and manufacturing functions. ${ }^{101}$ To this could be added nursing functions as an organic functionalization of the hospital organization. In each of these areas a minimal level of autonomy can be described which is complete in an area of professional specialization. ${ }^{102}$ Beyond This minimum area any further functionalization must be considered as task specialization. The autonomous nursing unit is then circumscribed by the definition of the nursing function--the task specialization may take place within this area but such elements as are created are something less than nursing per se.

As previously related, substantial evidence exists to indicate that the suzerainty of the professional nurse has been delimited in the not too distant past. However, there is little to indicate that a satisfactory accommodation has been obtained by the functionalization of the food

100 Joseph A. Litterer, The Analysis of Organizations (New York: John Wiley and Sons, Inc., 1965), p. 383.
101 bid.
102
Ibid. 
preparation and serving tasks, the drug and supply manipulation duties, or the cleaning and maintenance chores, to mention a few. Some persons would indicate that functionalization has gone too far. ${ }^{103}$ others would maintain that it has not gone far enough. ${ }^{104}$ Moreover, still others would appear to confuse the issue of task specialization within an autonomous area with functionalization. ${ }^{105}$ in so doing they argue that the nurse has been removed from the patient care function. 106 Mackachern reports that three patterns of assignment are typical within the functional area of nursing: the functional method, the case method, and the nursingteam method. 107 The first method has little to separate it from the description of the nursing-team method as both are essentially an application of task specialization. The only significance which can be derived from this separation is that in the case MacEachern describes erroneously as the functional method the workers who receive the task assignments are fully competent to perform the entire nursing function while under the team method the workers have skill limitations which would prevent a larger assignment. 108 Under both these methods a supervisory level is 103 kron, p. 11. 104 Luther P. Christman and Richard C. Jelinek, "0ld Patterns Waste Half the Nursing Hours," Modern Hospital, CVIII (January, 1967), 77-81. $105_{\text {Brown, Newer Dimensions, p. } 10 .}$ 106 bid.

107 Malcolm T. MacEachern, Hospital Organization and Management (Berwyn, 111.: Physicians' Record Co., 1962), pp. 524-525. 108 Ibid. 
provided which has cognizance over the complete nursing function. Under the case method the complete nursing function is performed by a single individual as its name suggests. 109 The research of Jelinek would suggest that the nursing-team method of performing the nursing function was employed in those institutions which he studied, 110 because he discovered that the addition of more registered nurses to the ward complement does not increase the amount of patient care provided. IIl If the other two forms of assignment had been employed it would be expected that patientcare would have increased proportionately.

But, in fact, it is not necessary to employ research studies to demonstrate that the nursing-team is the most frequently employed method of providing for the accomplishment of the nursing function. Kron has commented that today the role of the nurse is changing from one who gives care to one who directs and supervises the care given by others. However, the trend to team leadership as the role for the professional nurse is not without its detractors. Hughes argues that the emerging professionals ignore the mandate of society by passing their traditional tasks onto the shoulders of subordinates in their search for prestige. 113

$\log _{\text {lbid. }}$

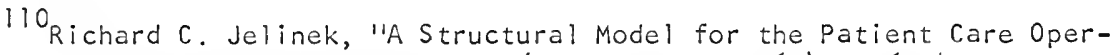
ation," Health Services Research, II (Fall-Winter, 1967), 226-242.

111 lbid.

112 Kron, p. v.

113 Everett $C$. Hughes, "The Professions in Society," Canadian Journal of Economics and Political Science, XXVI (February, 1960), 57. 
Gilb remarks that task specialization within a functional area provides the seed-bed for further functionalization through the development of vocational associations. 114 Brown fears that increasing task specialization within the hospital will result in a sub-division of tasks at the lowest echelons which provides jobs of little content or prestige much in the manner of American industry. 115

These fears are not only the concern of interested by-standers. The nurse herself resists the further fragmentation of the role which she is attempting to define as that of a professional, however reluctant she is to assume the managerial role which is provided under the concepts of team nursing. Henderson has attempted to describe the essence of the nursing function within a professional context by providing that the nurse supplies the patient with knowledge, will, and strength to perform his daily activities and to carry out the treatment prescribed for him by the physician. 116 she maintains that society wants and expects this service from the nurse and that no other worker is able, or willing, to provide it. 117 Apparently, the organization disagrees by casting the nurse into the managerial role implied by team-nursing.

The team concepts which have been suggested in industry as leading

$114_{\text {Gilb, p. } 102 .}$

115 Brown, p. 13.

116 Virginia Henderson, The Nature of Nursing (New York: The Macmillan Co., 1966), p. 21.

117 1bid. P. 68. 
to the organic form of organizational structure should be considered as a variety different from the hierarchical arrangement provided within the nursing-team concept although it does not rule out this modification. McGregor believes that the industrial team within the organic organization will be made up of partners on a co-equal level, and that they will choose the leader in each problem situation on the bas is of his competence in the particular area. 118 However, Likert believes that the organic team concepts are amenable within a superior-subordinate relationship when the superior is recognized as providing a coordinative and supportive requirement. 119 it seems obvious that in the literature concerned with industrial organizations different forms of structure have been included under the concept of team management. In the hospital organization, nursing-team organization still means the formal superiorsubordinate hierarchy and will be so considered in this essay.

While it has been necessary to intrude upon topics which will require further discussion from another point of view, the question of centralization and decentralization is essentially beside the point when the organic form of organization is being discussed. If the organic organization is viewed as a static entity many of the manifestations of the mechanistic structure seem to appear although these may well only be

118 Douglas McGregor, The Professional Manager, eds. Caroline McGregor and Warren G. Bennis (New York: McGraw-Hill Book Co., 1967), pp. $84-96$.

119 Rensis Likert, New Patterns of Management (New York: McGrawHill Book Co., Inc., ig61), p. 116. 
transitional tendencies. The appearance of a re-centralization of the nursing function may herald the development of new functional areas which are being devolved for future separation and elevation within the structure. It is, however, difficult within the developing lexicon of the organic form of organization to employ such mechanistic terms as centralization of authority.

Lambertson has commented upon the evolution away from the nursing service of the various institutional functions of the hospital organization by noting that after the normal working hours these functions again become the responsibility of the nursing staff. 120 While her source of knowledge of the evolutionary process which has taken place is unique there is nothing otherwise remarkable about this process as a common organization dynamic. Woodward has described this process of evolution of functional elements to divisional status in preference to previously popular departmentational arrangements in British industry. 121 Litterer has described the institutionalization of what he refers to as staff elements as a process of specialization of the management function. 122 The unusual feature in hospital organization is that in the process of restructuring the nursing role various management tasks which were traditionally associated with the nurse have been assigned to separate service departments. This evolution of the management tasks in the

120 Eleanor C. Lambertson, "Reorganize Nursing to Re-Emphasize Care," Modern Hospital, CVIII (January, 1967), 68-71.

121 Woodward, pp. 109-118.

122 Litterer, pp. 335-338. 
hospital organization is remarkable in the extent to which it has been carried.

The process by which managerial tasks are separated from an organizational position and assigned to such service elements is described by R. C. Davis, although he includes service elements as comparable to staff elements in his analysis. 123 His beginning stage of staff evolution is the point where the tasks involved are performed by the line manager along with the tasks normally associated with his function--a period of line integration. 124 This stage is followed by a period within which the tasks associated with the element to be evolved are differentiated from the functions of the manager which are to be retained, and specialized help is employed to perform these tasks under the direction of the line manager. 125 This period is referred to by Davis as distinct staff differentiation and is not dissimilar to the procedure followed in the devolution of line tasks to operative performers under the impetus of increased volumes of activity associated with the creation or distribution of the primary service values of the organization, except that in this case the tasks contain the potential for classification as staff and service functions through their only indirect association with the primary service objective. The third stage of this evolutionary process, which Davis refers to as complete staff differentiation, is also not dissimilar to the devolutionary aspects followed in the case of line differentiation. 126
${ }^{123}$ Ralph Currier
124 bid., p. 379.
$376-384$.
125 1bid., Pp. 379-380.
126 1bid., p. 380. 
The task elements which have been differentiated to a single individual are now dispersed among a group of individuals and a managerial unit is formed under the line manager with responsibility for the management of these tasks assigned to a person reporting directly to the line manager. ${ }^{127}$ The fourth stage in this process, which for reasons discussed later may or may not be accomplished, is called the period of staff integration. ${ }^{128}$ This stage is reached when it is recognized that staff elements of a similar nature have been created throughout the organization. The grouping of these elements within their own departmental structure would be advantageous. This stage would also require some decision as to the proper portion of the organization to which the newly created department should be attached for supervisory purposes. ${ }^{129}$ Again the criteria for each of these stages are not being discussed so that they may be considered along with the special circumstances existing in the hospital organization.

The fifth and sixth stages which Davis discusses are also alternative possibilities in the evolution of staff and service departments within the organizational structure. The stage of staff elevation is a possible alternative at the time of staff integration. It implies that the departmentalized elements or some portion of them may be shifted to report directly to top management of the organization or, at least, to some higher level of the organization than that to which they were originally attached. 130 The sixth stage, as an alternative, provides for a

lbid., pp. 380-382.

$129_{1 \text { bid. }}$

1301bid., pp. 382-383. 
period within which staff decentralization is accomplished--essentially a retrograde movement if the other stages are considered as progressive. It is interesting that this evolutionary stage may either provide for movement to a lower level in the hierarchy but with the retention of departmental status, or it may encompass the return of staff elements to line supervision at the lower reaches of the hierarchy as a divided function. 131

The final stage which Davis provides in this process of staff evolution is entitled "complete staff separation."132 His examples are mainly obtained from industry and would be difficult to visualize in the hospital setting; however, a number of similar processes have become frequent occurences on the health care scene. Many hospitals are grouping their efforts in data-processing and purchasing and creating a corporate identity for these functions separate from any individual hospital. Other hospitals have discontinued providing food-service and janitorial services as an internal function and are now purchasing such services from private contractors. In each of these cases where the internal management control of a function passes beyond the boundaries of the organization, complete staff separation can be said to have occurred.

This then is essentially the dynamic analysis which can be applied in the investigation of the staff and service department phenomena which appears in any organization. As Davis notes, different functions are frequently at different stages of staff evolution at any point in time. 133

131 lbid., p. $383 . \quad 132$ lbid., p. $384 . \quad 133$ lbid., 383.


However, it is probable that any element of the organization is in process of change at any point in time, and those elements which appear to be static may only be reflecting the gathering of forces which make a future change probable.

Dale believes that the evolution of these elements is largely a question of the economic factors involved, at least in the case of business organizations. 134 He recognizes that non-quantitative factors such as the ability of specialists to perform the tasks at hand may be the deciding factors; however, these must still be recognized in the profit and loss statement. 135 R. C. Davis generally adheres to the concept that staff and service departments owe their existence to the imperatives provided by the secondary service objectives of performance of the primary and collateral service objectives with efficiency and economy; however, the criteria for the evolutionary process of these functions may only be so determined in a round-about manner. He thinks that those task elements which have the greatest growth potential and are least similar to those with which they, are grouped are most likely to be differentiated first and set up in independent positions, and this is particularly true if these elements tend to become more complex and technical with organization growth. 136 He also provides, however, that task elements may be associated with dissimilar functions when the size

134 Dale, p. 105.

135 1bid., p. 107.

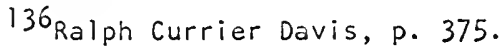


of the organization does not permit their economical independent development. 137 Their association with dissimilar functions may also be the result of their complementary nature in regard to that function. 138 Complete staff differentiation may often be noted when other functional areas of the organization have requirements which can be satisfied by an expansion of the task elements contained elsewhere in the organization. 139 Davis is able to summarize these criteria for staff evolution in his concept of the principle of functional emergence which provides that the tendency of a given function toward differentiation and independent grouping tends to vary directly with: the degree of dissimilarity between the particular function and the function with which it is grouped; the degree of correlation between its growth and development and the growth of the organization as a whole; and, the tendency of the function to become increasingly complex and technical with growth. 140 While Fox is basically in accord with this analysis he argues that sometimes it is very difficult to affix responsibility unless dissimilar functions, which otherwise might be separated, are grouped together within the same administrative element. 141 He also notes that functions may be assigned to administrative elements which contain individuals who have evidenced the greatest interest in the function or who have the greatest capacity
137 1bid.
138 ibid.
139 1bid.
140 lbid.
141 William McNair Fox, The Management Process (Homewood, 111.: Richard D. Irwin, Inc., 1963), p. 84 . 
for implementing the function in the proper manner. ${ }^{142}$ However, he also recognizes that these concessions to personal attributes must not be pushed to a point at which the basic rationale of the organization structure becomes confused. 143

Davis also comments on reasons why a staff or service function should be split, or decentralized. 144 If the function is placed in direct physical contact with the function which it serves, this service can be modified to suit the specific needs of the organizational element to which it is attached. 145 The service may also be rendered more promptly for it can be coordinated directly with the principal functions which it serves as the need arises, particularly in those cases where time is an important factor. 146 However, while such arrangements may increase the independence of the particular functional unit it will also place an increasingly heavy burden upon the management function in that unit.

As indicated previously there is a basis in each one of these criteria provided in the management literature for applying an economic calculus to the decision-making problem involved in the determination of the organizational structure which should exist. Such does not appear to be the case in the hospital organization where the criteria for staff and service department functionalization is argued on bases peculiar to

$\begin{array}{ll}142 \text { Ibid. } & 143 \text { Ibid. } \\ 144 \text { Ralph Currier Davis, p. } 253 . \\ 145 \text { lbid. } & 146 \text { lbid. }\end{array}$


the professional organization, although economic implications are often alluded to in these arguments. Henderson has perceived that in this country nurses have insisted that members of their occupation must be freed from all non-nursing tasks so that an environment can be developed within which they can function on a peer relationship with other professional medical workers. 147 Rourke has commented that the professional has traditionally exhibited a reluctance to undertake administrative responsibility and that he has openly subscribed to the idea that it is important to avoid wasting professional talent on management tasks. 148 It can be imputed that Rourke is referring to both the management functions and the tasks associated with these functions which receive definition in the service department setting. Corwin traces this phenomenon among nursing personnel as being one of the impacts involved in the shift from diploma to degree programs where an increasing emphasis is placed upon professionalization. 149 The diploma programs, on the other hand, provided an institutional setting wherein the aspiring nurse could become accustomed to the acceptance of the administrative tasks which were traditionally part of the nursing function. 150

147 Henderson, p. 31.

148 Francis E. Rourke, "Bureaucracy in Conflict: Administrators and Professionals," Ethics, LXX (April, 1960), 222.

149 Ronald G. Corwin, "The Professional Employee: A Study of Conflict in Nursing Roles," American Journal of Sociology, LXVI (June, 1961), 605. 
At the present time various proposals exist for extending the differentiation process within the nursing function of the hospital organization to accord with the professionalization of the nursing role. While these schemes are anenable to the analysis provided by Davis in the Stages of Staff Evolution they do not necessarily conform to the Principles of Functional Emergence which he elucidates. Brown summarizes the proposals that lay managers assume the administrative tasks associated with the nursing function. 151 one proposition is distinct staff differentiation of these tasks within the nursing function with the assignment of these managerial tasks to an individual above the competence of a clerk or secretary but not requiring the specific medical and nursing knowledge and judgment contained in the nurses's role. 152 Under this concept the "ward manager" would report directly to the nurse in charge of the ward as implied in the concept of staff differentiation. 153 Another variation of this concept is complete staff differentiation and integration of these managerial tasks utilizing a similar type of individual, but having this person report to an echelon of the hierarchy above the nursing department. 154 A more recent report summarizes a less radical evolution of many of the managerial tasks through a process of complete staff differentiation and elevation to the level of the head of the nursing department where these functional elements will perform staff services to the entire nursing department. 155

$15 i_{\text {Brown, p. } 63 .}$

152 Ibid.

153 lbid.

154 ibid.

155 Everett A. Johnson, "Nursing Reorganization Strenghthens Head Nurse Role, Provides Special Nursing Consultants," Hospitals, ILII (June 16, 1968), 85-90. 
It may appear difficult to understand why, after the extensive differentiation and separation of nursing tasks, the nursing role would appear cluttered with extensive management responsibilities. It would be logical to assume that the transfer of responsibility from the nursing function to newly created functional departments responsible for service activities would lessen the managerial responsibilities remaining to the nurse. However, evolution out of operative tasks of management does not necessarily reduce the scope of the management functions nor the responsibility of the manager to provide the coordination necessary to the accomplishment of the primary tasks which are assigned. Many of the management functions can be enumerated as physical tasks which are amenable to differentiation and separation but others can only remain as conceptual matters which appear to remain with the manager. R. C. Davis has analysed the management functions of planning, organizing, and controlling into elemental units for the purpose of discussing their feasibility for staff differentiation. 156 He concludes that while many aspects of the managerial functions could conceivably be separated to staff and service department echelons, essential elements of the control function--direction, supervision, and corrective action-are less readily assigned. 157 The function of direction reinforces unity of command and therefore basically a ine function. 158 The line function of supervision is a reflection of the lines of authority and

${ }^{156}$ Ralph Currier Davis, pp. 407-408.

157 lbid., p. 407 . 158 1 1 bid., pp. 702-703. 
responsibility which form the structure of the organization and therefore it too is inherent in the managerial role. ${ }^{159}$ Davis concludes that any considerable delegation to staff echelons of responsibility for direction, supervision, and corrective action would be tantamount to managerial abdication. 160

It would therefore appear that as long as the nursing function remains identified with the primary objective of the hospital organization, which it must, there will remain a managerial role for nursing personnel which cannot be avoided, however professionalized this role becomes. But this does not explain the range of managerial tasks which now exist in the nursing services. Saunders refers to the increasing managerial or administrative aspects of the nursing role. ${ }^{161}$ Marksch describes the daily round of the nurse's life which indicates the intensity of the administrative demands which are placed upon her, ${ }^{162}$ a description which is not dissimilar to that presented by Roethlisberger in his report on the industrial supervisor. ${ }^{163}$ The supervisor in industry finds himself as the "man-in-the-middle" in the working situation-responsible to everyone but with little effective control over the

159 1bid., p. $708 . \quad 160$ 1bid., p. 408.

16 iLyle Saunders, "The Changing Role of Nurses," Issues in Nursing, eds. Bonnie Bullough and Vern Bullough (New York: Springer Publishing Co., Inc., 1966), p. 126.

${ }^{162}$ Hans 0 . Marksch, "Nursing Dilemmas in the Organization of Patient Care," Nursing Outlook, V (January, 1957), 31-34.

$163 \mathrm{~F}$. J. Roethlisberger, "The Foreman: Master and Victim of Double Talk," Harvard Business Review, ILI11 (September-October, 1965), 22-37. 
affairs which surround him. 164 Similarly, as Corwin has described the hospital situation, the nurse finds herself torn between professional, humanitarian, and bureaucratic chores, she has no independent method of resolving the working situation. 165

In large part this increase in the administrative workload which the nurse supervisor experiences is a direct result of the differentiation and separation which has already taken place out of the nursing function. New organizational units have come into being to encompass these functions and these units each have their separate demands which must be met by the nurse. Woodward notes how in industry the separation of production administration from the supervisor of production operations has given rise to many problems as the relationship between the two must be controlled. 166 Wessen discovers the identical phenomenon in the hospital situation where the functionalization and separation of service activities has resulted in the appearance of many persons on the ward floor who are not responsible to the nurse but whose activities she must coordinate in the accomplishment of the primary service objective of the organization. 167 While many of the menial tasks which were involved in the management of the nursing function have been removed

\section{4}

Ibid.

${ }^{165}$ Corwin, p. 607.

166 Woodward, p. 214.

167 Albert F. Wessen, "Hospital Ideology and Communication between Ward Personnel," Patients, Physicians and 11lness, ed. E. Gartly Jaco (New York: The Free Press, 1958), pp. 452-453. 
from the nurse's authority these tasks return to haunt the service in their requirement for coordination and sometimes in the demands for reports and procedures which must occupy the concern and time of the nurse supervisor. Litterer summarizes the effects of the institutionalization of the staff functions as an outgrowth from the managerial function as consisting of a trimming of the manager's job and therefore making it less important, the downgrading of unique personal skills previously required of the manager, and the reduction of the managerial job to the point where the portion remaining is more easily subjected to control. 168

The present suggestions for an evolution of a ward manager's position out of the nursing function would appear to be the final stage of an evolutionary process which has continued down through the years as the nurse has attempted to define her professional role in the organization. Functionalization and separation of the operative tasks of management appear to have gone as far as they possibly can; the administrative tasks of management of the nursing function are proposed for the ward manager as a separate functional entity. What, if anything, remains which can be identified as management could reveal the essence of the coordinative function.

There is obviously a fine line which must be drawn in the definition of what is management under the circumstances of advanced functionalization created by professionalization and existing in an environment of

168 Litterer, pp. 359-360. 
unit-production. It is generally agreed that the nurse will remain the decision-maker in this functionalized setting when the primary service objectives are involved. 169 Whatever the nature of the coordinative function which will be involved in decision-making under such an organizational arrangement the nurse must be skilled in the requirements of this task in addition to the specialized duties of her profession. 170 The nurse will have to be familiar with the management process and be trained in its methods. 171

It has been feared that the functionalization of management would destroy the manager's job if carried to extremes. 172 Koontz and 0'Donnell believe that well-managed concerns recognize that functional authority should be used sparingly and only where a real necessity exists, for if a manager loses his authority to plan, organize, staff, direct, and control the activities within his department he can no longer manage. 173 Too great a proliferation of functional authority delegations provides the danger of a breakdown of the unity of command. 174 While each of these functional entities may have only a modicum of this form of line

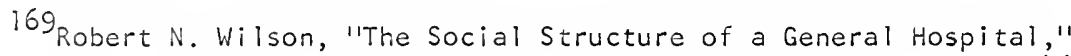
Annals of the American Academy of Political and Social Science, No. 346 (March, 1963), P. 72 .

170 Likert, "A Motivational Approach to a Modified Theory of Organization and Management," p. 193.

171 Stuart A. Wesbury, Jr., "Courses in Management Needed in Professional Training," Hospital Topics (September, 1967), pp. 68-70.

${ }^{172}$ Harold Koontz and Cyril O'Donnell, Principles of Management (3rd Edition, New York: McGraw-Hill Book, Co., 1964), P. 276.
173 Ibid.
174 ibid. 
authority, in total they may outweigh the authority which remains to the individual line manager. 175

R. C. Davis also recognizes that if his dynamic analysis is carried to its logical conclusion of complete functionalization the line management role would disappear along with the primary line organization. 176 Every executive would be a specialist and would hold primary line authority with respect to the primary operations involving his specialty. 177 The necessary result would be that the top administrative level of the organization would contain the only remaining executive who could make decisions for the organization as a whole. 178 But Davis is not overly concerned with the possibilities existing in this situation for economic considerations would rule the decision as to how far functionalization could proceed, and this criterion would insure that the integrity of the line organization was maintained because of its responsibility in regard to the primary service objective. 179

Nevertheless a real question exists in various forms of organization where functionalization has been extensively employed as to the feasibility of maintaining the more traditional line-staff form of organization and the concepts associated with it. 180 McGregor suggests that

$175_{1 \text { bid. }}$.

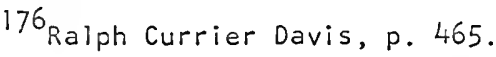

177 lbid. 178 1 bid. 179 1bid., pp. 431-432.

180 Douglas McGregor, The Human Side of Enterprise (New York: McGrawHill Book Co., Inc., 1960), p. 16. 
functionalization has progressed to the point where new forms of management are necessary. 181 Woodward's investigations reveal that the characteristics of extensive functionalization are quite advanced in many successful organizations with staff and service groups holding significant authority over traditional line activities. 182 However, she observed that a characteristic which was common to all successful firms was a status system which gave adequate recognition to the importance of the critical functions. 183 The observations of simon in regard to the acceptance of authority conclude that authority, unless buttressed by other forms of influence, is relatively impotent in the managerial process. 184

This would suggest that the degree of functionalization which has taken place in the hospital organization has been a rational process for this type of organization when it is considered against a background of professionalization and unit methods of producing a complex product. The product characteristics would dictate a full range of technical and supportive skills beyond the capacity of the generalist and a line form of organization. However, it is observed that this form of organization was traditional in the earlier days of the health care system, and as Woodward has noted in industry, it is the predominant style in other forms of

\footnotetext{
181

lbid., pp. 173-175.

182 Woodward, pp. 166-167.

183 1bid., pp. 126-217.

${ }^{184}$ simon, p. 227.
} 
unit-production firms which are not bound by the complexity of skill requirements to seek a new form of structure. The line form of organiation would appear to provide the autonomy desired by the professional if the associated factor of specialism is ignored; however, an additional factor in the professional make-up is the abhorrence of the operative tasks of management necessarily associated with the autonomy implied in the decentralized line operation.

The alternative form of organization which is immediately suggested under these circumstances is that which has been outlined as the linestaff form of structure. However, this structure requires a routinization of productive procedure to allow the full weight of the specialist staff skills and service department facilitating activities to be brought to bear. It also requires a great deal of formality in the management process. Together these requirements appear to be in opposition to the unit-production requirements of the hospital situation. Nevertheless, this form of organization appears, from the static descriptions which have been provided, to have been employed as a transitional mechanism in the organization of the hospital structure. The anomalies of hospital organization which have been recounted reflect the disturbance which this transition from the line structure occasioned. As long as this form of structure was coexistent with a continuation of unit-production techniques and an increasing trend toward professionalization of occupational skills its failure was foreordained. The pressures for routinization of procedures which Lentz has decried as the advent of bureaucracy 
and others deplored as mechanization and mass-production of health are all indications of this transition of the hospital organization through a line-staff form of organization which is the only route available under the circumstances to arrive at a viable form of organization. The static description of two chains-of-command noted by Smith reflects a stage in the transition of the hospital organization to its new form. Etzioni's notation on the confusion of roles within the hospital structure merely reflects the searching for an organizational identity in an organization in transition.

The logical conclusion of this evolution of structure is some variation on the theme of the functional organization. On the basis of the descriptions which have been provided it is difficult to maintain that the epitome of structural form has been attained in any existing hospital organization although all indications appear to indicate that this form of organization will be the ultimate result of the transitional form which now exists. Its merits provide that unit-production can be accomplished through the constant interaction of skilled experts, and the autonomy of the specialist can be maintained within his particular functional area. However, the detractions of this form of organization are numerous especially when it is revealed as a further extension of the line-staff form of structure. 185 But it should be noted that the objections which have been offered to this form of organization are not its

${ }^{185}$ Fox, pp. $95-96$. 
structural defects but concern over the foibles of its human inhabitants. It is therefore necessary to explore the peculiar characteristics of the professional organization to determine the method whereby these valid objections can be removed as the evolutionary process proceeds.

It must first be realized that the descriptions of the functional form of organization are basically cast within the mechanistic model and yet can only be appreciated when viewed as an organic form of organization. By that, it is meant that maximum interaction is a prerequisite to successful accomplishment of the primary service objective of the enterprise. Many of the objections to this form of organization show concern that intrusion of one element of the organization upon the affairs of another will be actively resisted. The usurption of formal authority by one element from another will be the cause of jealously guarded relationships. However, it has been observed that in the hospital organization the professional employee appears to welcome the passing of managerial tasks and the authority associated with them. Perhaps the reaction in industry has been different through its cultural emphasis upon the prestige associated with the managerial function and the skills of the generalist. In the hospital organization the professional welcomes the shedding of these tasks for he views his autonomy within the context of a value system external to the organization itself.

The functional organization, if it is to be attained and proved successful, must provide a parity within the power relationships which

${ }^{186}$ McGregor, p. 146. 
will exist. This concept of organizational balance has been central to the discussion of any organizational form of structure. 187 scott has discussed these power ramifications in regard to the mechanistic structure. $^{188}$ R. C. Davis offers a discussion of balance of organizational structure and its bearing in the case of staff groups which can be."taken as an incipient form of the functional arrangement. 189 Within a sociological context of organization theory, Etzioni has commented upon the requirements imposed by dual leadership of the expressive and instrumental type which appears to be the developing format within the functional organization. 190

In the professional organization with a functional structure the power of the professional rests in the prestige and status which is resident in such an occupational classification. The power implied is directed toward the primary service objective of the organization through the link between externally maintained professional values and the values of the organization. While the involvement of the professional organization will be less than complete it would be expected that the potency of this involvement would be high because of this essential value link. The Unity of Doctrine would be expected to be maintained intact.

187 Dale, p. 31.

188 William G. Scott, p. 253.

189 Ralph Currier Davis, pp. 535-537.

190 Amitai Etzioni, "Dual Leadership in Complex Organizations," American Sociological Review, XXX (October, 1965), 689-195. 
The power of the other functional elements of the organization, which have generally been discussed as staff and service elements in this essay, would be resident in the task assignment which is involved. However, it would be expected that this would be additionally reinforced as full functionalization is attained by the increased specialization and, perhaps, professionalization of these occupations if such is not already the case. A sound basis for this professionalization, in the case of ancillary and facilitating personnel of the hospital organization, is generally expected to be provided by the indoctrination and training programs for these individuals, which will include an emphasis upon incorporation of a value system compatable with the primary service objective of the organization. This purpose would be additionally served by the suggested development of future hospital administrators through the functional divisions of the organization where the value system which has been inculcated in these individuals can become part of the larger organization.

The provision of a common value system among all the members of the organization through these devices should maintain the essential elements which are imposed by the mechanistic, unity of command. The organic form of organization which has been described in terms of the functional format would provide the spontaneous adaptation to the need of the system required under unit-production. There would be a coordination of equals on a voluntary, informal, and expedient basis much as in the case of the project or innovational organization which is proving its success in 
organizations which do not have the requirement for multiple adaptations within a brief period of time. Likert's description of these optimal forms of organization appear to be well-suited in the hospital organization, and may well be apt comment on the form of organization which is evolving within these structures. 191

As Rosenberg has stated, it appears that the voluntary hospital may represent one of the more advanced and complex forms of successful organization in relation to its size in American society. ${ }^{192}$ It can be considered as a pioneer in the development of forms of structure and voluntary human cooperation which emphasizes the persuasive force of ideas rather than the coercive powers of authority. 193 The hospital organization appears to demonstrate the possibilities which exist for the successful combination of professional activities with an administrative structure while still maintaining the concepts of service. As such it represents a prototype for the service oriented organization which will undoubtedly play an increasingly expanding role in the American economy.

191 Likert, p. 186.

192 Rosenberger, p. 42.

193 lbid. 
CHAPTER IX

TOWARD EUPSYCHIAN MANAGEMENT

By recognizing the more limited primary service objective of the hospital organization, which does not encompass the entirety of the healing process, it has been possible to define the structure of the typical, voluntary, general hospital in a manner amenable to the analysis of organizations outlined in the management literature. The exclusion of the physician from this structure has allowed the hospital organization to be defined in the traditional line and staff format, and by dynamic analysis to be interpreted as a variation of the universal structure. This analysis demonstrated that the typical hospital is pursuing an evolutionary path along a continuum toward a functional structure under the impetus of the imperatives associated with the related factors of unit production and professionalization of the work force employed in this organization. The salient anomalies of hospital organization which have been reported tend to vanish under this analysis or reveal themselves as manifestations of the factors which have been suggested as being determinant of this prototype organization.

As a pattern of organizational structure which can be expected to result from the continued evolution of organizations which are of the present modal type it would be of benefit to investigate this structure in terms of its accommodation to the nature of the mature individual. 
As has been noted, the advent of professionalization with its attendant functionalization has greatly reduced the authoritarian character of the hospital. ' Professionals prefer maximum freedom and autonomy in their work and are adverse to the regimentation implied in more formal organizations. ${ }^{2}$ This would appear to place a heavier requirement on the coordinative functions of management within the hospital and increase the pressures upon the administrator. 3 However, there appears to be a high degree of agreement about the principal objective of the hospital organization among the participants and the personal needs and goals of the different members seem to be in accord with this objective. ${ }^{4}$ This agreement of objectives does not span all of the requirements that the various participants place upon the organization; as Lentz has noted, no one is getting rich on a hospital salary, but many are leading rich lives in terms of satisfaction. 5 The professional adheres to an ethic of service, by definition, rather than the unrestrained pursuit of self-interest. 6

'Basil S. Georgopoulos and Floyd C. Mann, "The Hospital as an Organization," Hospital Administration, VII (Fall, 1962), 54.

${ }^{2}$ ibid., p. 19.

3Edith M. Lentz, "Hospital Administration -- One of a Species," Administrative Sciences Quarterly, I (March, 1957), 461.

${ }^{4}$ Georgopoulos and Mann, p. 62.

5 Lentz, p. 462.

${ }^{6}$ Corinne L. Gilb, Hidden Hierarchies (New York: Harper and Row, 1966), p. 235. 
It appears that professionalism is associated with the concept of the operative nature of higher level needs within the individual. Greenwood sees this association in the professional's impulse to perform maximally rather than restricted to factors of self-interest. ${ }^{7}$ "Professional work is never viewed solely as a means to an end; it is the end itself." 8 The professional's work receives his total involvement and from this he obtains primarily psychic satisfactions and secondarily monetary compensation. 9 Wilson believes that this is an important factor in converting what would otherwise be a nightmare to the formal organization theorist into a viable scheme of work, for in fact the work of the hospital is accomplished with admirable dispatch. 10

Thompson believes that the relative success of all forms of the organic organization has this attribute of providing the professionally motivated individual with the opportunity to become successful, as his professional values might dictate success. ${ }^{11}$ The organization provides

7Ernest Greenwood, "Attributes of a Profession," Professionalization, eds. Howard M. Vollmer and Donald L. Mills (Englewood Cliffs, N.J.: Prentice-Hall, Inc., 1966), p. 15.

8 ibid., p. 17.

9 lbid.

10 Robert N. Wilson, "The Social Structure of a General Hospital," Annals of the American Academy of Political and Social Science, No. 346 (March, 1963), p. 73.

"Victor A. Thompson, "Bureaucracy and Innovation," Administrative Sciences Quarterly, X (June, 1965), 11. 
the individual with an avenue for such reward through the opportunity for professional growth and the esteem of his knowledgeable peers. 12 The research conducted by Herzberg, et al., indicated that perhaps the set consisting of achievement, recognition, responsibility, advancement, and the work itself is an all important source of satisfaction in these situations. 13 These sources of satisfaction are substantiated in part by Woodward who notes that in the case of the unit-production firms which she investigated the nature of the work itself and the responsibility associated with it called forth a unique effectiveness on the part of the individual workers. ${ }^{14}$

Keith Davis detects a positive relationship between the factors presented by Herzberg as the motivators of managerial and professional employees in organizations and the higher-level needs discussed by Maslow in his writings. 15 The research conducted by Blai suggests the same conclusion specifically for professional employees. ${ }^{16}$ Brown

12 lbid.

13 Frederick Herzberg, Bernard Mausner, and Barbara Bloch Snyderman, The Motivation to Work (2nd Edition; New York: John Wiley and Sons, Inc., 1959), p. 60 .

14 Joan Woodward, Industrial Organization: Theory and Practice (London: Oxford University Press, 1965), p. 159.

15 Keith Davis, Human Relations at Work (3rd ed. rev.; New York: MeGraw-Hi]l Book Co., 1967), p. 36.

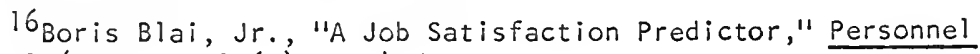
Journal (October, 1963), p. 455. 
definitely suggests that self-actualization and self-realization are the prime motivators in the case of professional workers in hospitals. 17 McGregor outlines the same conclusion in other types of organizations which employ the professional worker. ${ }^{18}$

Perhaps the best evidence for this higher-level need motivation in the case of the professional worker is provided by the writings of Maslow. 19 He maintains that at the highest level of the need hierarchy there is a fusion, or synergy, of selfish and altruistic motives. ${ }^{20}$ This point has already been noted in regard to the professional in the hospital organization, and this is supported by Herzberg, who remarks that such must be the case in hospitals where self-interest and the spirit of service would most likely be sundered in view of the generally poor extrinsic rewards provided. ${ }^{21}$ In each case, Maslow has discovered that the mark of the individual who is operating at the higher levels of the need hierarchy is in the devotion to some task or duty which is

17 Esther Lucile Brown, Newer Dimensions of Patient Care: Part 2 New York: Russell Sage Foundation, 1962), p. 115.

18 Douglas McGregor, The Human Side of Enterprise (New York: McGrawHill Book Co., Inc., 1960) , p. 43.

19 Abraham H. Maslow, Toward a Psychology of Being (Princeton, N.J.: D. Van Nostrand Co., Inc., 1962).

20 lbid., p. 192.

${ }^{21}$ Frederick Herzberg, Work and the Nature of Man (Cleveland, Ohio: The World Publishing Co., 1966), p. 183. 
outside his own self-interest and contains the set of values which are associated with a professional identification. 22

This is not to say that it would be expected that all professionals or emerging professionals will have the characteristic of an operative need for self-actualization, but such a motivation will be incipient in the value system of their vocation. The research of Herzberg indicates that the professional has the capacity through his work to obtain satisfactions of this higher-level need, but if this work is pursued within an organization setting the potential for dissatisfactions in terms of maintenance needs will also be present. ${ }^{23}$ Replication of the early Herzberg studies within the hospital setting has indicated that this phenomenon of high satisfaction with the positive motivators and dissatisfaction in regard to the maintenance factors provided by the organization is typical in the case of nursing personnel. 24

These observations in regard to the high potency of the higher-level needs in the case of the professional worker are substantiated by Katz and Kahn. 25 They believe that professionalization of the staff of an

${ }^{22}$ Abraham H. Maslow, "A Theory of Metamotivation: The Biological Rooting of the Value-Life," Journal of Humanistic Psychology, VII (Fall, 1967), 94.

23 Herzberg, et al., p. 111 .

24 Herzberg, pp. 92-129.

${ }^{25}$ Daniel Katz and Robert L. Kahn, The Social Psychology of Organizations (New York: John Wiley and Sons, Inc., 1966), pp. 368-370. 
organization suggests the characteristics of an expressive rather than instrumental cycle of rewards. ${ }^{26}$ The professional obtains much of his reward from the exercise of his skills, ${ }^{27}$ indicating that relative to other workers, and proportionate to the instrumental rewards provided by the organization, the professional worker will receive a higher degree of satisfaction within the organization. 28

The early work of Parsons indicates that this higher-level need satisfaction may not be exclusive with the professional worker. ${ }^{29} \mathrm{He}$ states that the apparent dichotomy between altruistic and egoistic motives in the case of professionals and other occupational groupings may merely be a reflection of institutional patterns of values which are split into two groups. 30 Both groups, when they rise to a level of satisfaction beyond the basic needs, may be motivated by self-realization with the measure of such satisfaction in the case of managerial employees, for example, being supplied by typically egoistic values. 31 Two individuals may both be seeking self-realization, but one manifests this through an altruistic pattern of behavior while the other strives for satisfaction through means which are normally associated with egoistic motivation. 32

$$
\begin{aligned}
& 26 \text { lbid., p. } 133 . \\
& 27 \text { lbid. } \\
& 28 \text { lbid., p. } 370 .
\end{aligned}
$$

${ }^{29}$ Talcott Parsons, "The Professions and Social Structure," Social Forces, XVII (May, 1939), 457-467.
30 lbid.
31 lbid.
32 Ibid. 
The profit score-card is typical of this latter phenomenon.

Management practitioners and theorists have been well aware of the need for synthesis between the goals of the individual and the objectives of the organization. Simon maintained that such an integration was essential to the decision-making process and suggested that the value system of the individual participants in the organization must reflect the values of the organization for such are the essential premises in the decision-making situation. ${ }^{33}$ Likert points out that such agreement in values must extend to each level of the organization in terms of the goals of the individuals working at that level and the sub-objectives of the organization which are prescribed for accomplishment at that echelon of the structure. 34 it is generally recognized that this is an essential function of the coordinative process of management which may prove to be quite difficult and requires a measure of ingenuity on the part of the manager. 35 For many organizations this process of synthesis may be reduced to an unconditional demand for loyalty to the values of the organization. 36 This method of integration, as

33 Herbert A. Simon, Administrative Behavior (2nd ed.; New York: The Free Press, 1957), p. 12 .

34 Rensis Likert, "A Motivational Approach to a Modified Theory of Organization and Management," Modern Organization Theory, ed. Mason Haire (New York: John Wiley and Sons, Inc., 1959), p. 206.

35 William McNair Fox, The Management Process (Homewood, 11linois: Richard D. Irwin, Inc., 1963), p. 74.

${ }^{36}$ Talcott Parsons, "Suggestions for a Sociological Approach to the Theory of Organizations -- 1," Administrative Sciences Quarterly, 1 (September, 1956), 81. 
Parsons suggests, may well be out of place with the norms of the larger society wherein the values of the individual are derived. 37

The professionally oriented organization may well be the advance guard of a tendency toward a maturity of organizational structure to match a developing psychological maturity of man. As professionalization of the various occupational groupings expands and the motivations of the individuals who identify themselves with such professional value systems rise above the more basic levels of needs the structure of a broader group of organizations will have to be modified to accommodate the satisfaction of higher level needs. To some extent this requirement for change will be manifest by the internal management problems arising through the demands for autonomy on the part of professionals or emerging professionals. It would also be expected that this problem might make its appearance through the mechanism of an external demand for the modification of the objective base upon which the structure of the enterprise is established. In this latter case the contention is that the values of the organization should approximate those of the individuals who man its structure if a congruency of individual goals and organizational objectives is to be obtained. This point is supported by Parsons in his discussion. 38 Etzioni, is also generally of the opinion that such a tendency toward the evolution of organizational structure is apparent in the society of the United States for many of the same reasons. 39 Mee

\section{7 lbid., p. 84 38 1bid., p. 67.}

39 Amitai Etzioni, A Comparative Analysis of Complex Organizations (New York: The Free Press, 1961), p. 310-311. 
agrees that future managerial organizing processes will consider human satisfactions and need fulfillment of a modified variety which reflects this psychological maturing of man. 40

It would, therefore, be expected that other organizations are committed to following the pattern which is developing within the prototype hospital organization. The impact of professionalization is already apparent in many other organizations. Keith Davis notes this fact through the appearance of higher-level needs on the part of individuals in a variety of organizations. 41 Blau and Scott recognize this requirement in the apparent potential for expanded specialist roles in automated plants, 42 which point is reiterated in the research conducted by Woodward. 43 A much broader brush is applied by C. Wright Mills who maintains that the rise of professionalism is the result of the technological revolution and the involvement of science in ever widening areas of economic life. ${ }^{44}$ He indicates that as business has become enlarged and complicated the skills needed to operate it have become difficult to

40 John F. Mee, Management Thought in a Dynamic Economy (New York: New York University Press, 1963), p. 106.

41 Davis, p. 479.

42 Peter M. Blau and W. Richard Scott, Formal Organizations (San Francisco: Chandler Publishing Co., 1962), p. 249.

43 Woodward, p. 96.

${ }^{44} \mathrm{C}$. Wright Mills, White Collar: The American Middle Class (New York: Oxford University Press, 7956), p. 113. 
acquire through apprenticeship, thus requiring the business organization to become a market for educated labor including the various emerging professions. 45 it would, therefore, appear that the hospital as a prototype organization would provide a model both of feasible structure as well as of management problems which are incipient in such organizations.

The hospital is an example of the organic organization, wherein much depends on voluntary discipline and professional self-control with a ready acceptance by each individual of the interdependence necessary to accomplish the objectives of the enterprise. 46 "Much depends on the spontaneous day-to-day adjustments which organizational members are able and willing to make so as to accommodate the patient and one another and to facilitate each other's work.147 The structure of the hospital appears to be loosely enough defined so that restructuring in light of the problems at hand is possible. ${ }^{48}$ The cost of this flexibility within the hospital structure has been the devaluation of authority and positional status and the recognition of the need to apportion power and influence among the organizational members. 49

45 lbid., p. 137.

46 Basil S. Georgopoulos, "The Hospital System and Nursing: Some Basic Problems and Issues," Nursing Forum, V (1966), 16.

$$
\begin{aligned}
& 47 \text { lbid., p. } 15 . \\
& 48 \text { Thompson, p. } 16 . \\
& 49 \text { lbid., p. } 18 .
\end{aligned}
$$


The hospital has had one distinct advantage in the formulation of this form of structure. The necessity for explicit control mechanisms in this type of enterprise has never been great because of the congruency of the values of the individual participants with the objectives of the organization. 50 Etzioni suggests that this congruency may not be as easily obtained in those organizations which do not have the advantage of serving cultural goals which support a normative compliance. 51 It would appear that the hospital has had many of the advantages suggested by McGregor as necessary for the employement of new forms of management. 52 Typically the hospital is, as Maslow suggests, holistic in structure. 53 There is a mutual interdependence among the members of the hospital organization which leads to a reliance upon one another and a contribution from each that would not be expected if they had acted individually. 54

In the management literature these observations are often relegated to a sphere of study separate from that of organizational structure. As

${ }^{50}$ Amitai Etzioni, Modern Organization (Englewood Cliffs, N.J.: Prentice-Hall, Inc., 1964), p. 58 .

51 Etzioni, Comparative Analysis, p. 82. 52 McGregor, p. 49.

53 Abraham H. Maslow, Eupsychian Management: A Journal (Homewood, 11 inois: Richard D. Irwin, Inc. and The Dorsey Press, 1965), p. 98. 54 lbid. 
has been indicated these factors of interest are inalterably interwoven with the elements of structural construction usually considered. It is no longer possible to relegate the interactions inherent in the organic form of organization to an informal sphere of explanation. These concepts which are determinant in the organic structure must be incorporated into the basic structure of the modern organization.

McGregor's argument suggests that a genuine innovation in managerial strategy is required rather than a simple refurbishing and patching of old theories. 55 He sees this as first a requirement to accept less limiting assumptions about the nature of the human resources which management is attempting to control, and, secondly, a readiness to adapt the structure and process of management to new assumptions which are being formulated. 56 Much of the reluctance to accept these modifications to organization theory rests in the apprehensions regarding the fate of the more familiar forms of organization. Argyris sees no real need for the abandonment of the ancient pyramidal structure in the incorporation of these new concepts about the nature of man. 57 The essence of this structure will be retained in the requirement of management to rise above the day-to-day matters of operations and to look ahead through planning toward the maintenance of

55 McGregor, p. 57.

56 1bid.

57Chris Argyris, Integrating the Individual and the Organization (New York: John Wiley and Sons, Inc., 1964), p. 194. 
the organization's link with society. ${ }^{58}$ Dale suggests that educated people are never entirely rational, hence the requirement for some form of coordination, at least on a standby basis, within the organization. 59 It also may not be necessary for any organization to be entirely organic or mechanistic for apparently gradations of each form of structure are possible. ${ }^{60}$ Nevertheless, in any organization where the spirit of scientific inquiry is required to be present and flourish the essence of the organic organization must be well established. ${ }^{61}$ This latter point is directly linked with the evolving nature of man's needs in fields beyond that of science, and, therefore, it is extended to the total realm of organized activity. 62

The psychological maturity of man has two interlinking aspects in terms of the structure of organizations. First, the organization must satisfy the higher-level psychological needs of the participants. To provide for anything less than such satisfactions would involve the loss to the organization of the talents of these individuals as they operate

58 lbid., p. 195.

59 Ernest Dale, Organization (New York: American Management Association, 1967), pp. 139-140.

60 1bid., p. 140.

${ }^{61}$ Warren G. Bennis, Changing Organizations (New York: McGraw-Hill Book Co., 1966), p. 21.

${ }^{62}$ Herzberg, p. 170. 
at these higher levels. ${ }^{63}$ The suggestions that man can seek satisfaction of higher-level needs outside the organization ignores the ever increasing necessity for the talents which are released at the higher need level. 64 What appears to be best for people is often what is best for production. 65

The second facet of this maturity of man will be the requirement that the organization must be prepared to provide the individualized economic goods and services demanded by a more psychologically mature society. A society which rises above the operative level of basic needs of $i$ ts members and passes beyond the emulative desires inherent in the intermediate level needs of belonging and status will find its organizations required to provide those unique outputs associated with the mature individual. Woodward sees this trend as apparent in an increasing standard of living which calls forth a requirement for 'bespoken' suits and gold-plated limousines and a general increase in the number of firms which cater to individual idiosyncracies. 66

As a general tendency then, it would be expected that the primary service objectives of organizations in terms of the values which they must provide society will have a level of mature interest attractive to the mature organizational participant. Organizations will provide tasks with

$$
\begin{aligned}
& 63 \text { 1bid., pp. 189-190. } \\
& 64 \text { Bennis, p. } 13 . \\
& 65 \text { Woodward, p. } 137 . \\
& 66 \text { 1bid., p. } 43 .
\end{aligned}
$$


more meaningful and satisfactory opportunities under these circumstanses. 67 Jobs will provide sufficient variety, complexity, challenge, and exercise of skill to engage the ability of workers and gratify their needs for personal expression. 68 Herzberg and his associates believe that the greatest fulfillment of man is to be found in activities that are meaningfully related to his own needs as well as those of society. ${ }^{69}$ In the hospital this is readily realized. 70 it is not impossible that this mesh of individual and social values will be more prevalent as a manifestation of organizations throughout society.

In speculating on new forms of organization theory Abraham Maslow has posed the situation where 1,000 self-actualizing persons were located on a sheltered island and described the regulation of their activities as Eupsychian Management. 71 Eupsychia, in his terms, is a culture which implies psychological healthiness on the part of its members, and eupsychian management is the administration of organizations which contain psychologically healthy individuals. ${ }^{72}$ He believes that from self-

67 Warren G. Bennis, "Organizational Developments and the Fate of Bureaucracy," Industrial Management Review (Spring, 1966), p. 53.

$68^{6 a t z}$ and Kahn, pp. 363-364.

69 Herzberg, et al., p. 139.

70 Katz and Kahn, pp. 133-134.

71 Masiow, Eupsychian Management, p. xi

72 lbid. 
actualizing persons it can be learned what the ideal attitude toward work might be under the most favorable circumstances. 73 Given the right organizational situation work tends to improve people, and this in turn tends to improve the organization. 74 This improvement in the organization can be related in terms of financial or economic success as well as by any other measure which might be applied. 75

The essential results of Maslow's speculation on the eupsychian organization would be the flexibility of structure which allows the participants to select their leader in any particular situation on the basis of his unique characteristics and competency to handle the problems at hand. 76 These selected leaders would have to be able to give up their powers as the problem situation is modified, for heal thy people have no need for power for the sake of power alone. 77 In such an organization personality traits of a general sort would be secondary to skill and capability and the general requirements of the situation. 78

$$
\begin{aligned}
& 73 \text { lbid., p. } 1 . \\
& 74 \text { bid. } \\
& 75 \text { lbid., p. } 41 . \\
& 76_{\text {lbid. }} \text {, pp. 149-150. } \\
& 77 \text { lbid., p. } 151 . \\
& 78 \text { lbid., p. } 152 .
\end{aligned}
$$


Functional leadership would be the managerial format, ${ }^{79}$ and every man in his ideal organization would be able to assume leadership whenever he was the one most suitable for the problem at hand. 80 It will not be pretended that the hospital organization describes such a utopian society. Yet it can be maintained that the hospital provides the setting for the participation of highly motivated individuals with an organizational goal compatible with the values of both its participants as well as the larger society. In many respects the hospital would be expected to be in the forefront of the exploration for new structural formats and new methods of management and thereby can be considered to provide a prototype situation.

\footnotetext{
79 ibid.

80 lbid., p. 131 .
} 


\section{APPENDIX}

\section{THEORIES OF ORGANIZATION AND THE BASIS FOR DYNAMIC ANALYSIS}

Mason Haire has noted that organization theory is a rare thing in the social sciences in that it is the natural focus of several disciplines. ' Haire recalls the parable of the blind man describing an elephant and equates it with the attempts of theorists to describe organization; each begins the description from a different point of view and with a different purpose in mind. ${ }^{2}$ "In this situation we can expect -- and we find -- not only different approaches to the problem, but different views of what the problem is."13 scott has also remarked that organization theory is not a homogeneous science based on generally accepted principles, but, rather, various theories of organization have been, and are being evolved. 4

Terry notes the existence of theories of organization bearing the labels: classical theory; neo-classical theory; fusion theory; systems

Mason Haire, "Introduction -- Recurrent Themes and General Issues in Organization Theory," Modern Organization Theory, ed. Mason Haire (New York: John Wiley and Sons, Inc., 1959), p. 2.

2 Ibid.

3 lbid.

4illiam G. Scott, "Organizational Theory: An Overview and an Appraisal," Journal of the Academy of Management, IV (April, 1961), 8. 
theory; and, quantitative theory. ${ }^{5}$ Scott subsumes many of the various approaches to organization theory under the categories: classical, neoclassical; and modern. ${ }^{6}$ Alexis and Wilson incorporate a variety of contributions to organization theory under the classifications: structural approaches; motivational approaches; and decision-making approaches. 7 Koontz and O'Donnell, who have specifically addressed themselves to the proliferation of managerial and organizational theories, describe the semantic jungle occasioned by such approaches as: the empirical school; the human behavior school; the social systems school; the decision theory school, and the mathematical school. ${ }^{8}$ They proceed then to describe what they call the operational school which concentrates on the management process, and which provides a focus for the contributions of the other schools. 9 Needless to say, their admonition in regard to the "management theory jungle," has not stilled the angry voices which demand recognition

5 George R. Terry, Principles of Management (5th ed. rev.; Homewood, 111 inois: Richard D. Irwin, Inc., 1968), Pp. 282-284.

6william G. Scott, Organization Theory: A Behavioral Analysis for Management (Homewood, Ilinois: Richard D. Irwin, Co., 1967), p. 102 .

7

Marcus Alexis and Charles Z. Wilson, Organizational Decision Making (Englewood Cliffs, N.J.: Prentice-Hall, Inc., 1967), p. 4.

8 Harold Koontz and Cyril O'Donnell, Principles of Management (3rd edition; New York: McGraw-Hill Book Co., 1964), pp. 26-37.

9lbid., pp. 27-29. 
as the legitimate organization theory. However, their contribution has undoubtediy made managers more aware of the insight provided by the various schools.

It would be impossible to describe the methods of organizational analysis employed in this paper as belonging to any of the above listed approaches. Because of the desire to typify the hospital as a prototype for study, the relationship between this form of organization and others which match the title of formal, or complex, organizations is essential. It has therefore been necessary to consider the organization as resident in an evolving culture which extends its influence in varying degrees upon all organizations depending upon the organization's link with the society and the culture. The objective of the organization has been accepted as this link for it appears to be the major determinant of structure. The format of this approach, and many of the concepts utilized, should then be classified as an institutional method. However, the level at which the analysis takes place and the dynamic processes which are employed in this essay are both below and beyond the descriptive method which is usually associated with this approach.

Static analysis can be categorized as a descriptive and comparative technique of analysis. The interest in those cases where these methods are employed is toward an outline of the design of differences between particular organizations. It has been the method in this study to critique 
those static analyses which describe salient differences between the hospital organization and the modal organization. The question is asked each time whether these marked differences are unique to the hospital organization or whether there are factors involved in these differences which are present in all organizations to some degree but are of insufficient magnitude to produce a similar structural phenomenon. The question is then posed as to whether an increase in magnitude of the particular phenomenon in the modal organization would produce a similar structural arrangement as that occurring in the hospital organization. The course of change is traced through the mechanism of the organizational process suggested by those authorities which adhere to the concept of the existence of a management process--loosely that which Koontz and O'Donnell suggest as the operational school of management. 10

Adherents to the management process approach of organizational analysis are willing to acknowledge the contribution of related disciplines to the sum of knowledge of management theorists. The present work does not disparage the contribution provided by the static analysis in establishing descriptions of organizations in comparative form. Without these conclusions it would have been impossible to perform the process analysis required to establish a continuum along which a dynamic

10 1bid. 
process is carrying many organizations. Litchfield has noted that most of the new thought on administration has come from the fields of mathematics, engineering, anthropology, sociology, or some one of the emerging behavioral sciences." 11 However, he also notes that these contributions have only been concerned with selected parts of administration and not with the whole; for the most part, the contributions from these other disciplines have been incidental to some other purpose. ${ }^{12}$ Mee remarks in a similar manner that: "Management thought has always had its identifiable channels, but it has always been fed by tributaries of thought streams from related disciplines."13 But, in turn he sees these contributions and the disciplines from which they come as being a challenge to the rightful place held by management thought as expressed in the management process. 14 it is hoped that this study has performed the twofold responsibility implied in these comments: that is has accepted the challenge of those disciplines which

1 "Edward H. Litchfield, "Notes on a General Theory of Administran tion," Administrative Sciences Quarterly, 1 (June, 1956), 4.

12 ibid.

13 John F. Mee, Management Thought in a Dynamic Economy (New York: New York University Press, 1963), p. 110.

14 lbid., pp. $x x-x x i$. 
reject the applicability of the management process in the hospital environment because of the dissimilarity of structural process between hospitals and those enterprises within which much of management thought has been developed, and that it has furthered the process of incorporam tion of new data from other disciplines into the body of management knowledge.

The management process approach in its present form is basically an amalgam of what have sometimes been referred to as the Formal and Informal schools of management thought. Basic to each of these separate schools of thought is a way of looking at the organizational structure which provides support to the management theories themselves. As the concept of a management process has fused the two approaches to management, so too, the theories of organization which underlie them have come together to provide the necessary support. Simon, in describing the influence of these separate theories upon his developed decision theory of organization which must be considered as adjunct to the model of organization provided in the management process theory, concluded that the contribution of the Formal theory of organization was structure or anatomy, while the Informal school of organization provided process or physiology. ${ }^{15}$ Etzioni, from a sociological approach, refers to the synthesis of the formal and Informal theories as a structuralist concept

15 Herbert A. Simon, Administrative Behavior (2nd ed.; New York: The Free Press, 1957), p. 220 . 
or organization theory. ${ }^{16}$ Again, Etzioni, sees this combination as a synthesis of structure and process but in the static sense of comparative description rather than as a prescriptive tool of management or a method of dynamic analysis. ${ }^{17}$ it is his endeavor to use this method to encompass all formal organizations in a comparative scheme. ${ }^{18}$ The incorporative powers of the management process approach to organization theory may be demonstrated by the activity of a group of organizational theorists from various disciplines to describe a Modern Organization theory in 1958. 19 This work was described by the editor as the ragged, leading edge of developments in the various fields of organization theory. ${ }^{20}$ Even at the time of that writing one of the contributors was willing to admit in a separate work that many of the conclusions reached were encompassed by a synthesis of the formal and Informal schools of thought. ${ }^{21}$ And, later this same author was willing

16 Amitai Etzioni, Modern Organizations (Englewood Cliffs, N.J.: Prentice-Hall, Inc., 1964), p. 20. Note: Etzioni, p. 4, identifies the Formal school as the Classical approach and the informal school as the Human Relationist. Etzioni, p. 25, also provides for a Neo-Classical school, which carries on the classical tradition of formal analysis but includes an empirical element in the search for more effective organizations.

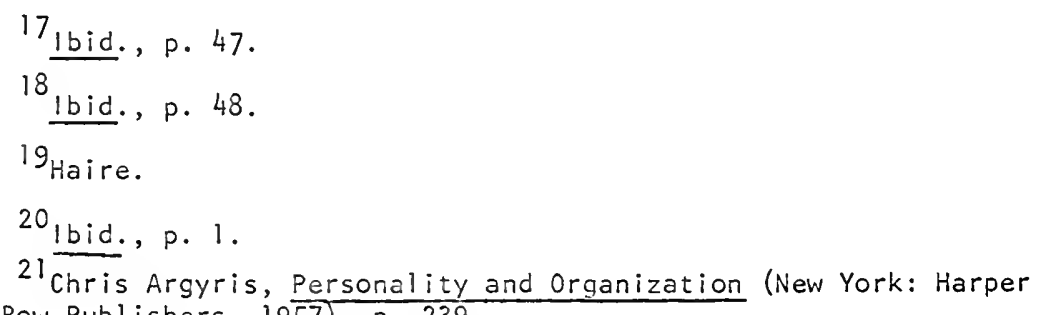
and Row Publishers, 1957), p. 239. 
to admit that many of the direct criticisms which he had expressed in earlier statements in regard to the pyramidal structure of organization described by the process school in adaptation of the Formal theory and basic to this underlying theory of management were without substantial foundation. 22 in large part this attempt to synthesize advanced organizational ramifications of such concepts as game theory and decision theory, information therory and communication theory, group theory, and motivation theory into a "new" theory of organization. merely provided a convenient consolidation of newer concepts which made them amenable to assimilation into the larger frame of reference provided by the management process school. It will, probably, always be possible to describe a new theory of organization which is acting as a way station, where newer concepts will be consolidated awaiting evaluation, reconstruction, and incorporation into the mainstream of management thought.

It is too soon to evaluate the most current of these concepts which has arrived on the scene. ${ }^{23}$ It is difficult to apprise whether systems theory is entirely a new concept, or whether it is an expression designed

${ }^{22}$ Chris Argyris, Integrating the Individual and the Organization (New York: John Wiley and Sons, Inc., 1964), p. 196.

${ }^{23}$ Scott, in Organization Theory: A Behavioral Analysis, pp. 122 and 135, refers to the systems concepts as modern organization theory insofar as they refer to human organizations. 
to connotate the whole of organization theory as it presently exists. Scott maintains that the aim of general systems theory is the creation of a science of organizational universals. 24 Johnson, et al. refer to general systems theory as providing an overall framework with which varied disciplines including management may relate specific findings and concepts of their own to those provided by other disciplines. 25 A more specific benefit according to these authors is that general systems theory if applied as a concept within organizations will prevent managers from making decisions which will have untoward consequences for the system as a whole for emphasis will be focused on overall performance. 26

However, beyond these broad generalities there are some specific questions which must be asked about the so called-- systems theories of organization. Starting at the level of General Systems Theory as described by Boulding we discover nine levels at which systems characteristics can be discerned. 27 These nine levels span man's knowledge of the universe, that is, knowledge which is extant may be categorized

24 ibid., pp. 120.

25 Richard A. Johnson, Fremont E. Kast, and James E. Rosenzweig, The Theory and Management of Systems (New York: McGraw-Hill Book Co., Inc., 1963), P. 10 .

26 ibid., p. 5.

27 Kenneth Boulding, "General Systems Theory -- The Skeleton of Science," Management Science, 11 (April, 1956), 197-208. 
within one of the various levels in regard to the level of sophistication of the system. ${ }^{28}$ The goal of the general systems theorist would be the classification of this knowledge at each level into a scheme of input, through-put and output. 29 It would therefore be possible for members of those disciplines which work in areas located at one level of system to relate their work to that of another discipline working at a different level of the hierarchy of systems. In essence, the general systems schema allows for the interrelationship of all knowledge. It will therefore be possible to discover both the universal characteristics of all levels and that knowledge contained at one level which by analogy can be imputed to another level.

The first stumbling block to the feasibility of this approach is the requirement that existing knowledge be converted into a form amenable to general systems structure. Secondly, the simple structure now provided of input, transformation, and output must be amplified to accommodate the mass of data below the most generalized level of expression. This amplin fied structure must conform at each level of the hierarchy if meaningful transference is to take place.

The long-range possibilities of such a scheme of order are beyond imagination. Problems of construction, cataloging, and education are

\section{1bid., p. 5 .}

29Daniel Katz and Robert L. Kahn, The Social Psychology of Organizations (New York: John Wiley and Sons, Inc., $(966)$, p. 8. 
perhaps surmountable. The resistance of many time honored areas of professional specialization could be overcome through the benefits to be obtained. However, if this point were reached it would be necessary to face up to the problem of the gaps in knowledge which existed. In many cases these gaps might be irrelevant to the scientist working at a particular level of the hierarchy where the gap exists. The knowledge may be complete to the tasks at hand at that particular level; however, the requirements for transfer of existing findings from that level to another level may necessitate more extensive data for the original findings to be of any use. Working hypotheses of one discipline may be essential factual data in another. Undoubtedly, an expanded scientific population could overcome this obstacle in time -- what might appear to be trivia to members of a particular discipline at the present time may hold attraction as a life-work for new members of that discipline in the future. Alternatively, members of a discipline normally found working at one level of the hierarchy of systems, say a sociologist, could invade the territory of a discipline at another level, say entomology, and research the necessary information required to transfer other scientific findings, say race predjudice of infant ants as a function of insect territory.

At our present level of attainment it is difficult to appreciate what benefits general systems theory may hold for the future. The degree of transferability presently being accomplished to the level of social 
organization are not of large magnitude. The most active work has taken place in the area of communications and cybernetic theory, but it appears that these systems networks will require a great deal more elaboration to contain the rich body of data which has been accumulated through the years in regard to human organizations. To characterize human communications and control in terms of these systems concepts is quite valid, but is is often accomplished at the expense of the nuances of insight suggested by the larger body of data which defies categorization under the general systems schema at the present time. Scott reminds us that care should be taken in using analogies which bridge systems levels that are mere literary devices: "For systems to be analogous, they must exhibit inherent structural similarities or implicitly identical operational principles. 130 The work of Mason Haire is perhaps typical of the analogies which attempt to transfer physical and biological laws to factors associated with the growth patterns of human organizations. 31 In spite of the potential prospects which these attempt might suggest to the computer scientist interested in constructing models of organization, it is unlikely that this method of approach will supplant the existing expositions on organizational growth which provide considerable insight to the operating executive with their infinite

${ }^{30}$ Scott, Organization Theory: A Behavioral Analysis, p. 122.

3 Mason Haire, "Biological Models and Empirical Histories of the Growth of Organizations," Modern Organization Theory, ed. Mason Haire (New York: John Wiley and Sons, Inc., 1959), pp. 272-306. 
number of variables.

Open-systems concepts have become much employed at the social organization level of the General Systems hierarchy. Those of interest employ the figurative relationship of input, process, and output prescribed by the general theory. One of the most comprehensive of these systems is that reported by Katz and Kahn. 32 This particular model is of particular importance both in that it encompasses the entirety of social organization as well as providing for a management process as a subsystem both of society and the separate component organizations. 33 Their model provides that society is made up of institutions which can be categorized into production or technical subsystems, supportive subsystems, maintenance subsystems, adaptive subsystems, and managerial subsystems. 34 In like manner, each of the organization which comprise the formal portions of the society can be described as containing these subsys tems. 35

The advantages proclaimed for the open-systems approach over more traditional methods of organization theory is its avoidance of goal directed models concentrating upon closed-systems which fail to recognize the interrelationship among organizations in a society. 36 systems models

32 Katz and Kahn.

33 lbid.

34 lbid., pp. 128-147.

35 lbid., pp. $39-47$.

36 Joseph A. Litterer, The Analysis of Organizations (New York: John Wiley and Sons, Inc., 1965), Pp. 147-156. 
of organization by avoiding goal limitations can be considered in dynamic interaction with the environment of other organizations. 37 Argyris describes the systems concept as providing an effectiveness model for a particular organization in its interrelationship with other elements of the system. 38 it is the system which has goals -the organization itself is measured in its effectiveness in service of these goals. 39 However, one of the earliest exponents of systems concepts, Talcott Parsons, in describing his model of social organization maintained that the basis of organization theory should rest with a cultural-institutional point of view. ${ }^{40}$ In large part, then, it can be maintained that the contribution of open-systems theory as a segment of general systems theory is mainly an attempt to bring these various disciplines employing this approach into the scheme upon which the management process and its dynamic analysis has always had its foundation.

The parts analyses of the earlier psychologists, sociologists,

37Douglas McGregor, The Professional Manager, eds. Carol ine McGregor and Warren G. Bennis (New York: McGraw-Hili Book Co., 1967), pp. $40-41$.

${ }^{38}$ Chris Argyris, Integrating the Individual and the Organization (New York: John Wiley and Sons, inc., 1964), p. 124.

39 lbid.

${ }^{40}$ Talcott Parsons, "Suggestions for a Sociological Approach to the Theory of Organizations -- 1," Administrative Sciences Quarterly, (September, 1956), 67. 
and anthropologists has always been an unsatisfying experience to the management theorists. The incorporation of the informal theories of management into the formal theory providing the management process was in reaction to the need to provide structure to the various role and group theories of the Human Relationists. The early work of F. W. Taylor in formulating a theory of management had many of these same defects which result from a synthesis approach to theory rather than an analytical approach. The real basis for management theory today can be attributed to the work of Fayol, 41 Mooney, ${ }^{42}$ and others of a later period who also adhered to an analytical and institutional approach to management and its underlying theory of organization. 43 This same appreciation of the institutional aspects of organization theory and the dynamic analysis which provides the basis for the universal concepts now being suggested by the exponents of General Systems theory is carried on in management theory today from this tradition. 44

${ }^{41}$ Henri Fayol, General and Industrial Management (London, Sir Isaac Pitman and Sons, Ltd., 1949).

42 James D. Mooney, The Principles of Organization (Revised Edition; New York: Harper and Brothers, Publishers, 1947).

43 Ralph Currier Davis is perhaps representative of this core of analysis in management theory, in his, The Fundamentals of Top Management (New York: Harper and Row, Publishers, 1951).

44 perhaps representative of this tradition, with appropriate incorporation of later concepts, are William McNair Fox, The Management Process (Homewood, Illinois: Richard D. Irwin, Inc., 1963), and Koontz, and O'Donnell. 
As was pointed out, the management process or operational management school of thought has successfully incorporated into the mainstream of management theory much of the valid contributions provided by other disciplines down through the years. The question remains as to the impact of systems theory upon the management process school of thought. Before it is predicted that incorporation will take place in this case also, it must be reiterated that systems theory is organization theory if the richness of organization theory is reduced to its essential elements. And, it is organization theory which provides the foundation, or assumptions, of management theory as it is expressed in the management process. It could therefore be suggested that systems theory provides the basis for incorporation of management theory itself. As Katz and Kahn have indicated in their outline of open-systems theory a necessary element within each organization and the society as a whole are the elements which they refer to as the managerial subsystem. 45 As they describe this subsystem it cuts through all of the other subsystems and provides the control and decision-making aspects of the organization, or society, and its parts. ${ }^{46}$ Its functions within the total system, as outlined by the authors, are: to coordinate the various substructures; to resolve conflicts between hierarchical levels; and, to

$$
\begin{aligned}
& 45_{\text {Katz and Kahn. }} \\
& 46 \text { Ibid., p. } 94 .
\end{aligned}
$$


coordinate external requirements with organizational resources and needs. 47 For those readers familiar with the functions of management provided by the management process school, of planning, organizing, and controlling, the similarity is apparent. In most respects, where the managerial subsystem described by Katz and Kahn receives any detailed treatment the connection with process and principles provided by management theory is apparent. In fact, the sound analytical basis and institutional flavor provided by the management process indicates that the managerial subsystem of open-systems theory and the management process described in managerial theory are one and the same. General Systems theory and the open-systems theory at the level of social organizations therefore provides support for the long-held contention that the principles of management and its underlying theory of organization as encompassed by the management process are universal to all organizations. 


\section{BI BLIOGRAPHY}

Books

Alexis, Marcus and Charles Z. Wilson. Organizational Decision Making. Englewood Cliffs, N.J.:Prentice-Hall, Inc., 1967.

American Hospital Association. Uniform Chart of Accounts and Definitions for Hospitals. Chicago: American Hospital Association, 1959.

American Nurses' Association. Facts About Nursing. New York: American Nurses' Association, 1967.

Argyris, Chris. Personality and Organization. New York: Harper and Row Pubiishers, 1957.

- Integrating the Individual and the Organization. New York: John Wiley and Sons, Inc., 1964.

Barnard, Chester 1. The Functions of the Executive. Cambridge, Mass.: Harvard University Press, 1938.

- Organization and Management. Cambridge, Mass.: Harvard University Press, 1948.

Bell, Gerald D. Organizations and Human Behavior. Englewood Cliffs, N.J.: Prentice-Hall, Inc., 1967.

Bennis, Warren G. Changing Organizations. New York: McGraw-Hill Book Co., 1966.

Berelson, Bernard and Gary A. Steiner. Human Behavior: Shorter Edition. New York: Harcourt, Brace, and World, Inc., 1967.

Blau, Peter M. and W. Richard Scott. Formal Organizations. San Francisco: Chandler Publishing Co., 1962 .

Bloom, Samuel W. The Doctor and His Patient. New York: The Free Press, 1963.

Brown, Esther Lucile. Newer Dimensions of Patient Care: Part 2: Improving Staff Motivation and Competence in the General Hospital. New York: Russell Sage Foundation, 1962.

Burling, Temple, Edith M. Lentz, and Robert N. Wilson. The Give and Take in Hospitals. New York: G. P. Putnam's Sons, 1956. 
Caplow, Theodore. The Sociology of Work. New York: McGraw-Hill Book Co., 1954.

Carzo, Rocco, Jr. and John N. Yanouzas. Formal Organizations: A Systems Approach. Homewood, 111.: Richard D. Irwin, Inc., 1967.

Cyert, Richard M. and James G. March. A Behavioral Theory of the Firm. Englewood Cliffs, N.J.: Prentice-Hall, Inc., 1963.

Dale, Ernest. Management Theory and Practice. New York: McGraw-Hill Book Co., 1965 . - Organizations. New York: American Management Association, 1967.

Davis, Keith. Human Relations at Work. 3rd ed. revised. New York: McGraw-Hill Book Co., 1967.

Davis, Ralph Currier. The Fundamentals of Top Management. New York: Harper and Row, Publishers, 1951.

Dubin, Robert. Human Relations in Administration. Englewood Cliffs, N.J.: Prentice-Hall, inc., 196i.

Etzioni, Amitai. A Comparative Analysis of Complex Organizations. New York: The Free Press, 1961. - Modern Organizations. Englewood Cliffs, N.J.: PrenticeHall, Inc., 1964 .

Fayol, Henri. General and Industrial Management. London: Sir Isaac Pitman and Sons, Ltd., 1949.

Fox, William Mc Nair. The Management Process. Homewood, 111.: Richard D. Irwin, Inc., 1963 .

Galbraith, John Kenneth. The New Industrial State. Boston: Houghton Mifflin, Co., 1967.

Gilb, Corinne L. Hidden Hierarchies. New York: Harper and Row, Publishers, 1966 .

Gouldner, Alvin W. Patterns of Industrial Bureaucracy. New York: The Free Press of Glencoe, 1954.

Henderson, Virginia. The Nature of Nursing. New York: The Macmillan Co., 1966. 
Herzberg, Frederick, Bernard Mausner, and Barbara Bloch Snyderman. The Motivation to Work. 2nd edition. New York: John Wiley and Sons, inc., 1959.

- Work and the Nature of Man. Cleveland, Ohio: The World Publishing Co., 1966.

Horty, John F., Nathan Hershey, EricW. Springer, and Donald M. Stocks. Student's Guide to Hospital Law: 2nd Editions. Pittsburgh, Pa.: Health Law Center, Graduate School of Public Health, University of Pittsburgh, 1962.

Hutchinson, John G. Organizations: Theory and Classical Concepts. New York: Holt, Rinehart and Winston, 1967.

Johnson, Richard A., Fremont E. Kast, and James E. Rosenzweig. The Theory and Management of Systems. New York: Mc Graw-Hi $\overline{\mathrm{II}}$ Book Co., inc., 1963.

Katz, Daniel and Robert L. Kahn. The Social Psychology of Organizations. New York: John Wiley and Sons, Inc., 1966.

Koontz, Harold and Cyril O'Donnell. Principles of Management. 3rd Edition. New York: McGraw-Hill Book Co., 1964.

Kron, Thora. Nursing Team Leadership. Philadelphia, Pa.: W. B. Saunders Co., 1961 .

Likert, Rensis. New Patterns of Management. New York: McGraw-Hill Book Co., Inc., 196?.

Litterer, Joseph A. The Analysis of Organizations. New York: John Wiley and Sons, inc., 1965.

MacEachern, Malcolm T. Hospital Orqanization and Management. Berwyn, 111.: Physicians' Record Co., 1962.

March, James G. and Herbert A. Simon. Organizations. New York: John Wiley and Sons, inc., 1958.

Marshall, Alfred. Principles of Economics. 8th Edition. London: Macmillan and Co., Ltd., 1920.

Maslow, Abraham H. Toward a Psychology of Being. Princeton, N.J.:

D. Van Nostrand Co., Inc., 1962. 
- Eupsychian Management: A Journal. Homewood, III: Richard D. Irwin, Inc., and the Dorsey Press, 1965.

McGregor, Douglas. The Human Side of Enterprise. New York: McGraw:ill Book Co., Inc., 1960.

- The Professional Manacer. Edited by C. McGregor and W. G. Bennis. New York: McGraw-Hill Book Co., Inc., 1967.

Mc Guire, Joseph W. Theories of Business Behavior. Englewood Cliffs, N.J.: Prentice-Hall, Inc., 1964.

McLuhan, Marshall. Understanding Media: The Extensions of Man. New York: The New American Library, 1964.

Mee, John F. Management Thought in a Dynamic Economy. New York: New York University Press, 1963.

Mills, C. Wright. White Collar: The American Middle Class. New York: Oxford University Press, 1956.

Mooney, James D. The Principles of Organization. Revised Edition. New York: Harper and Brothers, Publishers, 1947.

Newman, William H., Charles E. Summer, and E. Kirby Warren. The Process of Management, 2nd ed. revised. Englewood Cliffs, N.J.: Prentice-Hall, inc., 1967.

Parsons, Talcott. The Social System. New York: The Free Press, 1951.

- and Neil J. Smelser. Economy and Society. New York: The Free Press, 1956.

Pfiffner, John M. and Frank P. Sherwood. Administrative Organization. Englewood Cliffs, N.J.: Prentice-Hall, Inc., 1960.

Rayack, Elton. Professional Power and American Medicine: The Economics of the American Medical Association. Cleveland: The World Publishing Co., 1967.

Scott, William G. Organization Theory: A Behavioral Analys is for Management. Homewood, I11.: Richard D. Irwin, Co., 1967.

Simon, Herbert A. Administrative Behavior. 2nd Edition. New York: The Free Press, 1957.

Sloan, Raymond, P. Today's Hospital. New York: Harper and Row, Publishers, 1966. 
Somers, Herman Miles and Anne Ramsa Somers. Medicare and the Hospitals: lssues and Prospects. Wasnington, D.C.: The Brookings Institute, 1967.

Terry, George R. Principles of Management. 5th ed, rev. Homewood, 111.: Richard D. Irwin, Inc., 1968.

Tunley, Roul. The American Health Scandal. New York: Dell Publishing Co., 1966 .

Urwick, L. The Elements of Administration. New York: Harper and Row, Vollmer, Howard M. and Donald L. Mills. (eds.). Professionalization. Englewood Cliffs, N.J.: Prentice-Hall, Tnc., 1966.

Woodward, Joan. Industrial Organization: Theory and Practice. London: Oxford University Press, 1965. 
Bakke, E. Wight. "Concept of the Social Organization," in Modern Organization Theory, ed. Mason Haire (New York: John Wiley and Sons, inc., 1959), pp. 16-75.

Becker, Howard S. "The Professional Dance Musician and His Audience," in Professionalization, eds. Howard M. Vollmer and Donald $L$. Mills (Englewood Cliffs, N.J.: Prentice-Hall, Inc., 1966), pp. $212-216$.

Bennis, Warren G. "Organizational Developments and the Fate of Bureaucracy," Industrial Management Review (Spring, 1966), PP. $41-55$.

Bernstein, Arthur H. "Medical Staff Appointments, Pro and Con," Hospitals, ILII (May 1, 1968), 99.

Blai, Boris, Jr. "Job Satisfaction Predictor," Personnel Journal (October, 1963), pp. 453-456.

Blumer, Herbert. "Preface," in Professionalization, eds. Howard M. Vollmer and Donald L. Mills (Englewood Cliffs, N.J.: PrenticeHall, inc., 1966), p. xi.

Boulding, Kenneth. "General Systems Theory--The Skeleton of Science," Management Sciences, II (Apri 1, 1956), 197-208.

Brown, Esther Lucile. "The Need for Differentiation of Nursing Service," in lssues in Nursing, ed. Bonnie Bullough and Vern Bullough (New York: Springer Publishing Co., Inc., 1966), pp. 106-117.

Burns, Tom and G. M. Stalker. "Mechanistic and Organic Systems," in Readings in Management, ed. Ernest Dale (New York: McGrawHill Book Co., (965), pp. 234-236.

Carr-Saunders, A. M. 'Professions: Their Organization and Place in Society," in Professionalization, eds. Howard M. Vollmer and Donald L. Mills (Englewood Cliff's, N.J.: Prentice-Hall, Inc., 1966), pp. 3-9.

Christman, Luther $P$. and Richard C. Jelinek. "Old Patterns Waste Half the Nursing Hours," Modern Hospital, CVIII (January, 1967), 78-81. 
Clark, Burton R. "Faculty Organization and Authority," in Professionalization, eds. Howard M. Vollmer and Donald L. Mills (Engelwood Cliffs, N.J.: Prentice-Hall, Inc., 1966), pp. 283-29l.

Cogan, Morris L. "Toward a Definition of Profession," Harvard Educational Review, XX111 (Winter, 1953), 49, cited by Howard $M$. Volmer and Donald L. Mills, eds., Professionalization (Englewood Cliffs, N.J.: Prentice-Hall, Inc., 1966).

Corwin, Ronald G. "Role Conception and Career Aspiration: A Study of Identity in Nursing," Sociological Quarterly, II (April, 1961), pp. 69-86.

"The Professional Employee: A Study of Conflict in Nursing Roles," American Journal of Sociology, LXVI (June, 1961), 604-615.

Etzioni, Amitai. "Administration and the Consumer," Administrative Sciences Quarterly, 11 (September, 1958), 251-264.

"Authority Structure and Organizational Effectiveness," Administrative Sciences Quarterly, IV (June, 1959), 43-67.

- "Dual Leadership in Complex Organizations," American Sociological Review, XXX (October, 1965), 688-698.

Fichter, Joseph H. "What Determines Success," in Professionalization, eds. Howard M. Vollmer and Donald L. Mills (Englewood Cliffs, N.J: Prentice-Hall, Inc., 1966), pp. 145-147.

Flores, Florence. "Role of the Graduate Nurse Today," The New England Journal of Medicine, CCLX II (September 6, 1962), 487-491.

Freidson, Eliot. "Client Control and Medical Practice," in Medical Care: Readings in the Sociology of Medical Institutions, eds. W. Richard Scott and Edmund H. Volkart (New York: John Wiley and Sons, Inc., 1966), pp. 259-271.

"Specialties Without Roots: The Utilization of New Services," in Medical Care: Readinas in the Sociology of Medical Institutions, eds. W. Richard Scott and Edmund H. Volkart (New York: John Wiley and Sons, Inc., 1966), pp. 447-458.

"Review Essay: Health Factories, The New Industrial Sociology," Social Problems, XIV (Spring, 1967), 493-500. 
Georgopoulis, Basil S. "Hospital Organization and Administration: Prospects and Perspectives," Hospital Administration, IX (Summer, 1964), 23-35.

"The Hospital System and Nursing: Some Basic Problems and Issues," Nursing Forum, V, 3 (1966), 8-35.

, and Floyd C. Mann. "The Hospital as an Organization," Hospital Administration, VII (Fall, 1962), 50-64.

Goode, William J. "Community Within a Community: The Professions," American Sociological Review, XXII (April, 1957), 194-200.

Gordon, Paul J. "The Top Management Triangle in Voluntary Hospitals (1)," Academy of Mana'gement Journal, IV (December, 1961), $2 0 5 - 2 \longdiv { 4 }$.

- "The Top Management Triangle in Voluntary Hospitals (11)," Academy of Manacement journal, V (April, 1962), 66-75.

Goss, Mary E. W. "Patterns of Bureaucracy among Hospital Staff Physicians," The Hospital In Modern Society, ed. Eliot Freidson (New York: The Free Press of Glencoe, 1963), pp. 170-194.

Greenwood, Ernest. "Atrributes of a Profession," in Professionalization, eds. Howard M. Vollimer and Donaid L. Mills TEnglewood Cliffs, N.J.: Prentice-Hall, Inc., 1966), pp. 10-19.

Guzzardi, Walter, Jr. "What the Doctor Can't Order--but You Can," in Medical Care: Readinas in the Sociology of Medical Institutions, eds. W. Richard Scott and Edmund H. Volkart (New York: John Wiley and Sons, Inc., 1966), pp. 529-543.

Haire, Mason. "Introduction--Recurrent Themes and General Issues in Organization Theory," in Modern Orcanization Theory, ed. Mason Haire (New York: John Wiley and Sons, Inc., 1959), pp. 1-15.

- "Biological Models and Empirical Histories of the Growth of Organizations," in Modern Organization Theory, ed. Mason Haire (New York: John Wiley and Sons, Inc., 1959), pp. 272-306.

Hall, Oswald. "Some Problems in the Provision of Medical Service," Canadian Journal of Economics and Political Science, XX $(1954), 456-466$.

"Hospital Statistics," Hospitals: Guide Issue, ILI, 2 (August 1, 1967), $437-480$. 
Hughes, Everett C. "The Professions in Society," Canadian Journal of Economics and Political Science, XXVI (February, 1960), 54-61.

Jelinek, Richard C. "A Structural Model for the Patient Care Operation," Health Services Research, 11 (Fall-Winter, 1967) 226-242.

Johnson, Everett A. "Nursing Reorganization Strengthens Head Nurse Role, Provides Special Nursing Consultants," Hospitals, ILIII (June 16, 1968), 85-90.

Johnson, M. M. and H. W. Martin. "A Sociological Analys is of the Nurse Role," in Professionalization, eds. Howard M. Vollmer and Donald L. Mills (Englewood Cliffs, N.J.: Prentice-Hall, Inc., 1966), pp. 206-211.

Kast, Fremont E. and James E. Rosenzweig. "Hospital Administration and Systems Concepts," Hospital Administration, XI (Fall, 1966), $17-33$.

Kornhauser, William. "Scientists in Industry: Conflict and Accommodation," in Professionalization, eds. Howard M. Vollmer and Donald L. Mills (Englewood Cliffs, N.J.: Prentice-Hall, Inc., 1966), pp. 292-293.

Lambertson, Eleanor C. "Reorganize Nursing to Re-Emphasize Care," Modern Hospital, CVIII (January, 1967), 68-71 and 138.

Lentz, Edith M. "Hospital Administration--One of a Species," Administrative Sciences Quarterly, 1 (March, 1957), 444-463.

Likert, Rensis. "A Motivational Approach to a Modified Theory of Organization and Management," in Modern Organization Theory, ed. Mason Haire (New York: John wiley and Sons, Inc., 1959), pp. 184-217.

Litchfield, Edward H. "Notes on a General Theory of Administration," Administrative Sciences Quarterly, I (June, 1956), 3-29.

Marksch, Hans 0. "Nursing Dilemmas in the Organization of Patient Care," Nursing Out look, V (January, 1957), 31-34.

Maslow, Abraham H. "Eupsychia--The Good Society," Journal of Humanistic Psychology, I (Fall, 1961), 1-11.

- "Notes on Being-Psychology," Journal of Humanistic Psychology, 11 (Fall, 1962), 47-71. 
"A Theory of Metamotivation: The Biological Rooting of the Value-Life," Journal of Humanistic Psychology, VII (Fall, 1967), 93-127.

"Medical Technology," in Professionalization, eds. Howard M. Vollmer and Donald L. Milis (Englewood Cliffs, N.J.: Prentice-Hall, Inc., 1966), p. 20.

Merton, Robert K. "Bureaucratic Structure and Personality," in Complex Oraanizations: A Sociological Reader, ed. Amitai Etzioni (New York: Holt, Rinehart and Winston, 1961), pp. 48-61.

Orzack, Louis H. "Work as a 'Central Life Interest' of Professionals," Social Problems, VII (Fall, 1959), 125-132.

Parsons, Talcott, "The Professions and Social Structure," Social Forces, XVII (May, 1939), 457-467.

- "Suggestions for a Sociological Approach to the Theory of Organizations--1," Administrative Sciences Quarterly, 1 (September, 1956), 63-85.

"Suggestions for a Sociological Approach to the Theory of Organizations--11," Administrative Sciences Quarterly, I

(December, 1956), 225-239.

Perrow, Charles. "Organizational Prestige: Some Functions and Dysfunctions," in Medical Care: Readings in the Sociology of Medical Institutions, eds. W. Richard Scott and Edmund H. Volkart (New York: John Wiley and Sons, Inc., 1966), pp. 558-567.

"The Analysis of Goals in Complex Organizations," in Readings in Organization Theory: A Behavioral Approach, ed. Walter A. Hill and Douglas M. Egan (Boston: Allyn and Bacon, Inc., 1966), pp. $129-144$.

Roethlisberger, F. J. "The Foreman: Master and Victim of Double Talk," Harvard Business Review, ILIII (September-October, 1965), 22-37.

Rosenberger, Donald M. "A New Look at Hospital Organizations," Hospitals, XXXVI (February 1, 1962), 42-46.

Rourke, Francis E. "Bureaucracy in Conflict: Administrators and Professionals," Ethics, LXX (April, 1960), 220-227. 
Saunders, Lyle. "The Changing Role of Nurses," in Issues in Nursing, eds. Bonnie Bullough and Vern Bullough (New York: Springer Publishing Co., Inc., 1966), pp. i18-127.

Sayre, Wallace S. "Principles of Administration," Hospitals XXX (Janwary 16 and February $1,1956,34,35$, and 92 , and 50-52.

Scott, William G. "Organization Theory: An Overview and an Appraisal," Journal of the Academy of Management, IV (April, 1961), 7-26.

Scott, W. Richard. "Professionals in Bureaucracies--Areas of Conflict," in Professionalization, eds. Howard M. Vollmer and Donald L Mills (Englewood Cliffs, N.J.: Prentice-Hall, Inc., 1966!, pp. 265-275.

Seeman, Melvin and John W. Evans. "The Objective Criteria of Performance," in Medical Care: Readinas in the Sociology of Medica? Institutions, eds. W. Richard Scott and Edmund H. Volkart (New York: John Wiley and Sons, Inc., 1966), pp. 488-501.

Selznick, Philip. "Strengthening Leadership--Co-optation," Human Relations, in Administration, ed. Robert Dubin, 2nd edition (Englewood Cliffs, N.J.: Prentice-Hall, Inc., 1961), pp. 360-362.

Simmons, Leo W. and Harold G. Wolff, "Hospital Practice in Social science Perspective," in Medical Care: Readings in the Sociology of Medical Institutions, eds. W. Richard Scott and Edmund $H$. Volkart (New York: John Wiley and Sons, Inc., 1966), pp. $476-$
488 .

Smith, Harvey L. "Two Lines of Authority are One Too Many," Modern Hospital, LXXXIV (March, 1955), 59-64:

Starkweather, David B. "The Classicists Revisited," Hospital Administration, XII (Summer, 1967), 69-80.

Strauss, Anselm, et al. "The Hospital and Its Negotiated Order," in The $\frac{\text { Hospital in Modern Society, ed. Eliot Freidson (New York: The }}{\text { Free Press, 1963), 147-169. }}$

Thompson, Victor A. "Bureaucracy and Innovation," Administrative Sciences Quarterly, X (June, 1965), 1-20.

Wesbury, Stuart A., Jr. "Courses in Management Needed in Professiona? Training," Hospital Topics (September, 1967), 68-70. 
Wessen, Albert F. "Huspital Idiology and Communications between Ward Personnel," in Patients. Physicians and 1liness, ed. E. Gartly Jaco (New York: The Free Press, .958).

Wilson, Robert N. "The Physician's Changing Hospizal Role," Fuman Organization, XV111 (Winter, 1959-60), 177-183.

"The Social Structure of a General Hospital," Amals of the American Academy of Political and Social Sciences, No. 346 (March, 1963), 67-76.

Zalaznick, Sheldon. "The M.B.A.: the Man, the Myth, and the Method," Fortune, LXXV11 (May, 1968), 168-171, 200, 202, and 206. 


\section{BIOGRAPHICAL SKETCH}

Alan Donald Bauerschmidt was born November 23, 1927, in Brooklyn, New York. In January, 1945, he was graduated from Baldwin High School, Baldwin, New York, and enlisted in the United States Navy as a Hospital Apprentice Second Class. After serving on board various ships and stations both in the United States and abroad, he was commissioned as an Ensign, Medical Service Corps, U.S.N., in December, 1953. After his commissioning he served as a fiscal and supply officer at the U.S. Naval Hospital, St. Albans, New York; medical administrative officer aboard the U.S.S. Lake Chaplain, an attack aircraft-carrier on foreign station; commanding officer of a 100-bed field hospital attached to the 2 nd Marine Division; medical supply officer of the same Division; and, as medical administrative assistant to the Force Surgeon, Fleet Marine Force, Atlantic, performing medical logistic and personnel planning functions.

During his commissioned service with the U.S. Navy he graduated from the Naval School of Hospital Administration, and received the Bachelor of Arts degree in 1964, from The George Washington University with a major in business administration. He received the Master of Arts degree in financial management from the University the same year. He retired from the U.S. Navy as a Lieutenant Commander, Medical Service Corps, in August, 1965, while serving as the Comptroller of the National

Naval Medical Center, Bethesda, Maryland.

Since retiring from the U.S. Navy he has worked as a research 
assistant in the College of Health Related Professions and as an instructor in the Department of Management at the University of Florida while completing his work toward the degree of Doctor of Philosophy with major fields of study in management and economics. His minor field of study has been hospital and health care administration. Alan Donald Bauerschmidt is married to the former Connally Crawford, of Jacksonville, Florida, and they reside with their two sons in Columbia, South Carolina where he is presently an assistant professor of management at the University of South Carolina. 
This dissertation was prepared under the direction of the chairman of the candidate's supervisory committee and has been approved by all members of that committee. It was submitted to the Dean of the College of Business Administration and to the Graduate Council, and was approved as partial fulfillment of the requirements for the Degree of Doctor of Philosophy.

August, 1968

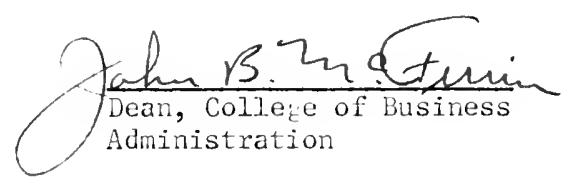

Dean, Graduate School

Supervisory Committee:
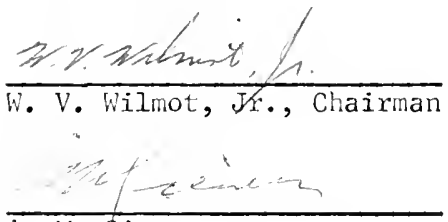

A. M. Sievers

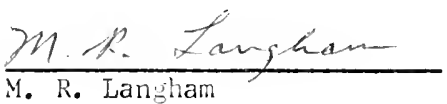

$\frac{11 / \text { Afuredecter }}{\text { J. M. Champion }}$ 
1

$20 \pm 5$ 